\title{
TO BE, OR NOT TO BE A STELIS
}

\author{
AdAM P. KarREMANS
}

\author{
Jardín Botánico Lankester, Universidad de Costa Rica, Cartago, Apartado 302-7050, Costa Rica \\ Naturalis Biodiversity Center, Endless Forms, Sylviusweg 72, Leiden 2333 BE, The Netherlands. \\ adam.karremans@ucr.ac.cr
}

\begin{abstract}
Despite the availability of multiple sources of evidence and consistency in the support for a broadly circumscribed Stelis Sw. (Orchidaceae: Pleurothallidinae), some authors continue to be hesitant in its use. It is certain that the more typical species of Stelis, with their triangular, flattish flowers with very short fleshy petals and lip, form a monophyletic group that is easily recognized. However, it is likewise undisputed that they are not an isolated lineage in the subtribe and that several groups of species with a similar vegetative habit but lacking the typical Stelis flower are in fact very close relatives, sharing a relatively recent common ancestor. Those species groups need to be classified in a way that also reflects their own evolutionary history; alternatives to a broadly circumscribed Stelis are possible yet neither straightforward or practical at this time. An infrageneric classification for the whole group is provided here in an attempt to clarify which species belong where in this highly complex affinity. Emphasis is made on the difficulty of diagnosing the less typical members of each proposed subgenus or section, and on the importance of floral convergence and divergence as a result of pollinator adaptation. As here defined, Stelis is the largest genus in the Pleurothallidinae, with 1243 species.
\end{abstract}

KEY wORDS: convergence; evolutionary history; floral morphology; generic circumscription; Pleurothallidinae; pollinator adaptation

Introduction. What is a Stelis? Or better yet, what isn't a Stelis? Some authors may think this is the question we are still asking ourselves today, but in fact the matter has been settled for years. We have an indisputable answer. Rather, what we are still actually asking ourselves is how can we classify the different groups of species within the Stelis affinity in a way that both reflects their evolutionary history and satisfies most users of such a classification system. That is the only question that still remains, and for that we may never have an answer that pleases everyone.

Species of Stelis Sw. (Orchidaceae: Pleurothallidinae) in the tradicional, strict, sense are characterized by a more or less flat, triangular flower, bearing three subequal, larger, spreading sepals, compact petals and lip, and a short column, with an apical anther and stigma. It was one of the first genera to be recognized in subtribe Pleurothallidinae, and has been used relatively consistently for around two centuries. With few exceptions, members of Stelis s.s. have an easily recognizable standard flower morphology. DNA data proves they form a monophyletic group, and there is no dispute as to which species belong to it, and which do not. Let's be clear, there is no doubt that all 1,030 currently accepted species bearing flowers with the classic Stelis morphology are more closely related to each other than they are to any other species of Pleurothallidinae. In every sense, Stelis in its traditional circumscription is a well supported group. Why, then, don't we simply recognize them as a genus on their own and get on with it? Well, because the species of Stelis s.s. are not an island within the subtribe. They have many close relatives that need to be classified in a way that reflects their own evolutionary history as well. After all, there is undisputed evidence that species of Stelis in the strict sense share an ancestor with many species that lack the typical Stelis-like flowers.

Historically, recognition of genera in Pleurothallidinae has been done by segregating groups of species that could be easily set aside from all others through key morphological features (Karremans 2016). Most other species simply remained in a broadly defined Pleurothallis R.Br., not for being related to each other or sharing particular characteristics, but for the lack of the highly distinctive features of the segregated genera. Pleurothallis sensu lato had always been expected to 
be polyphyletic (Lindley 1859, Luer 1986, Neyland et al. 1995, Stenzel 2000). DNA based phylogenetic reconstructions essentially came to demonstrate how polyphyletic it actually was and to stress the necessity for a new circumscription of genus Pleurothallis, whose members were found to be diversely related to most of the other genera in Pleurothallidinae. What is relevant to this discussion is that several groups of species previously assigned to Pleurothallis were proven to be more closely related to Stelis in the strict sense than anything else, despite their floral morphology. These species can no longer be treated as Pleurothallis because we know for a fact that their ancestors took a different evolutionary path, which ultimately gave origin to Stelis in the strict sense.

It is undeniable that the generic circumscription of Stelis, as defined by Pridgeon (2005) and modified by Karremans et al. (2013), has not been broadly accepted. That is most likely due to the ease of florally recognizing a member of Stelis sensu scrito and the lack of obvious floral features uniting species of Stelis sensu lato (Solano-Gómez \& Salazar 2013). It is desirable that genera are diagnosable using morphological features, and not only through DNA analyses. However, it is also very important to be accurate about the phylogenetic relationships among species, establishing groups that reflect the evolutionary histories of its members. If one were to look past the obvious differences in floral morphology, which undoubtedly respond to pollinator pressure, all members of Stelis s.l. are vegetatively very similar to each other. So much so that without flowers it is difficult to tell them apart.

A partitioning of Stelis s.l. into several smaller, discrete, morphologically better-defined genera is possible. It was in fact advocated by Karremans (2010) and Karremans \& Bogarín (2013), and could be desirable. Nevertheless, to do so one needs to have a clear evolutionary picture of the whole group. It is not as easy as separating the most obvious close relatives into genera, or simply separating Stelis s.s. from everything else. The whole picture is much more complex and the reality is that although some relationships within Stelis s.l. are easily diagnosable, the placement of many species continues to be a challenge, even with DNA data. Anyone can diagnose a species as belonging to either Salpistele Dressler, Stelis s.s., or Physosiphon Lindl., for example. However, not even the most adamant expert could've predicted that species of Pleurothallis sect. Petiolatae Luer were sister to those of Salpistele, or that the Stelis imraei (Lindl.) Pridgeon \& M.W.Chase group belonged in a completely isolated lineage. It is this lack of predictability that makes classifying these groups challenging. Unfortunately, there is no easy way out. The recognition of any segregate genus from Stelis s.l. requires the recognition of several additional new genera and the recircumscription of most of the existing ones (Karremans 2016). The resulting classification would be neither intuitive or very useful. At this time, it is preferable to maintain Stelis s.l. rather than to promote the use of Stelis s.s. together with a series of ill-defined, non-monophyletic satellite genera.

Some authors may believe that solving the "Stelis issue" is merely a matter of segregating the members of Stelis s.s. from the remaining Stelis s.l., but this is not a viable solution. Several groups within Stelis s.l. are more closely related to Stelis s.s. than to other members of Stelis s.l. It is also not a matter of simply recognizing the more apparent genera like Crocodeilanthe Rchb.f., Dracontia (Luer) Luer and Salpistele, as advocated by several authors (Karremans 2010; Karremans \& Bogarín 2013; Toscano de Brito 2018a; Damián 2019). Most Crocodeilanthe species are indeed easily distinguished from other members of Stelis s.l., but certainly not all of them have those very evident morphological features of their most distinctive members. They are closely related to the species previously assigned to Pleurothallis sect. Acuminatae Lindl. and those placed in genus Physothallis Garay, which look nothing like the Crocodeilanthe morphologically and should be either included or segregated as a genus as well. Dracontia may also seem straightforward, but it is not. At least one species placed in Elongatia (Luer) Luer, another from Pseudostelis Schltr., a few placed in Effusiella Luer, and the type of Mystacorchis Szlach. \& Marg. are all intermingled with species of Dracontia. Species of Salpistele, which have the most divergent floral morphology among the Stelis s.l. are not only closely related to species of Dracontia, but they are sister to two species previously assigned to genus Elongatia and which are florally completely different. What do these species groups have in common? Most are vegetatively similar to each other, but again, this is true for all members of Stelis s.l. 


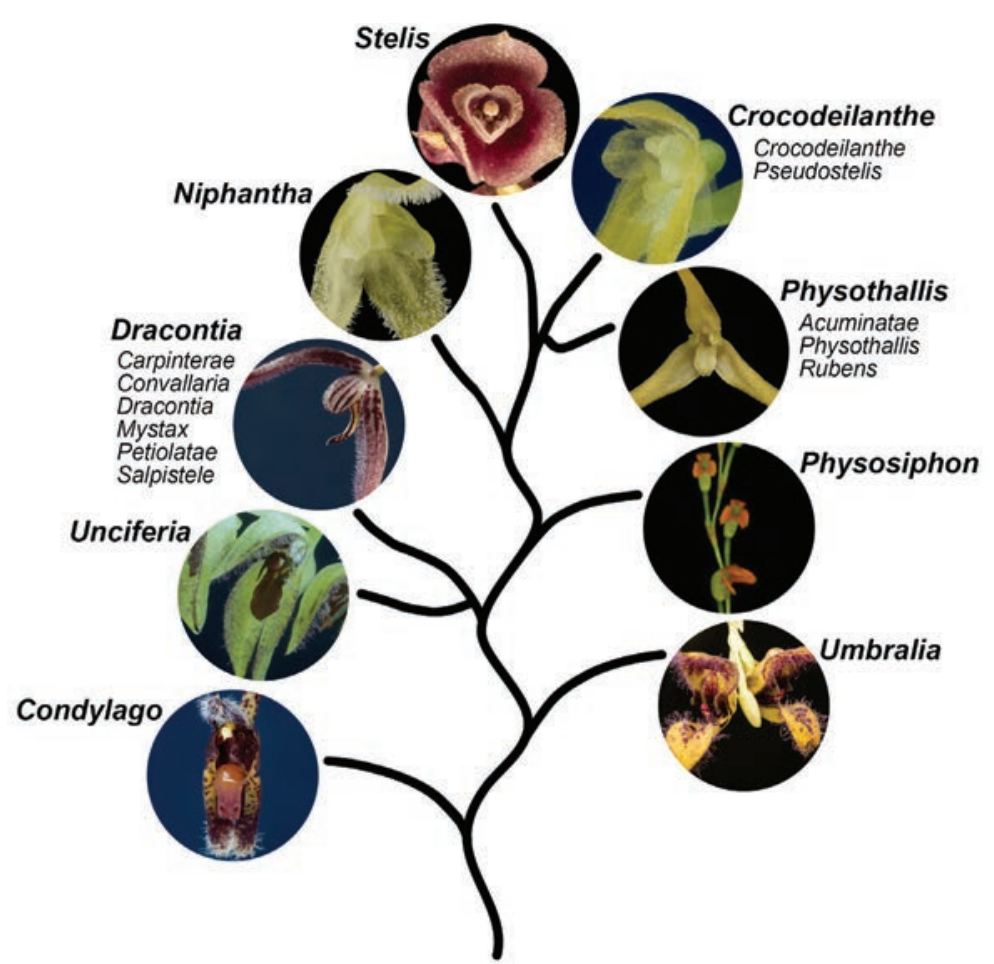

FIGURE 1. Relationships among the subgenera of Stelis sensu lato based on diverse phylogenetic reconstructions (Pridgeon et al. 2001, Solano-Gómez 2005, Karremans 2010, Chiron et al. 2012, Ramos-Castro et al. 2012; Karremans et al. 2013, Wilson et al. 2017, Pérez-Escobar et al. 2017, Chumová et al. 2018, Ponert et al. 2019), showing the proposed subgenera and sections.

Every single phylogenetic study including members Stelis s.l., as proposed by Pridgeon (2005) and modified by Karremans et al. (2013), finds the genus to be monophyletic (Karremans 2010, Chiron et al. 2012, Ramos-Castro et al. 2012, Karremans et al. 2013, Wilson et al. 2013, 2017, Pérez-Escobar et al. 2017), and this continues to be the case in multi-gene genomic studies (Chumová et al. 2018, Ponert et al. 2019). Accepting Stelis s.s. as a genus on its own necessarily entails the recognition of many ill-defined genera that no user would be happy to adopt. The alternatives to Stelis s.l. are even less appealing than it itself. Does a broader concept of Salpistele, which as the oldest name in the group has priority over all others, be a more acceptable circumscription for the species of the Dracontia clade? Perhaps a more inclusive concept of Physothallis, harboring the species of Pleurothallis sect. Acuminatae? Or the recognition of monotypic genera for Stelis carpinterae (Schltr.) Pridgeon \& M.W.Chase, Stelis convallaria (Schltr.) Pridgeon \& M.W.Chase, and Stelis mystax (Luer) Pridgeon \& M.W.Chase? Perhaps.
Nevertheless, the fact remains that it is difficult to assign species to discrete groups in Stelis s.l., any grouping being more or less artificial, and any alternative classification of this group results in genera that will not be more accepted and better defined or recognizable than Stelis s.l. Even though members of Stelis s.s. are florally very easily diagnosable for anyone, and, evidently, the flowers of other members of Stelis s.l. are very different, a broader circumscription of Stelis, with all its defects, still seems preferable over its alternatives. After all, we need to remember that although flowers are easily comparable with each other, they are under high selective pressure of pollinators, and may be more or less similar independently of relatedness (Karremans \& Díaz-Morales 2019).

For the sake of consistency with previous works in related genera, including Acianthera Scheidw. (Karremans et al. 2016), Andinia (Luer) Luer (Wilson et al. 2017) and Specklinia Lindl. (Karremans et al. 2016), and in the interest of aiding the reader, an infrageneric classification of Stelis s.l. is provided (Fig. 1). 


\section{TAXonomic Treatment}

Stelis Sw., J. Bot. (Schrader) 1799(2): 239. 1800, nom. cons.

Syn. Humboltia Ruiz \& Pav., Fl. Peruv. Prodr.: 121. 1794, nom. rej.

Syn. Physosiphon Lindl., Edwards's Bot. Reg. 21: t. 1797.1835.

Syn. Dialissa Lindl., Ann. Mag. Nat. Hist. 15: 107. 1845.

Syn. Crocodeilanthe Rchb.f. \& Warsz., Bonplandia (Hannover) 2: 113. 1854.

Syn. Pseudostelis Schltr., Anexos Mem. Inst. Butantan, Secç. Bot. 1(4): 36. 1922.

Syn. Physothallis Garay, Svensk Bot. Tidskr. 47: 199. 1953.

Syn. Steliopsis Brieger in F.R.R.Schlechter, Orchideen Beschreib. Kult. Zücht., ed. 3, 8(29-32): 457. 1976, nom. nud.

Syn. Apatostelis Garay, Bot. Mus. Leafl. 27: 185. 1979, nom. illeg.

Syn. Salpistele Dressler, Orquideologia 14: 6. 1979.

Syn. Condylago Luer, Orquideologia 15: 118. 1982.

Syn. Mystacorchis Szlach. \& Marg., Polish Bot. J. 46: 117. 2001.

Syn. Dracontia (Luer) Luer, Monogr. Syst. Bot. Missouri Bot. Gard. 95: 257. 2004.

Syn. Unciferia (Luer) Luer, Monogr. Syst. Bot. Missouri Bot. Gard. 95: 265. 2004, nom. illeg. Non Uncifera Lindl., J. Proc. Linn. Soc., Bot. 3: 39. 1859.

Syn. Lomax Luer, Monogr. Syst. Bot. Missouri Bot. Gard. 105: 88. 2006.

Syn. Effusiella Luer, Monogr. Syst. Bot. Missouri Bot. Gard. 112: 106. 2007.

Syn. Niphantha Luer, Monogr. Syst. Bot. Missouri Bot. Gard. 120: 154. 2010.

\section{Stelis subgen. Stelis (Figs. 2-4)}

Syn. Humboltia Ruiz \& Pav., Fl. Peruv. Prodr.: 121. 1794, nom. rej.

Syn. Dialissa Lindl., Ann. Mag. Nat. Hist. 15(96):

107. 1845. Type: Dialissa pulchella Lindl. Ann. Mag. Nat. Hist. 15(96): 107. 1845.

Syn. Steliopsis Brieger, Orchideen (Schlechter) 8(29-32): 457. 1976, nom. nud. Type: Steliopsis anneliesae Brieger, Orchideen (Schlechter) 8(29-32): 457. 1976, nom. nud.
Syn. Apatostelis Garay, Bot. Mus. Leafl. 27: 185. 1979, nom. illeg. Type: Stelis hylophila Rchb.f., Bonplandia (Hannover) 3: 241. 1855.

Stelis cochabambensis Karremans, nom. nov.

Repl. syn.: Stelis dasysepala Luer \& R.Vásquez, Selbyana 32(1,2): 37. 2018, nom. illeg. Non Stelis dasysepala Luer \& R.Escobar, Harvard Pap. Bot. 21(2): 198. 2016.

\section{Stelis luerii Karremans, nom. nov.}

Repl. syn.: Stelis marginata Luer \& R.Vásquez, Selbyana 32(1,2): 71. 2018, nom. illeg. Non Stelis marginata Luer \& R.Escobar, Harvard Pap. Bot. 21: 205. 2016.

\section{Stelis peculiaris Karremans, nom. nov.}

Repl. syn.: Stelis praecipua Luer \& R.Vásquez, Selbyana 32(1,2): 87. 2018, nom. illeg. Non Stelis praecipua Luer, Harvard Pap. Bot. 22: 101. 2017.

Stelis subgen. Stelis is synonymous to Stelis s.s. as defined by Luer (2009). In other words, it includes all the classical species of Stelis with triangular, flattish flowers with very short petals and lip, the very short column has an apical anther and stigma, and the pollinaria have a drop-like viscidium attached to the short caudicles. Many species of Stelis subgen Stelis have been analyzed genetically and they always group together into a highly supported clade with low genetic variation. There is a single exception, and that is an accession labeled Stelis nexipous Garay in Karremans et al. (2013) that appeared associated with members of Stelis subgen. Niphantha. It is surely either a lab mixup or sequencing mistake.

A comprehensive species list is not yet presented here. However, of the 1243 species currently accepted in genus Stelis s.l. (Karremans, in prep.), 1030 belong to Stelis s.s. The remaining 213 species are listed under one of the other subgenera hereafter.

Stelis subgen. Crocodeilanthe (Rchb.f. \& Warsz.) Karremans, comb. nov.

Bas. Crocodeilanthe Rchb.f. \& Warsz., Bonplandia (Hannover) 2: 113. 1854. Pleurothallis subgen. Crocodeilanthe (Rchb.f. \& Warsz.) Luer, Monogr. Syst. Bot. Missouri Bot. Gard. 20: 34. 1986. Type: Crocodeilanthe xiphizusa Rchb.f., Bonplandia (Hannover) 2(9): 114. 1854. 


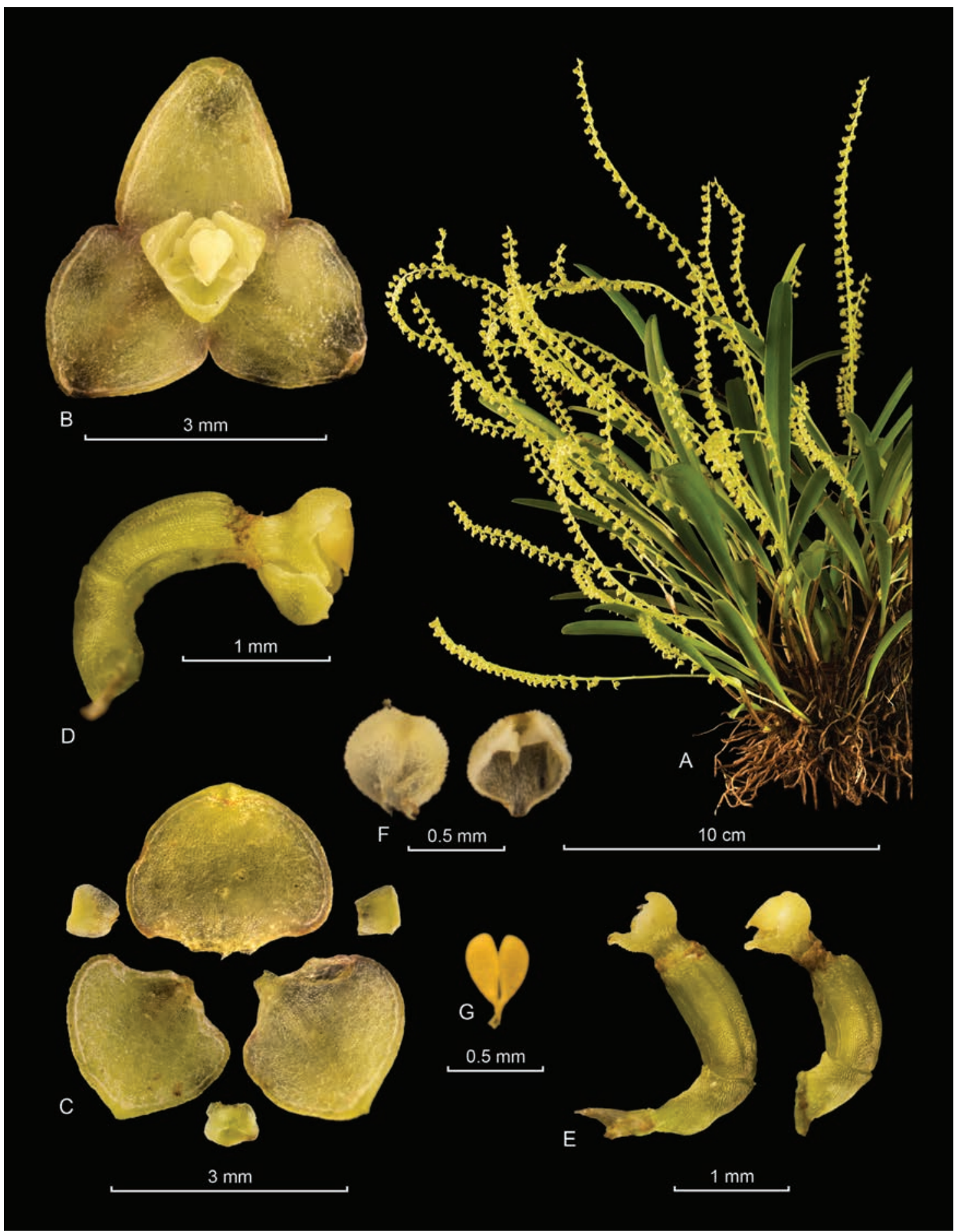

Figure 2. Lankester Composite Digital Plate (LCDP) of Stelis sp. A. Habit. B. Flower. C. Dissected perianth. D. Column with lip, lateral view. E. Column ventral and lateral view. F. Anther cap. G. Pollinarium. Photographs by AK and I. Chinchilla based on Karremans 7293 (JBL-spirit). 


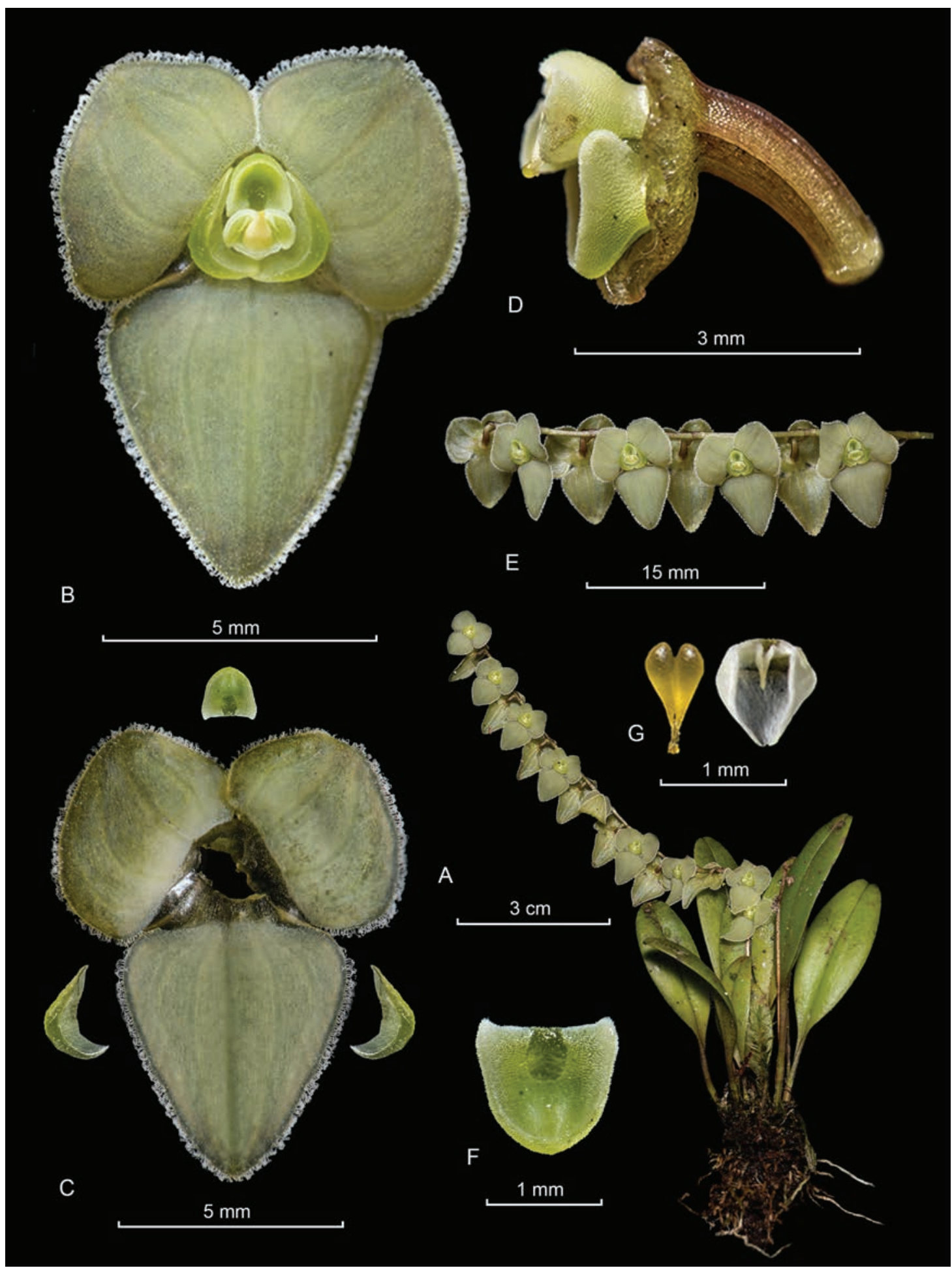

Figure 3. LCDP of a typical Stelis s.s. species. A. Habit. B. Flower. C. Dissected perianth. D. Column with lip, lateral view. E. Inflorescence. F. Lip. G. Anther cap and pollinarium. Photographs by J.S. Moreno based on Moreno 519 (CAUP). 
Syn. Pseudostelis Schltr., Anexos Mem. Inst. Butantan, Secç. Bot. 1(4): 36. 1922. Pleurothallis subgen. Pseudostelis (Schltr.) Luer, Monogr. Syst. Bot. Missouri Bot. Gard. 76: 87. 1999. Lectotype: Physosiphon spiralis Lindl., Edwards's Bot. Reg. 21: sub t. 1797. 1835 (Garay 1974).

Stelis subgen. Crocodeilanthe includes 85 species, divided in two sections. Stelis sect. Crocodeilanthe is composed of 84 species of which $90 \%$ are found at high elevations in the Andes of Bolivia, Colombia, Ecuador, Peru and Venezuela. Many are local endemics. A few species are known from Costa Rica and Panama, and a single species is reported from the Greater Antilles, another from the Lesser Antilles and yet another from Brazil. Sect. Pseudostelis includes only one species, the common and widespread Stelis deregularis Barb. Rodr. which is found at mid elevations from Mexico to Brazil, through Central America.

Toscano de Brito (2018a) recognizes Crocodeilanthe at the generic level suggesting it may be easily defined by merging Luer's Pleurothallis subgen. Crocodeilanthe and Pleurothallis subgen Pseudostelis. The species of Pseudostelis, excluding P. rufobrunnea "which is clearly a member of the genus Stelis", are said to "share the same habit and floral morphology with Crocodeilanthe". Nevertheless, the placement of Stelis magdalenae (Rchb.f.) Pridgeon \& M.W.Chase in Crocodeilanthe is not straight forward at all, and Stelis simplex (Ames \& C.Schweinf.) Pridgeon \& M.W.Chase certainly belongs to the Dracontia clade rather than Crocodeilanthe. Also, even though it may now seem obvious that Stelis rufobrunnea is in fact a member of Stelis s.s. and that Stelis deregularis belongs to Crocodeilanthe, both species were only faithfully placed on the basis of DNA data.

Furthermore, the suggestion that Stelis gelida (Lind1.) Pridgeon \& M.W.Chase (type species of Niphantha) belongs to Crocodeilanthe is not supported genetically or morphologically. The subpandurate, arcuate lip, elongate column, incumbent anther and stigma, and whale-tail pollinaria clearly separate it from other Crocodeilanthe species. Multiple Stelis gelida accessions analyzed by Karremans et al. (2013) and again by Pérez-Escobar et al. (2017), were consistently found only distantly related to Crocodeilanthe. An

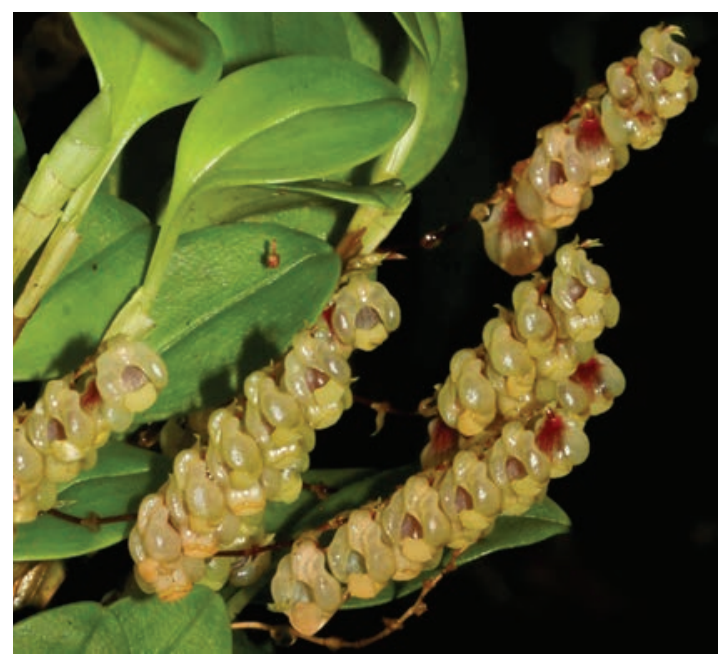

FIGURE 4. Stelis hualluapampensis Collantes \& Karremans, a non-typical species of Stelis s.s. with subglobose flowers, fused lateral sepals and a lip-like dorsal sepal that sticks out of the flower. Photograph by B. Collantes.

accession labeled Stelis antillensis in Karremans et al. (2013), which was retrieved among those of S. gelida, is likely misidentified by the original sequence author (Stenzel) as was stated therein.

The unresolved relationships between Crocodeilanthe species and those of the non-monophyletic Pseudostelis, in addition to the misplacement of the unrelated Stelis gelida, are evidence that the definition of this genus is not as straightforward as suggested. Even though it is possible to recognize most Crocodeilanthe species morphologically, the short lip and petals, the stout column with an apical anther, and pollina with a drop-like viscidium are a step prior to the typical Stelis s.s. floral morphology. As closest relative to Stelis in the strict sense, its recognition at generic level entails the recognition of several other splinter genera, which is not advised at the time.

\section{Stelis subgen. Crocodeilanthe sect. Crocodeilanthe}

Syn.: Crocodeilanthe Rchb.f. \& Warsz., Bonplandia (Hannover) 2: 113. 1854. Pleurothallis subgen. Crocodeilanthe (Rchb.f. \& Warsz.) Luer, Monogr. Syst. Bot. Missouri Bot. Gard. 20: 34. 1986. Type: Crocodeilanthe xiphizusa Rchb.f., Bonplandia (Hannover) 2(9): 114. 1854.

Stelis aligera (Luer \& R.Vásquez) Pridgeon \& M.W.Chase, Lindleyana 16(4): 261. 2001.

Bas.: Pleurothallis aligera Luer \& R.Vásquez, 


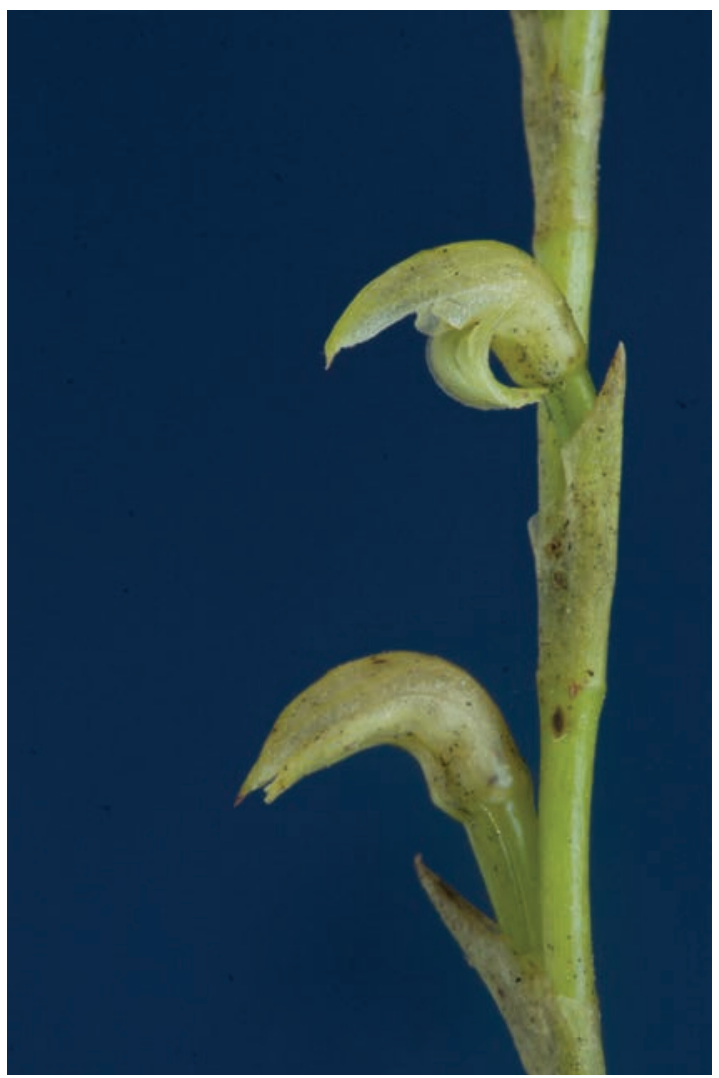

Figure 5. Stelis atwoodii (Luer) Pridgeon \& M.W.Chase, an untypical member of Stelis subgen. Crocodeilanthe. Photograph by AK.

Revista Soc. Boliv. Bot. 1(2): 9.1997. Syn.: Crocodeilanthe aligera (Luer \& R.Vásquez) Luer, Monogr. Syst. Bot. Missouri Bot. Gard. 95: 256. 2004.

Stelis aloisii (Schltr.) Pridgeon \& M.W.Chase, Lindleyana 16(4): 261. 2001.

Bas.: Pleurothallis aloisii Schltr., Repert. Spec. Nov. Regni Veg. Beih. 8: 57. 1921. Syn.: Crocodeilanthe aloisii (Schltr.) Luer, Monogr. Syst. Bot. Missouri Bot. Gard. 95: 256. 2004.

Stelis antillensis Pridgeon \& M.W.Chase, Lindleyana 17(2): 98. 2002.

Repl. syn.: Pleurothallis domingensis Cogn., Symb. Antill. 6: 402. 1909. Syn.: Crocodeilanthe domingensis (Cogn.) Luer, Monogr. Syst. Bot. Missouri Bot. Gard. 95: 256. 2004. Stelis domingensis (Cogn.) Pridgeon \& M.W.Chase, Lindleyana 16: 262. 2001, nom. illeg. Non Stelis domingensis Cogn. in I.Urban, Symb. Antill. 6: 692. 1910.
Stelis apposita (Luer) Pridgeon \& M.W.Chase, Lindleyana 16(4): 261. 2001.

Bas.: Pleurothallis apposita Luer, Monogr. Syst. Bot. Missouri Bot. Gard. 65: 12. 1998. Syn.: Crocodeilanthe apposita (Luer) Luer, Monogr. Syst. Bot. Missouri Bot. Gard. 95: 256. 2004.

Stelis atwoodii (Luer) Pridgeon \& M.W.Chase, Lindleyana 16(4): 261. 2001. (Fig. 5)

Bas.: Pleurothallis atwoodii Luer, Lindleyana 11(2): 67. 1996. Syn.: Crocodeilanthe atwoodii (Luer) Luer, Monogr. Syst. Bot. Missouri Bot. Gard. 95: 256. 2004.

Stelis avirostris (Luer \& Hirtz) Pridgeon \& M.W.Chase, Lindleyana 16(4): 261. 2001.

Bas.: Pleurothallis avirostris Luer \& Hirtz, Monogr. Syst. Bot. Missouri Bot. Gard. 65: 13. 1998. Syn.: Crocodeilanthe avirostris (Luer \& Hirtz) Luer, Monogr. Syst. Bot. Missouri Bot. Gard. 95: 256. 2004.

Stelis batillacea (Luer) Pridgeon \& M.W.Chase, Lindleyana 16(4): 261. 2001.

Bas.: Pleurothallis batillacea Luer, Selbyana 3(12): 58. 1976. Syn.: Crocodeilanthe batillacea (Luer) Luer, Monogr. Syst. Bot. Missouri Bot. Gard. 95: 256. 2004.

Stelis bracteosa (C.Schweinf.) Pridgeon \& M.W.Chase, Lindleyana 16(4): 261. 2001.

Bas.: Pleurothallis bracteosa C.Schweinf., Fieldiana, Bot. 33: 20. 1970. Syn.: Crocodeilanthe bracteosa (C.Schweinf.) Luer, Harvard Pap. Bot. 16(2): 358. 2011.

Stelis bucaramangae (Luer \& R.Escobar) Pridgeon \& M.W.Chase, Lindleyana 16(4): 261. 2001.

Bas.: Pleurothallis bucaramangae Luer \& R.Escobar, Orquideología 20: 38. 1996. Syn.: Crocodeilanthe bucaramangae (Luer \& R.Escobar) Luer, Monogr. Syst. Bot. Missouri Bot. Gard. 95: 256. 2004.

Stelis cassidis (Lindl.) Pridgeon \& M.W.Chase, Lindleyana 16(4): 261. 2001.

Bas.: Pleurothallis cassidis Lindl., Ann. Mag. Nat. Hist. 15: 384. 1845. Syn.: Crocodeilanthe cassidis (Lind1.) Luer, Monogr. Syst. Bot. Missouri Bot. Gard. 95: 256. 2004. 
Stelis cauliflora (Lindl.) Pridgeon \& M.W.Chase, Lindleyana 16(4): 261. 2001.

Bas.: Pleurothallis cauliflora Lindl., Companion Bot. Mag. 2: 355. 1836. Syn.: Crocodeilanthe cauliflora (Lindl.) Luer, Monogr. Syst. Bot. Missouri Bot. Gard. 95: 256. 2004.

Stelis choerorhyncha (Luer) Pridgeon \& M.W.Chase, Lindleyana 16(4): 261-262. 2001.

Bas.: Pleurothallis choerorhyncha Luer, Orquideología 20: 204. 1996. Syn.: Crocodeilanthe choerorhyncha (Luer) Luer, Monogr. Syst. Bot. Missouri Bot. Gard. 95: 256. 2004.

Stelis cosangae (Luer \& Hirtz) Pridgeon \& M.W.Chase, Lindleyana 16(4): 262. 2001.

Bas.: Pleurothallis cosangae Luer \& Hirtz, Monogr. Syst. Bot. Missouri Bot. Gard. 65: 18. 1998. Syn.: Crocodeilanthe cosangae (Luer \& Hirtz) Luer, Monogr. Syst. Bot. Missouri Bot. Gard. 95: 256. 2004.

Stelis cuatrecasasii (Luer) Pridgeon \& M.W.Chase, Lindleyana 16(4): 262. 2001.

Bas.: Pleurothallis cuatrecasasii Luer, Orquideología 20: 208. 1996. Syn.: Crocodeilanthe cuatrecasasii (Luer) Luer, Monogr. Syst. Bot. Missouri Bot. Gard. 95: 256. 2004.

Stelis cyathiflora (C.Schweinf.) Pridgeon \& M.W.Chase, Lindleyana 16(4): 262. 2001.

Bas.: Pleurothallis cyathiflora C.Schweinf., Bot. Mus. Leafl. 15: 90, t. 27. 1951. Crocodeilanthe cyathiflora (C.Schweinf.) Luer, Monogr. Syst. Bot. Missouri Bot. Gard. 95: 256. 2004.

Stelis damianii Karremans, nom. nov.

Repl. syn.: Crocodeilanthe chachapoyensis Damian, Ann. Bot. Fenn. 56: 302. 2019. Non Stelis chachapoyensis Rchb.f., Bonplandia (Hannover) 3: 225. 1855.

Stelis dapsilis Pridgeon \& M.W.Chase, Lindleyana 17(2): 99. 2002.

Repl. syn.: Pleurothallis maxima Luer, Selbyana 3(1-2): 140. 1976. Syn.: Crocodeilanthe maxima (Luer) Luer, Monogr. Syst. Bot. Missouri Bot. Gard. 95: 256. 2004. Stelis maxima (Luer) Pridgeon \& M.W.Chase, Lindleyana 16: 264. 2001, nom. illeg. Non Stelis maxima Lindl., Ann. Mag. Nat. Hist. 15: 106. 1845.
Stelis decurrens Pridgeon \& M.W.Chase, Lindleyana 17(2): 99. 2002.

Repl. syn.: Pleurothallis croatii Luer, Monogr. Syst. Bot. Missouri Bot. Gard. 65: 18-19. 1998. Syn.: Crocodeilanthe croatii (Luer) Luer, Monogr. Syst. Bot. Missouri Bot. Gard. 95: 256. 2004. Stelis croatii (Luer) Pridgeon \& M.W.Chase, Lindleyana 16: 262. 2001, nom. illeg. Non Stelis croatii Luer, Lindleyana 11: 97. 1996.

Stelis toscanoi Karremans, nom. nov.

Repl. syn.: Crocodeilanthe dewildei Luer \& Toscano (2018: 47). Stelis dewildei (Luer \& Toscano) Karremans, Phytotaxa 406(5): 265. 2019, nom. illeg. Non Stelis dewildei Luer \& R.Escobar, Harvard Pap. Bot. 22(1): 34. 2017.

Stelis duckei E.M.Pessoa \& M.Alves, Brittonia 66(2): 156-157. 2014.

Syn.: Crocodeilanthe duckei (E.M.Pessoa \& M.Alves) Toscano, Harvard Pap. Bot. 23(1): 54. 2018.

Stelis erectiflora (Luer) J.M.H.Shaw, Orchid Rev. 122(1308): 77. 2014.

Bas.: Crocodeilanthe erectiflora Luer, Monogr. Syst. Bot. Missouri Bot. Gard. 103: 311. 2005.

Stelis expansa (Lindl.) Pridgeon \& M.W.Chase, Lindleyana 16(4): 262. 2001.

Bas.: Pleurothallis expansa Lindl., Fol. Orchid. $\sim$ Pleurothallis 4. 1859. Syn.: Crocodeilanthe expansa (Lindl.) Luer, Monogr. Syst. Bot. Missouri Bot. Gard. 95: 256. 2004.

Stelis fons-florum (Lindl.) Pridgeon \& M.W.Chase, Lindleyana 16(4): 263. 2001.

Bas.: Pleurothallis fons-florum Lindl., Fol. Orchid. $\sim$ Pleurothallis 5, no. 15. 1859. Syn.: Crocodeilanthe fons-florum (Lindl.) Luer, Monogr. Syst. Bot. Missouri Bot. Gard. 95: 256. 2004.

Stelis galeata (Lindl.) Pridgeon \& M.W.Chase, Lindleyana 16(4): 263. 2001.

Bas.: Pleurothallis galeata Lindl., Ann. Mag. Nat. Hist. 15: 107. 1845. Syn.: Crocodeilanthe galeata (Lindl.) Luer, Monogr. Syst. Bot. Missouri Bot. Gard. 95: 256. 2004.

Stelis galerasensis (Luer) Pridgeon \& M.W.Chase, Lindleyana 16(4): 263. 2001. 
Bas.: Pleurothallis galerasensis Luer, Monogr. Syst. Bot. Missouri Bot. Gard. 65: 28. 1998. Syn.: Crocodeilanthe galerasensis (Luer) Luer, Monogr. Syst. Bot. Missouri Bot. Gard. 95: 256. 2004.

Stelis gargantua Pridgeon \& M.W.Chase, Lindleyana 17(2): 99. 2002.

Repl. syn.: Pleurothallis gigas Luer \& R.Escobar, Orquideología 20(1): 52. 1996. Crocodeilanthe gigas (Luer \& R.Escobar) Luer, Monogr. Syst. Bot. Missouri Bot. Gard. 95: 256. 2004. Stelis gigas (Luer \& R.Escobar) Pridgeon \& M.W.Chase, Lindleyana 16: 263 (2001), nom. illeg. Non Stelis gigas Barb. Rodr., Gen. Spec. Orchid. 2: 89. 1881.

Stelis globosa Pridgeon \& M.W.Chase, Lindleyana 17(2): 99. 2002.

Repl. syn.: Pleurothallis popayanensis F.Lehm. \& Kraenzl., Bot. Jahrb. Syst. 26: 438. 1898. Crocodeilanthe popayanensis (F.Lehm. \& Kraenzl.) Luer, Monogr. Syst. Bot. Missouri Bot. Gard. 95: 256. 2004. Stelis popayanensis (F.Lehm. \& Kraenzl.) Pridgeon \& M.W.Chase, Lindleyana 16: 265. 2001, nom. illeg. Non Stelis popayanensis F.Lehm. \& Kraenzl., Bot. Jahrb. Syst. 26(3-4): 448. 1899.

\section{Stelis heros Karremans, nom. nov.}

Repl. syn.: Crocodeilanthe steinbachii Luer \& Toscano, Harvard Pap. Bot. 23: 48. 2018. Stelis steinbachii (Luer \& Toscano) Karremans, Phytotaxa 406(5): 267. 2019, nom. illeg. Non Stelis steinbachii Luer, Selbyana 32(1,2): 110. 2018.

ETYMology: The name honors the three largerthan-life orchidologists that sadly passed away in 2019, Carl A. Luer, Robert L. Dressler and W. Mark Whitten.

Stelis infundibulosa (Luer) Pridgeon \& M.W.Chase, Lindleyana 16(4): 263. 2001.

Bas.: Pleurothallis infundibulosa Luer, Orquideología 20: 210. 1996. Syn.: Crocodeilanthe infundibulosa (Luer) Luer, Monogr. Syst. Bot. Missouri Bot. Gard. 95: 256. 2004.

Stelis jurisdixii (Luer \& R.Escobar) Pridgeon \& M.W.Chase, Lindleyana 16(4): 264. 2001.

Bas.: Pleurothallis jurisdixii Luer \& R.Escobar, Orquideología 20: 64. 1996. Syn.: Crocodeilanthe jurisdixii (Luer \& R.Escobar) Luer, Monogr. Syst. Bot. Missouri Bot. Gard. 95: 256. 2004.

Stelis juxta (Luer, Thoerle \& F.A.Werner) J.M.H.Shaw, Orchid Rev. 122(1308): 77. 2014.

Bas.: Crocodeilanthe juxta Luer, Thoerle \& F.A.Werner, Harvard Pap. Bot. 16(2): 320. 2011.

Stelis laevigata (Lindl.) Pridgeon \& M.W.Chase, Lindleyana 16(4): 264. 2001.

Bas.: Pleurothallis laevigata Lindl., Ann. Mag. Nat. Hist. 15: 106. 1845. Crocodeilanthe laevigata (Lind1.) Luer, Monogr. Syst. Bot. Missouri Bot. Gard. 95: 256. 2004.

Stelis laevis (Luer \& Hirtz) Pridgeon \& M.W.Chase, Lindleyana 16(4): 264. 2001.

Bas.: Pleurothallis laevis Luer \& Hirtz, Monogr. Syst. Bot. Missouri Bot. Gard. 65: 33. 1998. Syn.: Crocodeilanthe laevis (Luer \& Hirtz) Luer, Monogr. Syst. Bot. Missouri Bot. Gard. 95: 256. 2004.

Stelis laminata (Luer) Pridgeon \& M.W.Chase, Lindleyana 16(4): 264. 2001.

Bas.: Pleurothallis laminata Luer, Monogr. Syst. Bot. Missouri Bot. Gard. 65: 33-34. 1998. Syn.: Crocodeilanthe laminata (Luer) Luer, Monogr. Syst. Bot. Missouri Bot. Gard. 95: 256. 2004.

Stelis lehmanniana (Schltr.) Karremans, Phytotaxa 203(3): 293. 2015.

Bas.: Pleurothallis lehmanniana Schltr., Repert. Spec. Nov. Regni Veg. Beih. 7: 235. 1920. Crocodeilanthe lehmanniana (Schltr.) Luer, Monogr. Syst. Bot. Missouri Bot. Gard. 95: 256. 2004.

Stelis ligulata (Lind1.) Pridgeon \& M.W.Chase, Lindleyana 16(4): 264. 2001.

Bas.: Pleurothallis ligulata Lind1., Fol. Orchid. $\sim$ Pleurothallis $\sim$ 29. 1859. Syn.: Crocodeilanthe ligulata (Lindl.) Luer, Monogr. Syst. Bot. Missouri Bot. Gard. 95: 256. 2004.

Stelis magdalenae (Rchb.f.) Pridgeon \& M.W.Chase, Lindleyana 16(4): 264. 2001.

Bas.: Pleurothallis magdalenae Rchb.f., Bonplandia (Hannover) 3: 72. 1855. Crocodeilanthe magdalenae (Rchb.f.) Toscano, Harvard Pap. Bot. 23(1): 54. 2018. 
Stelis mandonii (Rchb.f.) Pridgeon \& M.W.Chase, Lindleyana 16(4): 264. 2001.

Bas.: Pleurothallis mandonii Rchb.f., Xenia Orchid. 3: 24. 1878. Syn.: Crocodeilanthe mandonii (Rchb.f.) Luer, Monogr. Syst. Bot. Missouri Bot. Gard. 95: 256. 2004.

Stelis melanostele (Luer \& R.Vásquez) Pridgeon \& M.W.Chase, Lindleyana 16(4): 264. 2001.

Bas.: Pleurothallis melanostele Luer \& R.Vásquez, Phytologia 49(3): 210. 1981. Syn.: Crocodeilanthe melanostele (Luer \& R.Vásquez) Toscano, Harvard Pap. Bot. 23(1): 54. 2018.

Stelis mendietae (Luer, Thoerle \& F.A.Werner) J.M.H.Shaw, Orchid Rev. 122(1308): 77. 2014.

Bas.: Crocodeilanthe mendietae Luer, Thoerle \& F.A.Werner, Harvard Pap. Bot. 16(2): 321. 2011.

Stelis molleturoi (Luer \& Dodson) Pridgeon \& M.W.Chase, Lindleyana 16(4): 264. 2001.

Bas.: Pleurothallis molleturoi Luer \& Dodson, Monogr. Syst. Bot. Missouri Bot. Gard. 65: 38 . 1998. Crocodeilanthe molleturoi (Luer \& Dodson) Luer, Monogr. Syst. Bot. Missouri Bot. Gard. 95: 256. 2004.

Stelis moritzii (Rchb.f.) Pridgeon \& M.W.Chase, Lindleyana 16(4): 264. 2001.

Bas.: Pleurothallis moritzii Rchb.f., Linnaea 22: 824. 1849. Syn.: Crocodeilanthe moritzii (Rchb.f.) Luer, Monogr. Syst. Bot. Missouri Bot. Gard. 95: 256. 2004.

Stelis neowerneri J.M.H.Shaw, Orchid Rev. 122(1308): 78. 2014.

Bas.: Crocodeilanthe werneri Luer \& Thoerle, Harvard Pap. Bot. 16(2): 323. 2011. Non Stelis werneri Schltr., Repert. Spec. Nov. Regni Veg. Beih. 27: 42.1924.

Stelis nivalis (Luer) Pridgeon \& M.W.Chase, Lindleyana 16(4): 264-265. 2001.

Bas.: Pleurothallis nivalis Luer, Selbyana 1(4): 420. 1976. Syn.: Crocodeilanthe nivalis (Luer) Luer, Monogr. Syst. Bot. Missouri Bot. Gard. 95: 256. 2004.

Stelis orectopus (Luer) Pridgeon \& M.W.Chase, Lindleyana 16(4): 265. 2001.

Bas.: Pleurothallis orectopus Luer, Selbyana 3(3-4):
356. 1977. Syn.: Crocodeilanthe orectopus (Luer) Luer, Monogr. Syst. Bot. Missouri Bot. Gard. 95: 256. 2004.

Stelis pachypus F.Lehm. \& Kraenzl., Bot. Jahrb. Syst. 26: 447. 1899.

Bas.: Pleurothallis pachypus (F.Lehm. \& Kraenzl.) Garay, Canad. J. Bot. 34: 254. 1956. Syn.: Crocodeilanthe pachypus (F.Lehm. \& Kraenzl.) Luer, Monogr. Syst. Bot. Missouri Bot. Gard. 95: 256. 2004.

Stelis patateënsis (Luer) Pridgeon \& M.W.Chase, Lindleyana 16(4): 265. 2001.

Bas.: Pleurothallis patateënsis Luer, Monogr. Syst. Bot. Missouri Bot. Gard. 65: 42. 1998. Syn.: Crocodeilanthe patateënsis (Luer) Luer, Monogr. Syst. Bot. Missouri Bot. Gard. 95: 256. 2004.

Stelis pellucida (Luer \& Hirtz) Pridgeon \& M.W.Chase, Lindleyana 16(4): 265. 2001.

Bas.: Pleurothallis pellucida Luer \& Hirtz, Monogr. Syst. Bot. Missouri Bot. Gard. 65: 42-43. 1998. Syn.: Crocodeilanthe pellucida (Luer \& Hirtz) Luer, Monogr. Syst. Bot. Missouri Bot. Gard. 95: 256. 2004.

Stelis pennelliana (Luer) Pridgeon \& M.W.Chase, Lindleyana 16(4): 265. 2001.

Bas.: Pleurothallis pennelliana Luer, Monogr. Syst. Bot. Missouri Bot. Gard. 65: 43. 1998. Syn.: Crocodeilanthe pennelliana (Luer) Luer, Monogr. Syst. Bot. Missouri Bot. Gard. 95: 256. 2004.

Stelis pilifera (Lind1.) Pridgeon \& M.W.Chase, Lindleyana 16(4): 265. 2001.

Bas.: Pleurothallis pilifera Lindl., Fol. Orchid. $\sim$ Pleurothallis $\sim$ 9. 1859. Syn.: Crocodeilanthe pilifera (Lind1.) Luer, Monogr. Syst. Bot. Missouri Bot. Gard. 95: 256. 2004.

Stelis pittieri (Schltr.) Rojas-Alv. \& Karremans, Phytotaxa 406(5): 266. 2019.

Bas.: Pleurothallis pittieri Schltr., Repert. Spec. Nov. Regni Veg. 3(42-43): 247. 1907.

Syn.: Crocodeilanthe floribunda (Poepp. \& Endl.) Luer, Monogr. Syst. Bot. Missouri Bot. Gard. 95: 256. 2004. Pleurothallis floribunda Poepp. \& Endl., Nov. Gen. Sp. Pl. 1: 48-49, t. 84.1835 [1836]. Non Stelis floribunda Kunth, Nov. Gen. Sp. (folio ed.) 1: 362. 1815 [1816]. 
Stelis possoae (Luer) Karremans, Phytotaxa 203(3): 293. 2015.

Bas.: Pleurothallis possoae Luer, Monogr. Syst. Bot. Missouri Bot. Gard. 79: 129-130. 2000 Crocodeilanthe possoae (Luer) Luer, Monogr. Syst. Bot. Missouri Bot. Gard. 95: 256. 2004.

Stelis praealta (Luer \& Hirtz) Pridgeon \& M.W.Chase, Lindleyana 16(4): 265. 2001.

Bas.: Pleurothallis praealta Luer \& Hirtz, Monogr. Syst. Bot. Missouri Bot. Gard. 65: 45. 1998. Crocodeilanthe praealta (Luer \& Hirtz) Luer, Monogr. Syst. Bot. Missouri Bot. Gard. 95: 256. 2004.

Stelis prolificans (Luer \& Hirtz) Pridgeon \& M.W.Chase, Lindleyana 16(4): 265. 2001.

Bas.: Pleurothallis prolificans Luer \& Hirtz, Monogr. Syst. Bot. Missouri Bot. Gard. 65: 45. 1998. Syn.: Crocodeilanthe prolificans (Luer \& Hirtz) Luer, Monogr. Syst. Bot. Missouri Bot. Gard. 95: 256. 2004.

Stelis pulchella Kunth, Nov. Gen. Sp. (quarto ed.) 1(4): 364, t. 90. 1816. (Fig. 6)

Syn.: Pleurothallis pulchella (Kunth) Lindl., Exot. Fl. 2(14): sub t. 123. 1825 [1824]. Crocodeilanthe pulchella (Kunth) Luer, Monogr. Syst. Bot. Missouri Bot. Gard. 95: 256. 2004.

Stelis reptans Pridgeon \& M.W.Chase, Lindleyana 17(2): 100. 2002.

Bas.: Pleurothallis scansor Luer, Phytologia 49(3):

216. 1981. Syn.: Crocodeilanthe scansor (Luer) Luer, Monogr. Syst. Bot. Missouri Bot. Gard. 95: 257. 2004. Non Stelis scansor Rchb.f., Bonplandia (Hannover) 3(17): 241. 1855.

Stelis retusiloba (C.Schweinf.) Pridgeon \& M.W.Chase, Lindleyana 16(4): 266. 2001.

Bas.: Pleurothallis retusiloba C.Schweinf., Bot. Mus. Leafl. 15: 100. 1951. Syn.: Crocodeilanthe retusiloba (C.Schweinf.) Luer, Monogr. Syst. Bot. Missouri Bot. Gard. 95: 256. 2004.

Stelis rhodotantha (Rchb.f.) Pridgeon \& M.W.Chase, Lindleyana 16(4): 266. 2001.

Bas.: Pleurothallis rhodotantha Rchb.f., Linnaea 22: 825. 1849. Syn.: Crocodeilanthe rhodotantha (Rchb.f.) Luer, Monogr. Syst. Bot. Missouri Bot. Gard. 95: 257. 2004.
Stelis rictoria (Rchb.f.) Pridgeon \& M.W.Chase, Lindleyana 16(4): 266. 2001.

Bas.: Pleurothallis rictoria Rchb.f., Linnaea 41: 14. 1877. Crocodeilanthe rictoria (Rchb.f.) Luer, Monogr. Syst. Bot. Missouri Bot. Gard. 95: 257. 2004.

Stelis roseopunctata (Lindl.) R. Bernal, Phytoneuron 22: 5. 2015.

Bas.: Pleurothallis roseopunctata Lindl., Orchid. Linden. 2. 1846.

Syn.: Dendrobium elegans Kunth, Nov. Gen. Sp. 1: 358. 1816. Pleurothallis elegans (Kunth) Lindl., Edwards's Bot. Reg. 28(Misc): 70. 1842. Crocodeilanthe elegans (Kunth) Luer, Monogr. Syst. Bot. Missouri Bot. Gard. 95: 256. 2004. Non Stelis elegans Luer \& R.Vásquez, Phytologia 49(3): 228. 1981.

Stelis rostriformis Zambrano \& Solano, Phytotaxa 376(4): 181. 2018.

Stelis sagittata Zambrano \& Solano, Phytotaxa 376(4): 183. 2018.

Repl. syn.: Pleurothallis jamiesonii Lindl., Edwards's Bot. Reg. 21: sub t. 1797. 1835. Syn.: Crocodeilanthe jamiesonii (Lindl.) Luer, Monogr. Syst. Bot. Missouri Bot. Gard. 95: 256. 2004. Stelis jamiesonii (Lindl.) Pridgeon \& M.W.Chase, Lindleyana 16: 264. 2001, nom. illeg. Non Stelis jamesonii Lindl., J. Bot. (Hooker) 1: 11. 1834.

Stelis salpingantha (Luer \& Hirtz) Pridgeon \& M.W.Chase, Lindleyana 16(4): 266. 2001.

Bas.: Pleurothallis salpingantha Luer \& Hirtz, Monogr. Syst. Bot. Missouri Bot. Gard. 65: 50-51. 1998. Syn.: Crocodeilanthe salpingantha (Luer \& Hirtz) Luer, Monogr. Syst. Bot. Missouri Bot. Gard. 95: 257. 2004.

Stelis simplicilabia (C.Schweinf.) Pridgeon \& M.W.Chase, Lindleyana 16(4): 266. 2001.

Bas.: Pleurothallis simplicilabia C.Schweinf., Revista Acad. Colomb. Ci. Exact. 5(19): 350. 1943. Syn.: Crocodeilanthe simplicilabia (C.Schweinf.) Luer, Monogr. Syst. Bot. Missouri Bot. Gard. 95: 257. 2004.

Stelis siphonantha (Luer) Pridgeon \& M.W.Chase, Lindleyana 16(4): 266. 2001. 


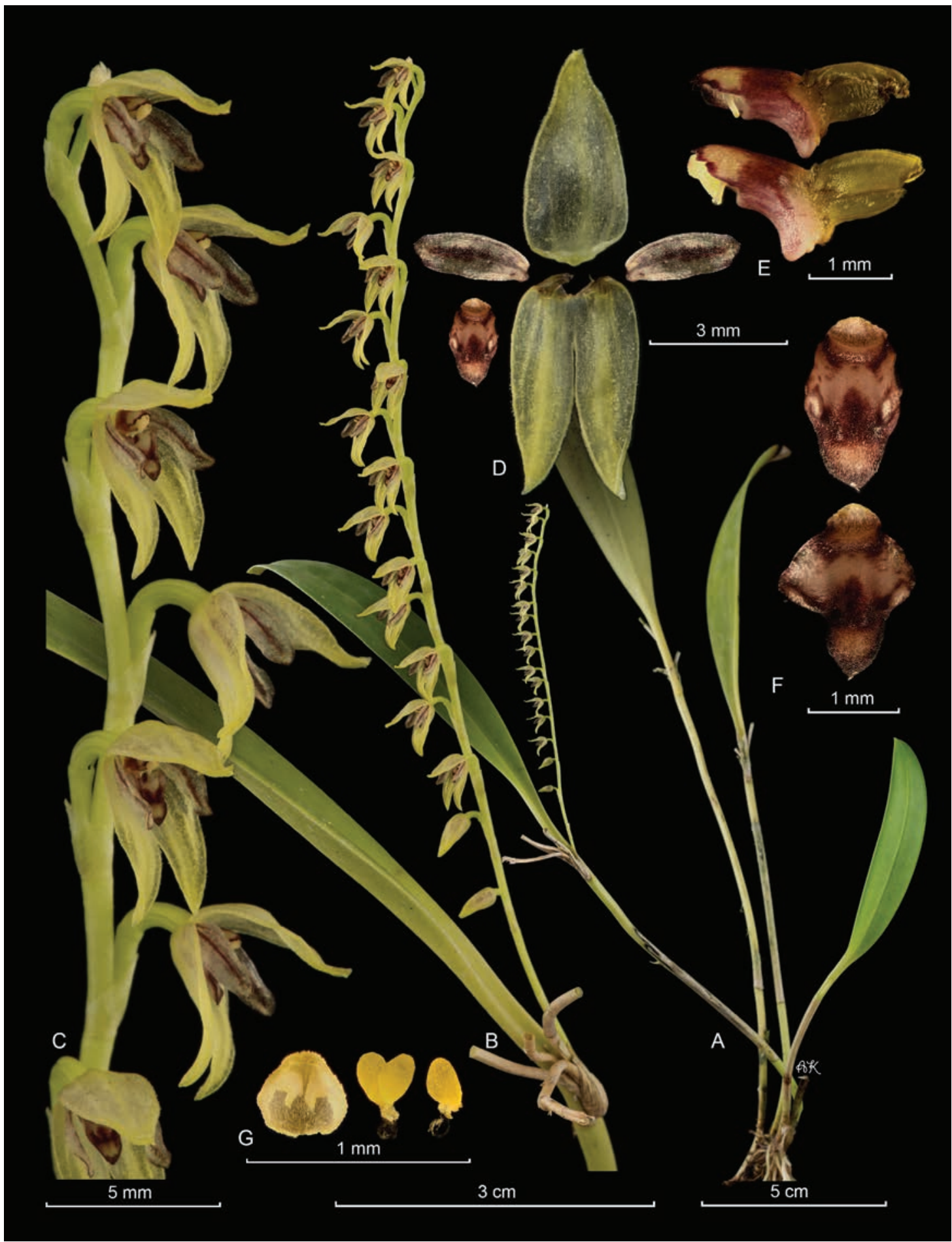

FIgURE 6. LCDP of Stelis pulchella a typical representative of Stelis sect. Crocodeilanthe. A. Habit. B. Inflorescence. C. Flowers. D. Dissected perianth. E. Column ventral and lateral view. F. Lip naturally and expanded. G. Anther cap and pollinarium. Photographs by AK based on $J B L-28245$ (JBL-spirit). 
Bas.: Pleurothallis siphonantha Luer, Monogr. Syst. Bot. Missouri Bot. Gard. 65: 52-53. 1998. Crocodeilanthe siphonantha (Luer) Luer, Monogr. Syst. Bot. Missouri Bot. Gard. 95: 257. 2004.

Stelis spathosa (Luer \& R.Escobar) Pridgeon \& M.W.Chase, Lindleyana 16(4): 266. 2001.

Bas.: Pleurothallis spathosa Luer \& R.Escobar, Orquideología 20: 86. 1996. Syn.: Crocodeilanthe spathosa (Luer \& R.Escobar) Luer, Monogr. Syst. Bot. Missouri Bot. Gard. 95: 257. 2004.

Stelis speciosa (Luer, Thoerle \& F.A.Werner) E.M.Pessoa \& M. Alves, Brittonia 66(2): 157. 2013.

Bas.: Crocodeilanthe speciosa Luer, Thoerle \& F.A. Werner, Harvard Pap. Bot. 16(2): 321. 2011. Syn.: Stelis speciosa (Luer, Thoerle \& F.A.Werner) J.M.H.Shaw, Orchid Rev. 122(1308): 78. 2014, nom. illeg.

Stelis stelidiopsis (Luer) Pridgeon \& M.W.Chase, Lindleyana 16(4): 266-267. 2001.

Bas.: Pleurothallis stelidiopsis Luer, Phytologia 49(3): 218. 1981. Syn.: Crocodeilanthe stelidiopsis (Luer) Luer, Monogr. Syst. Bot. Missouri Bot. Gard. 95: 257. 2004.

Stelis stergiosii (Carnevali \& I.Ramírez) Karremans, Phytotaxa 203(3): 293. 2015.

Bas.: Pleurothallis stergiosii Carnevali \& I.Ramírez, Harvard Pap. Bot. 3: 247. 1998. Syn.: Crocodeilanthe stergiosii (Carnevali \& I.Ramírez) Carnevali \& I.Ramírez, Nuevo Cat. Fl. Vasc. Venezuela 578. 2008 .

Stelis suinii (Luer) J.M.H.Shaw, Orchid Rev. 122(1308): 78. 2014.

Bas.: Crocodeilanthe suinii Luer, Monogr. Syst. Bot. Missouri Bot. Gard. 105: 249. 2006. Syn.: Pleurothallis suinii (Luer) Pfahl, Internet Orchid Sp. Photo Encycl. Nomencl. Notes 2. 2013. 2013.

Stelis taxis (Luer) Pridgeon \& M.W.Chase, Lindleyana 16(4): 267. 2001.

Bas.: Pleurothallis taxis Luer, Selbyana 5(2): 184. 1979. Crocodeilanthe taxis (Luer) Luer, Monogr. Syst. Bot. Missouri Bot. Gard. 95: 257. 2004.

Stelis tepuiensis (Carnevali \& I.Ramírez) Karremans, Phytotaxa 203(3): 294. 2015.
Bas.: Pleurothallis tepuiensis Carnevali \& I.Ramírez, Novon 3(2): 121. 1993. Syn.: Crocodeilanthe tepuiensis (Carnevali \& I.Ramírez) Carnevali \& I.Ramírez, Nuevo Cat. Fl. Vasc. Venezuela 758. 2008.

Stelis tunguraguae (F.Lehm. \& Kraenzl.) Pridgeon \& M.W.Chase, Lindleyana 16(4): 267. 2001.

Bas.: Pleurothallis tunguraguae F.Lehm. \& Kraenzl., Bot. Jahrb. Syst. 26: 439. 1899. Syn.: Crocodeilanthe tunguraguae (F.Lehm. \& Kraenzl.) Luer, Monogr. Syst. Bot. Missouri Bot. Gard. 95: 257. 2004.

Stelis uvaegelata Doucette ex L.E.Matthews, OrchideenJ. 6(3): 13. 2018.

Stelis vargasii (C.Schweinf.) Pridgeon \& M.W.Chase, Lindleyana 16(4): 267. 2001.

Bas.: Pleurothallis vargasii C.Schweinf., Bot. Mus. Leafl. 10: 192. 1942. Syn.: Crocodeilanthe vargasii (C.Schweinf.) Luer, Monogr. Syst. Bot. Missouri Bot. Gard. 95: 257. 2004.

Stelis vasqueziana Karremans, Phytotaxa 203(3): 294. 2015.

Bas.: Crocodeilanthe vasquezii Luer, Harvard Pap. Bot. 17(2): 340. 2012.

Stelis vegrandis (Luer \& Dodson) Pridgeon \& M.W.Chase, Lindleyana 16(4): 267. 2001.

Bas.: Pleurothallis vegrandis Luer \& Dodson, Monogr. Syst. Bot. Missouri Bot. Gard. 65: 56. 1998. Syn.: Crocodeilanthe vegrandis (Luer \& Dodson) Luer, Monogr. Syst. Bot. Missouri Bot. Gard. 95: 257. 2004.

Stelis velaticaulis (Rchb.f.) Pridgeon \& M.W.Chase, Lindleyana 16(4): 267. 2001.

Bas.: Pleurothallis velaticaulis Rchb.f., Linnaea 22: 824. 1849. Syn.: Crocodeilanthe velaticaulis (Rchb.f.) Luer, Monogr. Syst. Bot. Missouri Bot. Gard. 95: 257. 2004.

Stelis velatipes (Rchb.f.) Karremans, Phytotaxa 406(5): 267. 2019.

Bas.: Pleurothallis velatipes Rchb.f., Linnaea 22: 828. 1849. Syn.: Crocodeilanthe velatipes (Rchb.f.) Carnevali \& G.A.Romero, Nuevo Cat. Fl. Vasc. Venezuela 758. 2008. 
Stelis verbiformis (Luer) Pridgeon \& M.W.Chase, Lindleyana 16(4): 267. 2001.

Bas.: Pleurothallis verbiformis Luer, Selbyana 2: 389. 1978. Crocodeilanthe verbiformis (Luer) Luer, Monogr. Syst. Bot. Missouri Bot. Gard. 95: 257. 2004

Stelis virgata (Luer) Pridgeon \& M.W.Chase, Lindleyana 16(4): 267. 2001.

Bas.: Pleurothallis virgata Luer, Monogr. Syst. Bot. Missouri Bot. Gard. 65: 59. 1998. Crocodeilanthe virgata (Luer) Luer, Monogr. Syst. Bot. Missouri Bot. Gard. 95: 257. 2004.

Stelis weddelliana (Rchb.f.) Pridgeon \& M.W.Chase, Lindleyana 16(4): 267. 2001.

Bas.: Pleurothallis weddelliana Rchb.f., Xenia Orchid. 3: 24. 1878. Crocodeilanthe weddelliana (Rchb.f.) Luer, Monogr. Syst. Bot. Missouri Bot. Gard. 103: 309. 2005.

Stelis xiphizusa (Rchb.f.) Pridgeon \& M.W.Chase, Lindleyana 16: 268. 2001.

Bas.: Crocodeilanthe xiphizusa Rchb.f., Bonplandia (Hannover) 2(9): 114. 1854. Syn.: Pleurothallis xiphizusa (Rchb.f.) Rchb.f., Ann. Bot. Syst. 6(2): 172-173. 1861.

Stelis zunagensis (Luer \& Hirtz) Pridgeon \& M.W.Chase, Lindleyana 16(4): 268. 2001.

Bas.: Pleurothallis zunagensis Luer \& Hirtz, Monogr. Syst. Bot. Missouri Bot. Gard. 65: 61. 1998.

Syn.: Crocodeilanthe zunagensis (Luer \& Hirtz)

Luer, Monogr. Syst. Bot. Missouri Bot. Gard. 95: 257. 2004.

DNA data is available for Stelis atwoodi, $S$. galeata, S. pulchella, S. velaticaulis; the latter species are morphologically highly similar to Stelis xiphizusa, type species of Crocodeilanthe, of which no DNA data is currently available. There is no doubt that all typical species of Crocodeilanthe belong here. They consistently group together into a well supported clade that is very closely related to Stelis in the strict sense (Pridgeon et al. 2001, Solano-Gómez 2005, Karremans et al. 2013, Pérez-Escobar et al. 2017, Wilson et al. 2017, Ponert et al. 2019). This is consistent with the Stelis-like morphology of their flower, especially in an overall reduction in the column and lip, and pollinaria with a viscidium.
Stelis subgen. Crocodeilanthe sect. Pseudostelis (Schltr.) Karremans, comb. et stat. nov.

Bas.: Pseudostelis Schltr., Anexos Mem. Inst. Butantan, Secç. Bot. 1(4): 36. 1922. Syn. Pleurothallis subgen. Pseudostelis (Schltr.) Luer, Monogr. Syst. Bot. Missouri Bot. Gard. 76: 87. 1999. Lectotype: Physosiphon spiralis Lindl., Edwards's Bot. Reg. 21: sub t. 1797. 1835 (Garay 1974).

Stelis deregularis Barb.Rodr., Gen. Sp. Orchid. 2: 94. 1882. (Fig. 7)

Syn.: Physosiphon deregularis (Barb.Rodr.) Cogn., Fl. Bras. 3(4): 341-342. 1896. Pseudostelis deregularis (Barb.Rodr.) Schltr., Anexos Mem. Inst. Butantan, Secc. Bot. 1(4): 38. 1922. Pleurothallis deregularis (Barb.Rodr.) Luer, Selbyana 2(4): 385 386. 1978.

Syn.: Physosiphon spiralis Lindl., Edwards's Bot. Reg. 21: sub t. 1797. 1835. Crocodeilanthe spiralis (Lindl.) Toscano, Harvard Pap. Bot. 23(1): 54. 2018. Pseudostelis spiralis (Lindl.) Schltr., Anexos Mem. Inst. Butantan, Secc. Bot. 1(4): 38. 1922. Non Stelis spiralis (Ruiz \& Pav.) Pers., Syn. P1. 2: 524. 1807.

DNA studies consistently find the accessions of Stelis deregularis as sister to the remaining species of Stelis subgen. Crocodeilanthe (Karremans et al. 2013, Pérez-Escobar et al. 2017). No DNA data is available for Stelis bracteosa, S. magdalenae and $S$. melanostele which have been suggested to be close relatives of $S$. deregularis (Luer 1999, Toscano de Brito 2018a). Based on morphology Stelis bracteosa and $S$. melanostele are consistent with Stelis subgen. Crocodeilanthe but their affinity with $S$. deregularis is not as clear. They, together with the unresolved Stelis magdalenae, are excluded from this section until proven to belong here.

Stelis subgen. Physothallis (Garay) Karremans, comb. nov.

Bas. Physothallis Garay, Svensk Bot. Tidskr. 47: 199. 1953. Pleurothallis subgen. Physothallis (Garay) Luer, Monogr. Syst. Bot. Missouri Bot. Gard. 20: 53. 1986. Type: Physothallis harlingii Garay, Svensk Bot. Tidskr. 47(2): 199. 1953.

Syn. Pleurothallis subgen. Acuminatia Luer, Monogr. Syst. Bot. Missouri Bot. Gard. 76: 98. 


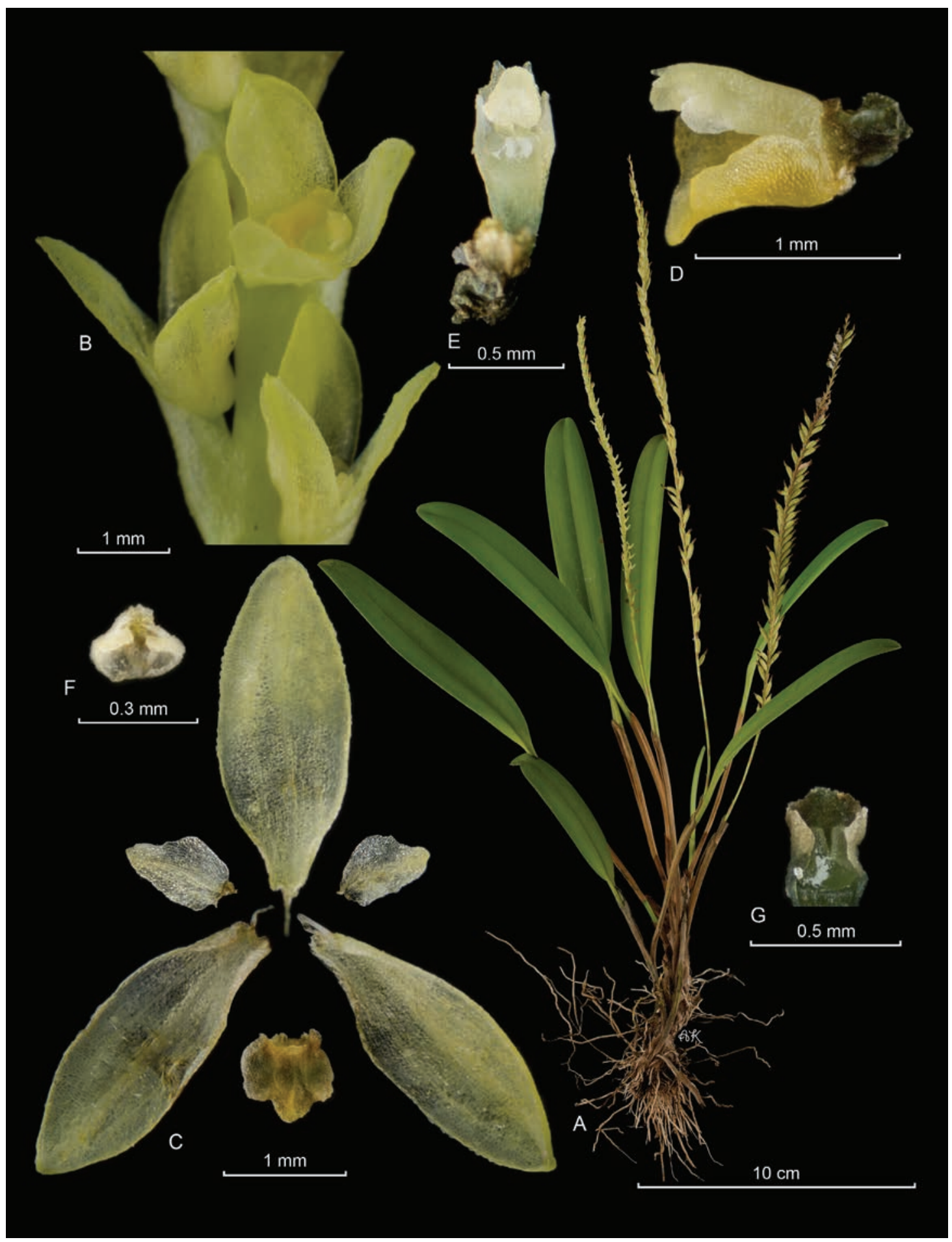

Figure 7. LCDP of Stelis deregularis, type species of Stelis sect. Pseudostelis. A. Habit. B. Flower. C. Dissected perianth. D. Column with lip, lateral view. E. Column ventral view. F. Anther cap. G. Pollinarium on the stigma. Photographs by AK based on Karremans 7303 (JBL-spirit). 
1999. Type: Dendrobium acuminatum Kunth, Nov. Gen. Sp. (quarto ed.) 1: 357. 1816.

The 31 species that belong to Stelis subgen. Physothallis are mostly found at high elevations in the Andes of Bolivia, Colombia, Ecuador, Peru and Venezuela. They are divided in three sections. Stelis sect. Acuminatae includes 27 species that generally have rather narrow distributions in the Andean countries, especially Bolivia and Peru, a single species from Central America, and a couple are reported from Mexico, Guyana and Brazil. The three members of Stelis sect. Physothallis are endemic to Ecuador. The sole member of Stelis sect. Rubens is widely distributed from Colombia to Bolivia and Brazil.

Despite being consistently found to be closely related to Stelis s.s. and Crocodeilanthe in every single phylogenetic study of the group (Karremans 2010, Chiron et al. 2012, Ramos-Castro et al. 2012, Karremans et al. 2013, Pérez-Escobar et al. 2017, Wilson et al. 2017), the inclusion of the members of Luer's Pleurothallis sect. Acuminatae in Stelis s.l. is still met with inexplicable resistance (e.g. Santos et al. 2018, 2019, Toscano de Brito 2018b, Govaerts et al. 2019). The exclusion of these species from genus Anathallis is not only evident morphologically (Karremans 2014), but is highly supported even in multi-gene genomic studies (Ponert et al. 2019). That they belong within a broadly defined Stelis is indisputable. What remains to be proven at this time is how these species interrelate as the analyses are inconclusive and the groupings proposed may be artificial. Three different clades are brought together: a) composed of the two species previously placed in genus Physothallis, plus Stelis lennartii (= Pleurothallis anderssonii Luer); b) the controversial Stelis montserratii (= Pleurothallis rubens Lindl.); and c) the remaining members of Pleurothallis sect. Acuminatae, including the type species Stelis aurea [= Pleurothallis acuminata (Kunth) Lindl.]. Each one is given sectional status.

The recognition of Stelis s.s. and Crocodeilanthe at generic level necessarily entails the recognition of Physothallis and probably of Pleurothallis sect. Acuminatae at generic level as well. This can only be done after resolving how the members of these two groups interrelate. .
Stelis subgen. Physothallis sect. Acuminatae (Lindl.)

Karremans, comb. nov.

Bas. Pleurothallis sect. Acuminatae Lindl. Fol. Orchid. Pleurothallis 32. 1859. Type: Dendrobium acuminatum Kunth, Nov. Gen. Sp. (quarto ed.) 1: 357. 1816.

Stelis ariasii (Luer \& Hirtz) Karremans, Lankesteriana 13(3): 328. 2014.

Bas.: Pleurothallis ariasii Luer \& Hirtz, Lindleyana 12(1): 42. 1997. Syn.: Anathallis ariasii (Luer \& Hirtz) Pridgeon \& M.W.Chase, Lindleyana 16(4): 247. 2001.

Stelis asperilinguis (Rchb.f. \& Warsz.) Karremans, Lankesteriana 13(3): 328. 2014.

Bas.: Pleurothallis asperilinguis Rchb.f. \& Warsz., Bonplandia (Hannover) 2: 114. 1854. Syn.: Anathallis asperilinguis (Rchb.f. \& Warsz.) Pridgeon \& M.W.Chase, Lindleyana 16(4): 247. 2001.

Stelis aurea (Lindl.) Karremans, Lankesteriana 13(3): 328. 2014. (Fig. 8)

Bas.: Pleurothallis aurea Lindl., Ann. Mag. Nat. Hist. 12(79): 397. 1843.

Syn.: Anathallis racemosa Barb.Rodr., Gen. Sp. Orchid. 1: 24. 1877. Syn.: Pleurothallis racemosa (Barb.Rodr.) Cogn., Fl. Bras. 3(4): 554. 1896.

Syn.: Dendrobium acuminatum Kunth, Nov. Gen. Sp. 1: 357. 1816. Anathallis acuminata (Kunth) Pridgeon \& M.W.Chase, Lindleyana 16(4): 247. 2001. Pleurothallis acuminata (Kunth) Lindl., Edwards's Bot. Reg. 28(Misc.): 70, no. 13. 1842. Non Stelis acuminata Luer \& Hirtz, Monogr. Syst. Bot. Missouri Bot. Gard. 95: 141. 2004.

Stelis bevilacquana (Carnevali \& I.Ramírez) Karremans, Phytotaxa 406(5): 265. 2019.

Bas.: Pleurothallis bevilacquana Carnevali \& I.Ramírez, Orchids Venez. (ed. 2) 1141. 2000.

Stelis candida (Luer \& Hirtz) Karremans, Lankesteriana 13(3): 328. 2014.

Bas.: Pleurothallis candida Luer \& Hirtz, Monogr. Syst. Bot. Missouri Bot. Gard. 76: 107. 1999. Anathallis candida (Luer \& Hirtz) Pridgeon \& M.W.Chase, Lindleyana 16(4): 248. 2001.

Stelis catenata Karremans, Lankesteriana 13(3): 328. 2014.

LANKESTERIANA 19(3). 2019. (C) Universidad de Costa Rica, 2019. 


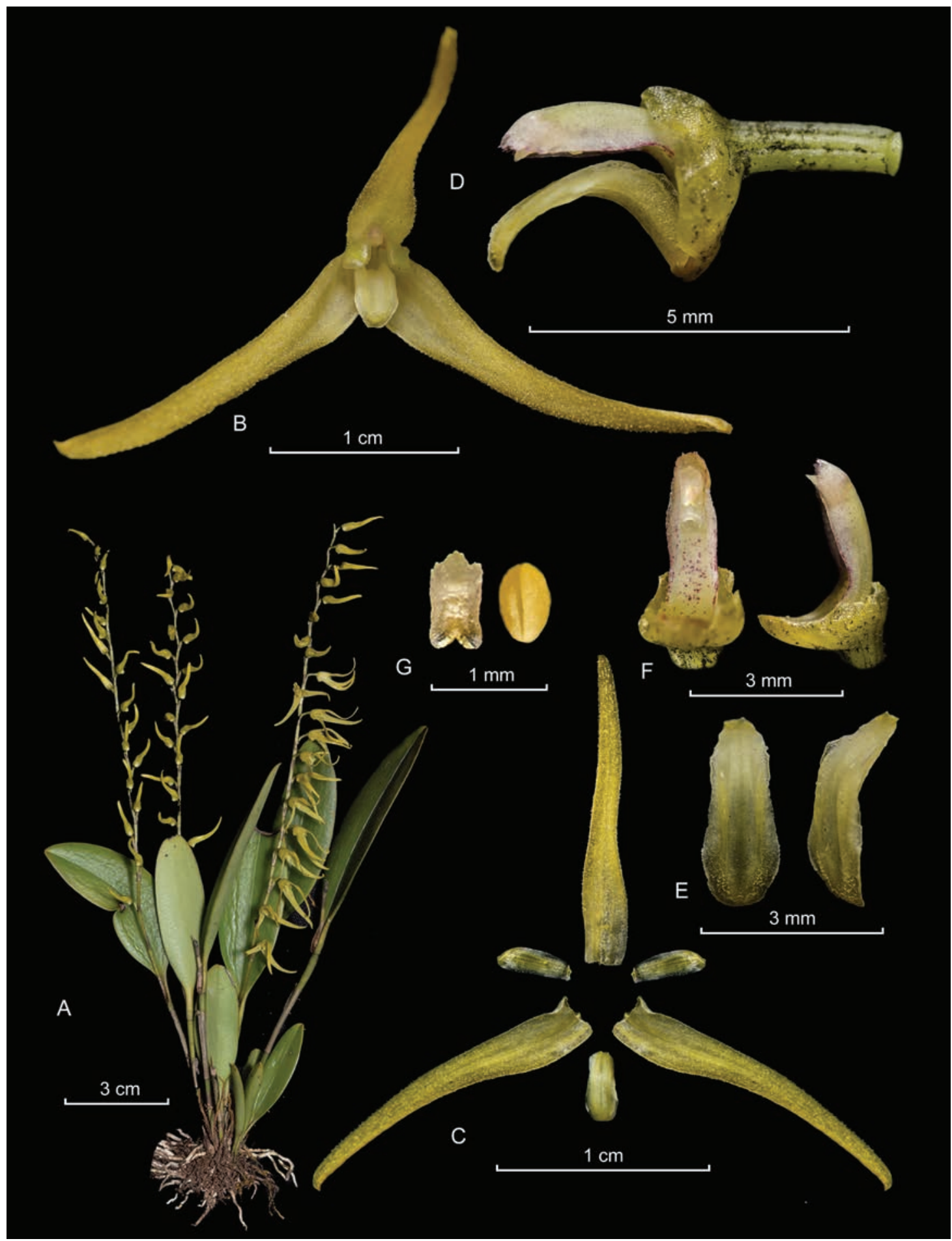

Figure 8. LCDP of Stelis aurea, type species of Stelis sect. Acuminatae. A. Habit. B. Flower. C. Dissected perianth. D. Column with lip, lateral view. E. Column ventral and lateral view. F. Lip. G. Anther cap and pollinarium. Photographs by J.S. Moreno based on Moreno 520 (CAUP). 
Repl. syn.: Pleurothallis ramulosa Lindl., Fol. Orchid. $\sim$ Pleurothallis $\sim$ 33. 1859. Syn.: Anathallis ramulosa (Lind1.) Pridgeon \& M.W.Chase, Lindleyana 16(4): 250. 2001. Non Stelis ramulosa Luer \& Dalström, Monogr. Syst. Bot. Missouri Bot. Gard. 95: 169. 2004.

Stelis coripatae (Luer \& R.Vásquez) Karremans, Lankesteriana 13(3): 328. 2014.

Bas.: Pleurothallis coripatae Luer \& R.Vásquez, Phytologia 46(6): 362. 1980. Syn.: Anathallis coripatae (Luer \& R.Vásquez) Pridgeon \& M.W.Chase, Lindleyana 16(4): 248. 2001.

Stelis dimidia (Luer) Karremans, Lankesteriana 13(3): 328. 2014.

Bas.: Pleurothallis dimidia Luer, Monogr. Syst. Bot. Missouri Bot. Gard. 76: 109. 1999. Syn.: Anathallis dimidia (Luer) Pridgeon \& M.W.Chase, Lindleyana 16(4): 248. 2001.

Stelis jesupiorum (Luer \& Hirtz) Karremans, Lankesteriana 13(3): 329. 2014.

Bas.: Pleurothallis jesupiorum Luer \& Hirtz, Lindleyana 11(3): 164. 1996. Syn.: Anathallis jesupiorum (Luer \& Hirtz) Pridgeon \& M.W.Chase, Lindleyana 16(4): 249. 2001.

Stelis lagarophyta (Luer) Karremans, Lankesteriana 13(3): 329. 2014.

Bas.: Pleurothallis lagarophyta Luer, Monogr. Syst. Bot. Missouri Bot. Gard. 76: 112-113. 1999. Syn.: Anathallis lagarophyta (Luer) Pridgeon \& M.W.Chase, Lindleyana 16(4): 249. 2001.

Stelis lauta Karremans, Lankesteriana 13(3): 329. 2014.

Repl. syn.: Pleurothallis concinna Luer \& R.Vásquez, Revista Soc. Boliv. Bot. 2(2): 133. 1999. Syn.: Anathallis concinna (Luer \& R.Vásquez) Pridgeon \& M.W.Chase, Lindleyana 16(4): 248. 2001. Non Stelis concinna Lindl., J. Bot. (Hooker) 1: 11.1834.

Stelis maguirei (Luer) Karremans, Lankesteriana 13(3): 329. 2014.

Bas.: Pleurothallis maguirei Luer, Monogr. Syst. Bot. Missouri Bot. Gard. 76: 113. 1999. Anathallis maguirei (Luer) Pridgeon \& M.W.Chase, Lindleyana 16(4): 249. 2001.
Stelis mediocarinata (C.Schweinf.) Karremans, Lankesteriana 13(3): 329. 2014.

Bas.: Pleurothallis mediocarinata C.Schweinf., Fieldiana, Bot. 33: 26. 1970. Syn.: Anathallis mediocarinata (C.Schweinf.) Pridgeon \& M.W.Chase, Lindleyana 16(4): 249. 2001.

Stelis melanopus (F.Lehm. \& Kraenzl.) Karremans, Lankesteriana 13(3): 329. 2014.

Bas.: Pleurothallis melanopus F.Lehm. \& Kraenzl., Bot. Jaarb. 26: 443. 1899.

Syn.: Pleurothallis stenophylla F.Lehm. \& Kraenzl., Bot. Jahrb. Syst. 26: 442. 1899. Anathallis stenophylla (F.Lehm. \& Kraenzl.) Pridgeon \& M.W.Chase, Lindleyana 16(4): 251. 2001. Non Stelis stenophylla Rchb.f., Bonplandia (Hannover) 3: 70.1855.

Stelis meridana (Rchb.f.) Karremans, Lankesteriana 13(3): 329. 2014.

Bas.: Pleurothallis meridana Rchb.f., Linnaea 22: 826. 1849. Syn.: Anathallis meridana (Rchb.f.) Pridgeon \& M.W.Chase, Lindleyana 16(4): 249. 2001.

Stelis papuligera (Schltr.) Karremans, Lankesteriana 13(3): 329. 2014.

Bas.: Pleurothallis papuligera Schltr., Repert. Spec. Nov. Regni Veg. 10: 453. 1912. Syn.: Anathallis papuligera (Schltr.) Pridgeon \& M.W.Chase, Lindleyana 16(4): 250. 2001.

Stelis peruviana Damián \& Karremans, Systematic Botany 41(2): 293. 2016.

Stelis poasensis (Ames) Chinchilla \& Karremans, Phytotaxa 406(5): 266. 2019. (Fig. 9)

Bas.: Pleurothallis poasensis Ames, Sched. Orch. 1: 10-11. 1922.

Syn.: Pleurothallis dolichopus Schltr., Repert. Spec. Nov. Regni Veg. 10(257-259): 394. 1912. Anathallis dolichopus (Schltr.) Pridgeon \& M.W.Chase, Lindleyana 16(4): 248. 2001. Non Stelis dolichopus Schltr., Orchis 6: 63. 1912.

Syn.: Pleurothallis lamprophylla Schltr., Repert. Spec. Nov. Regni Veg. 15(427-433): 205-206. 1918, nom. illeg. Stelis lamprophylla Karremans, Lankesteriana 13(3): 329. 2014, nom. nov. Non Pleurothallis lamprophyllum G.Nicholson, Ill. Dict. Gard., Cent. Suppl. 608. 1901. 


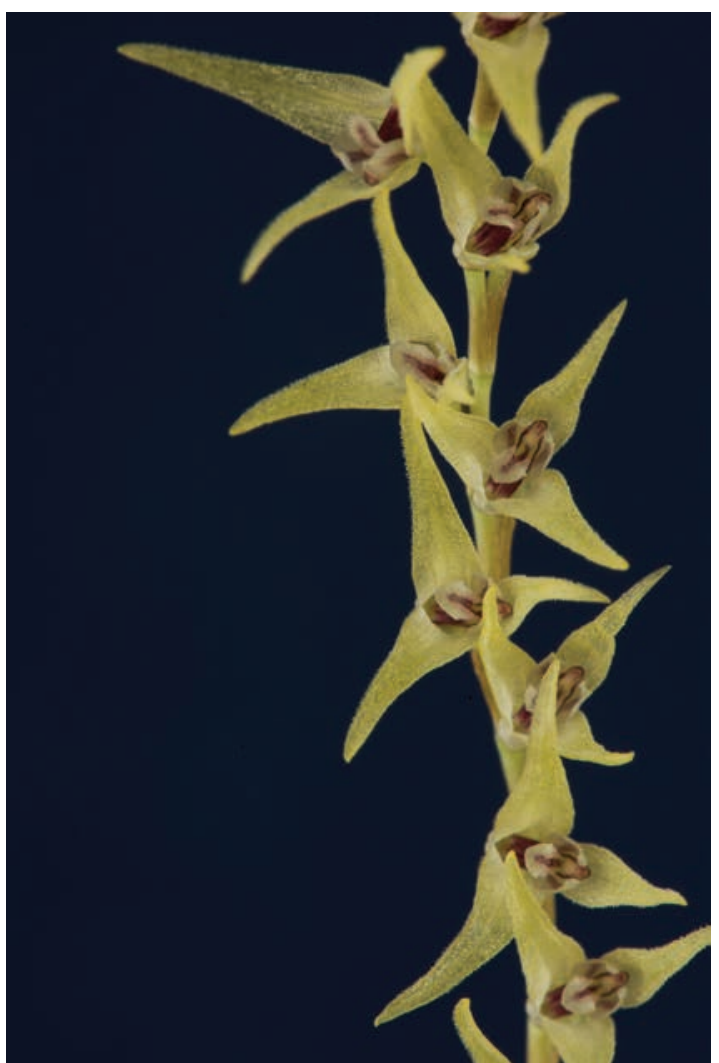

Figure 9. Stelis poasensis (Ames) Chinchilla \& Karremans, a typical species of Stelis sect. Acuminatae. Photograph by AK.

Syn.: Pleurothallis peregrina Ames, Sched. Orch. 6: 67-68. 1923.

Stelis regalis (Luer) Karremans, Lankesteriana 13(3): 329. 2014.

Bas.: Pleurothallis regalis Luer, Selbyana 5(2): 178. 1979. Syn.: Anathallis regalis (Luer) Pridgeon \& M.W.Chase, Lindleyana 16(4): 250. 2001.

Stelis scariosa (Lex.) Karremans, Lankesteriana 13(3): 330. 2014.

Bas.: Dendrobium scariosum Lex., Nov. Veg. Descr. 2(Orchid. Opusc.): 39-40. 1825. Syn.: Pleurothallis scariosa (Lex.) Lindl., Edwards's Bot. Reg. 28: Misc. 71. 1842. Anathallis scariosa (Lex.) Pridgeon \& M.W.Chase, Lindleyana 16(4): 250. 2001.

Stelis schlimii (Luer) Karremans, Lankesteriana 13(3): 330. 2014.

Bas.: Pleurothallis schlimii Luer, Monogr. Syst. Bot.
Missouri Bot. Gard. 76: 120. 1999. Syn.: Anathallis schlimii (Luer) Pridgeon \& M.W.Chase, Lindleyana 16(4): 250. 2001.

Stelis sclerophylla (Lindl.) Karremans, Lankesteriana 13(3): 330. 2014.

Bas.: Pleurothallis sclerophylla Lindl., Edwards's Bot. Reg. 21, sub. t. 1797 no. 31. 1835. Anathallis sclerophylla (Lindl.) Pridgeon \& M.W.Chase, Lindleyana 16(4): 250. 2001.

Stelis soratana (Rchb.f.) Karremans, Lankesteriana 13(3): 330. 2014.

Bas.: Pleurothallis soratana Rchb.f., Xenia Orchid. 3: 25. 1878. Syn.: Anathallis soratana (Rchb.f.) Pridgeon \& M.W.Chase, Lindleyana 16(4): 250. 2001.

Stelis spathilabia (Schltr.) Karremans, Lankesteriana 13(3): 330. 2014.

Bas.: Pleurothallis spathilabia Schltr., Repert. Spec. Nov. Regni Veg. Beih. 27: 56. 1924. Syn.: Anathallis spathilabia (Schltr.) Pridgeon \& M.W.Chase, Lindleyana 16(4): 251. 2001.

Stelis spathuliformis (Luer \& R.Vásquez) Karremans, Lankesteriana 13(3): 330. 2014.

Bas.: Pleurothallis spathuliformis Luer \& R.Vásquez, Revista Soc. Boliv. Bot. 2(2): 137. 1999. Syn.: Anathallis spathuliformis (Luer \& R.Vásquez) Pridgeon \& M.W.Chase, Lindleyana 16(4): 251. 2001.

Stelis unduavica (Luer \& R.Vásquez) Karremans, Lankesteriana 13(3): 330. 2014.

Bas.: Pleurothallis unduavica Luer \& R.Vásquez, Phytologia 46(6): 372. 1980. Syn.: Anathallis unduavica (Luer \& R.Vásquez) Pridgeon \& M.W.Chase, Lindleyana 16(4): 251. 2001.

Stelis vasquezii (Luer) Karremans, Lankesteriana 13(3): 330. 2014.

Bas.: Pleurothallis vasquezii Luer, Phytologia 49(3): 220. 1981. Anathallis vasquezii (Luer) Pridgeon \& M.W.Chase, Lindleyana 16(4): 251. 2001.

DNA data is available for several species belonging to this group, including the type of the section Stelis aurea (as Anathallis angustipetala), as well as S. dimidia, S. jesupiorum, S. poasensis (as Anathallis dolichopus and S. lamprophylla), S. sclerophylla (as Anathallis sclerophylla). They consistently group together into a 


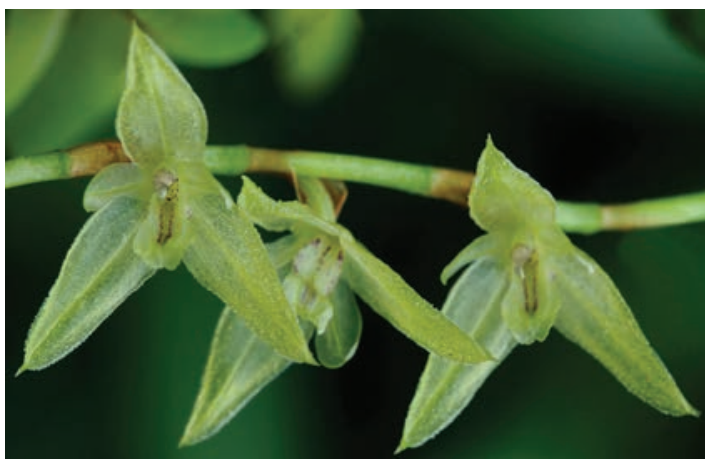

FIgURE 10. Stelis montserratii (Porsch) Karremans, type species of Stelis sect. Rubens. Photograph by J. Meijvogel.

well supported clade that is closely related to Stelis in the strict sense (Karremans et al. 2013, Pérez-Escobar et al. 2017, Wilson et al. 2017, Ponert et al. 2019).

Stelis subgen. Physothallis sect. Rubens Karremans, sect. nov.

Type: Pleurothallis rubens Lindl., Edwards's Bot. Reg. 21: pl. 1797, no. 32. 1836.

Distinguished from sect. Acuminatae by the subpandurate lip, the long-cucullate, pointed apex of the column.

Stelis montserratii (Porsch) Karremans, Lankesteriana 13(3): 329. 2014. (Fig. 10)

Bas.: Pleurothallis montserratii Porsch, Oesterr. Bot. Z. 158. 1905.

Syn.: Pleurothallis rubens Lindl., Edwards's Bot. Reg. 21: pl. 1797, no. 32. 1836. Specklinia rubens (Lindl.) F.Barros, Hoehnea 10: 110. 1984. Anathallis rubens (Lindl.) Pridgeon \& M.W.Chase, Lindleyana 16(4): 250. 2001. Specklinia rubens (Lindl.) Luer, Monogr. Syst. Bot. Missouri Bot. Gard. 95: 263. 2004. Stelis neorubens Chiron, Phytotaxa 46: 55. 2012. Non Stelis rubens Schltr., Repert. Spec. Nov. Regni Veg. 8(191-195): 564. 1910.

Syn.: Anathallis amblyopetala (Schltr.) Pridgeon \& M.W. Chase, Lindleyana 16(4): 247. 2001. Pleurothallis amblyopetala Schltr., Repert. Spec. Nov. Regni Veg. 12: 486. 1913.

Syn.: Pleurothallis excisa C.Schweinf., Bot. Mus. Leafl. 16: 48. 1953.

DNA studies confirm that the species previously known as Pleurothallis rubens is closely related to Stelis

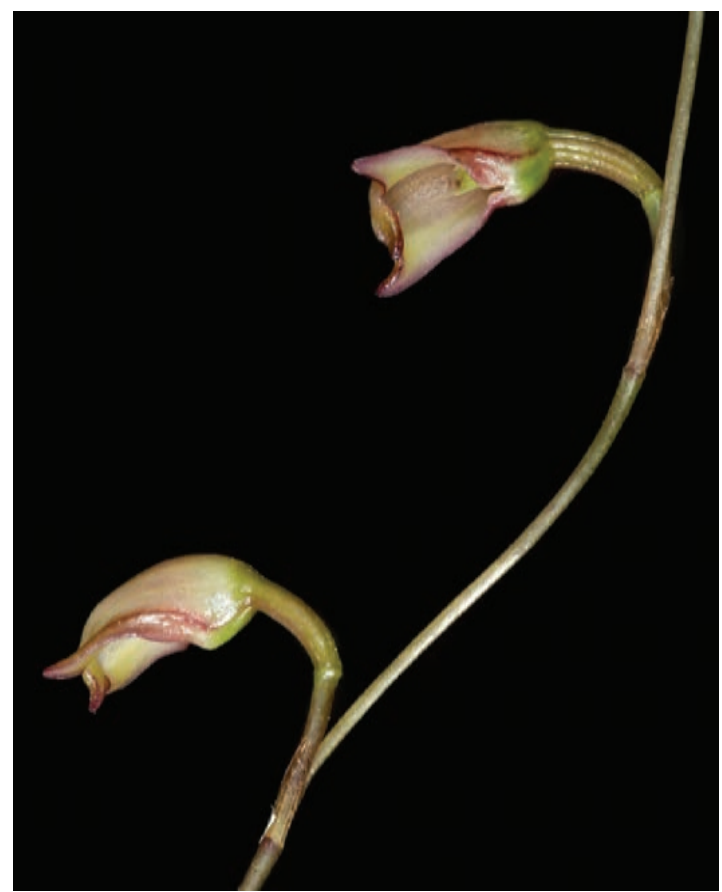

FIGURE 11. Stelis harlingii (Garay) Pridgeon \& M.W.Chase, type species of Stelis subgen. Physothallis. Photograph by E. Hunt.

in the strict sense (Chiron et al. 2012, Ramos-Castro et al. 2012, Karremans et al. 2013, Pérez-Escobar et al. 2017). It is yet unclear how it relates to other members of Stelis subgen. Physothallis and until that is resolved it is recognized as a distinct lineage within the group.

\section{Stelis subgen. Physothallis sect. Physothallis}

Stelis cylindrica (Luer) Pridgeon \& M.W.Chase, Lindleyana 16(4): 262. 2001.

Bas.: Physothallis cylindrica Luer, Selbyana 3(34): 224. 1977. Pleurothallis cylindrica (Luer) Luer, Monogr. Syst. Bot. Missouri Bot. Gard. 20: 53. 1986.

Stelis harlingii (Garay) Pridgeon \& M.W.Chase, Lindleyana 16(4): 263. 2001. (Fig. 11)

Bas.: Physothallis harlingii Garay, Svensk Bot. Tidskr. 47(2): 199-202. 1953. Pleurothallis neoharlingii Luer, Monogr. Syst. Bot. Missouri Bot. Gard. 20: 53. 1986.

Stelis lennartii Karremans, Lankesteriana 13(3): 329. 2014. 


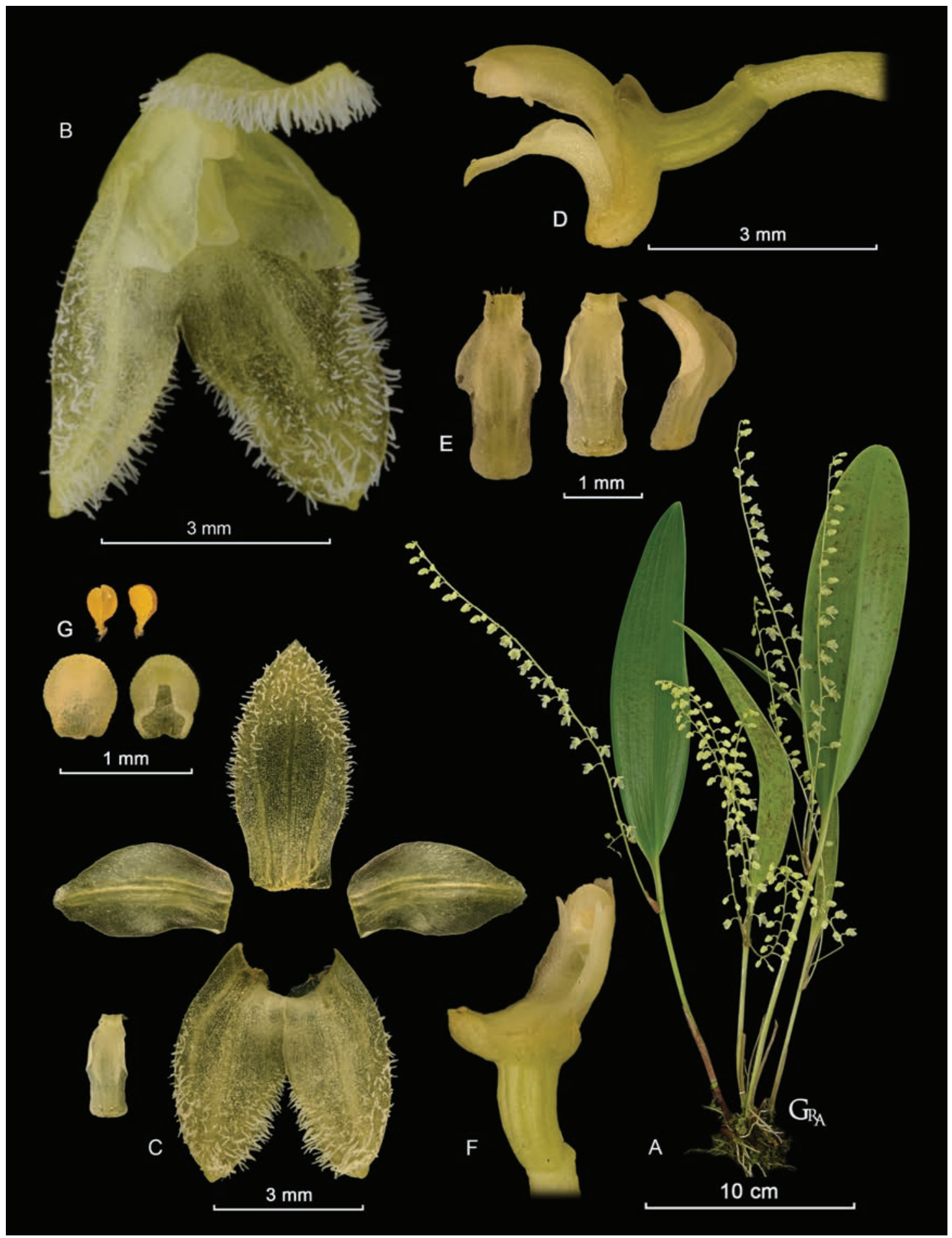

FiguRE 12. LCDP of Stelis gelida, type species of Stelis subgen. Niphantha. A. Habit. B. Flower. C. Dissected perianth. D. Column with lip, lateral view. E. Lip, three views. F. Column, three quarters view. G. Pollinarium and anther cap, two views. Photographs by G. Rojas-Alvarado based on Díaz-Morales 216 (JBL-spirit). 
Repl. syn.: Pleurothallis anderssonii Luer, Lindleyana 11(3): 145. 1996. Anathallis anderssonii (Luer) Pridgeon \& M.W.Chase, Lindleyana 16(4): 247. 2001. Non Stelis anderssonii Luer \& Endara, Monogr. Syst. Bot. Missouri Bot. Gard. 112. 2007.

Despite their morphological appearances, accessions of Stelis harlingii and Stelis lennartii form a well supported clade that appears to be somehow related to the other members of Stelis subgen. Physothallis (Karremans et al. 2013, Pérez-Escobar et al. 2017). Altogether they are sisters of Stelis subgen. Stelis and Stelis subgen. Crocodeilanthe (RamosCastro et al. 2012, Karremans et al. 2013, PérezEscobar et al. 2017, Ponert et al. 2019)

Stelis subgen. Niphantha (Luer) Karremans, comb. nov. Bas.: Niphantha Luer, Monogr. Syst. Bot. Missouri Bot. Gard. 120: 154. 2010. Type: Pleurothallis gelida Lindl., Edwards's Bot. Reg. 27: Misc. 91. 1841.

Stelis gelida (Lindl.) Pridgeon \& M.W.Chase, Lindleyana 16(4): 263. 2001. (Fig. 12)

Bas.: Pleurothallis gelida Lindl., Edwards's Bot. Reg. 27: Misc. 91. 1841. Syn.: Specklinia gelida (Lind1.) Luer, Monogr. Syst. Bot. Missouri Bot. Gard. 95: 260. 2004. Niphantha gelida (Lindl.) Luer, Monogr. Syst. Bot. Missouri Bot. Gard. 120: 154. 2010. Crocodeilanthe gelida (Lindl.) Carnevali \& I.Ramírez, Smithsonian Contr. Bot. 100: 133. 2014.

Stelis pidax (Luer) Karremans, Phytotaxa 203(3): 293. 2015.

Bas.: Pleurothallis pidax Luer, Selbyana 5(2): 174-175. 1979. Syn.: Anathallis pidax (Luer) Pridgeon \& M.W.Chase, Lindleyana 16(4): 250. 2001. Specklinia pidax (Luer) Luer, Monogr. Syst. Bot. Missouri Bot. Gard. 95: 263. 2004. Niphantha pidax (Luer) Luer, Monogr. Syst. Bot. Missouri Bot. Gard. 120: 154. 2010.

Stelis subgen. Niphantha currently includes two species of whitish, hirsute flowers. Stelis gelida is a common species with the widest distribution in the genus, it is found from Florida and Mexico, through Central America and the Antilles, down to Peru, Bolivia and Brazil. Stelis pidax is only known from Ecuador.

Accessions of both Stelis gelida and S. pidax where consistently found to form a clade sister to Stelis s.s., Crocodeilanthe and Physothallis (Karremans 2010, Karremans et al. 2013, Pérez-Escobar et al. 2017). This is consistent with the highly unusual morphology of these two species. Some authors have suggested that Stelis gelida is morphologically similar to species of Crocodeilanthe, and may be belong there (Carnevali \& Dorr 2014; Toscano de Brito 2018a). However, the similarities are at best superficial. The reddish, tightly clasping ramicaul bracts, pandurate lip, elongate and curved column, with conspicuous apical teeth, the incumbent anther, and lack of viscidium, among many other features, are unlike any Crocodeilanthe species.

Stelis subgen. Physosiphon (Lindl.) Karremans, comb. nov.

Bas.: Physosiphon Lindl., Edwards's Bot. Reg. 21: t. 1797. 1835. Pleurothallis subgen. Physosiphon (Lind1.) Luer, Monogr. Syst. Bot. Missouri Bot. Gard. 20: 50. 1986. Lectotype: Stelis tubata G.Lodd., Bot. Cab. 17: t. 1601. 1830, selected here. (Fig. 13)

Syn. Lomax Luer, Monogr. Syst. Bot. Missouri Bot. Gard. 105: 88. 2006. Type: Physosiphon punctulatus Rchb.f., Botanische Zeitung (Berlin) 24(49): 385. 1866.

Stelis asperrima (Luer) Pridgeon \& M.W.Chase, Lindleyana 16(4): 261. 2001.

Bas.: Pleurothallis asperrima Luer, Phytologia 49(3): 201. 1981. Syn.: Physosiphon asperrimus (Luer) Luer, Monogr. Syst. Bot. Missouri Bot. Gard. 105: 252. 2006.

Stelis emarginata (Lindl.) Soto Arenas \& Solano, Icon. Orchid. (Mexico) 5-6: t. 681. 2002 [2003].

Bas.: Pleurothallis emarginata Lindl., Gen. Sp. Orchid. Pl. 6. 1830. Physosiphon emarginatus (Lindl.) Lindl., Edwards's Bot. Reg. 21: sub t. 1797. 1835 .

Syn.: Stelis tubata G.Lodd., Bot. Cab. 17(161): t. 1601. 1830. Physosiphon loddigesii Lindl., Edwards's Bot. Reg. 21: sub t. 1797. 1836, nom. inval. Physosiphon loddigesii Lindl. ex Hook. Icon. P1. 6: t. 508. 1843, nom. inval. Pleurothallis tubata (G.Lodd.) Steud., Nomencl. Bot. (ed. 2) 2: 356. 1841. Physosiphon tubatus (G.Lodd.) Rchb.f., Ann. Bot. Syst. 6(2): 188. 1861. 


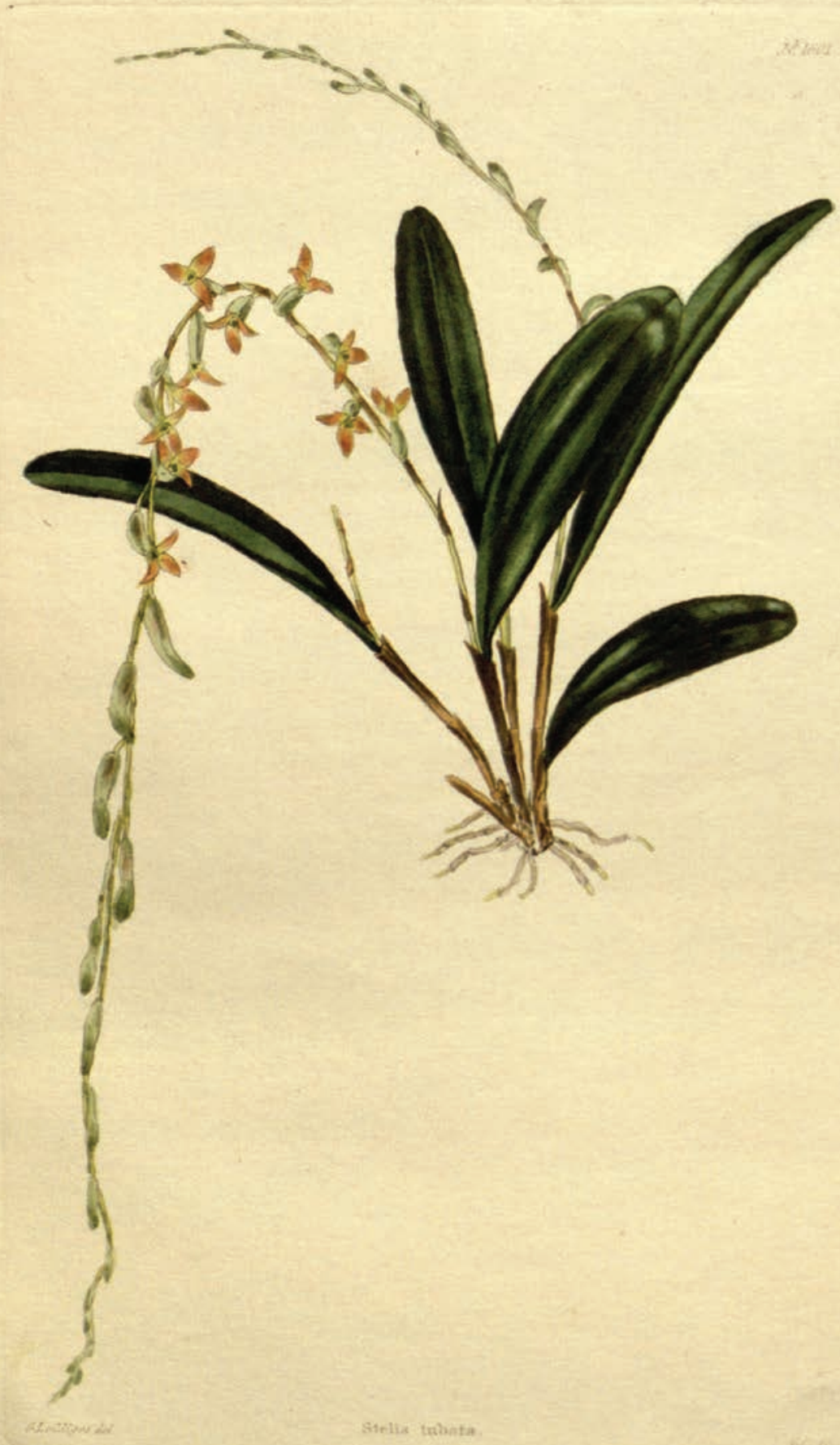

FiguRE 13. Stelis tubata G.Lodd., selected as lectotype of genus Physosiphon Lindl., illustration of type reproduced in the Botanical Cabinet 17: t. 1601. 1830. 
Stelis greenwoodii Soto Arenas \& Solano, Icon. Orchid. (Mexico) 5-6: , t. 682. 2002 [2003].

Syn.: Physosiphon greenwoodii (Soto Arenas \& Solano) Pfahl, Internet Orchid Sp. Photo Encycl. Nomencl. Notes 1. 2014. 2014.

Stelis pertusa I.Jiménez, Lankesteriana 15(3): 192. 2015.

Stelis punctulata (Rchb.f.) Soto Arenas, Icon. Orchid. (Mexico) 5-6: t. 690. 2002 [2003]. (Fig. 14)

Bas.: Physosiphon punctulatus Rchb.f., Bot. Zeitung (Berlin) 24(49): 385. 1866. Syn.: Lomax punctulata (Rchb.f.) Luer, Monogr. Syst. Bot. Missouri Bot. Gard. 105: 88-89. 2006.

Stelis tacanensis Solano \& Soto Arenas, Icon. Orchid. (Mexico) 5-6: t. 693. 2002 [2003].

Syn.: Physosiphon tacanensis (Solano \& Soto Arenas) Archila \& Szlach., Orchid Gen. Sp. Guatemala 643. 2018.

The six species that belong to Stelis subgen. Physosiphon are distributed from Mexico and Guatemala, where the highest diversity is found, through Central America, and down to Bolivia.

DNA data is available for Stelis emarginata, $S$. punctulata and $S$. tacanensis, they consistently group together in a clade that is sister to a clade that includes Stelis subgen. Niphantha, Stelis subgen. Physothallis, Stelis subgen. Crocodeilanthe and Stelis subgen. Stelis (Pridgeon et al. 2001, Solano-Gómez 2005, Karremans 2010, Karremans et al. 2013, Pérez-Escobar et al. 2017).

Alrich and Higgins (2011) mistakenly indicate that Physosiphon spiralis Lindl. (= Stelis deregularis) was selected as lectotype for genus Physosiphon by Garay (1974). The author selects $P$. spiralis as lectotype for Pseudostelis, not Physosiphon. Here Stelis tubata (= S. emarginata), which had already been mentioned by Pfeiffer (1873) as type, is selected as lectotype for this species as it is clearly what Lindley based his concept of Physosiphon on.

Stelis subgen. Dracontia (Luer) Karremans, comb. nov.

Bas. Pleurothallis subgen. Dracontia Luer, Monogr. Syst. Bot. Missouri Bot. Gard. 20: 38. 1986. Dracontia (Luer) Luer, Monogr. Syst. Bot. Missouri Bot. Gard. 95: 257. 2004. Type:

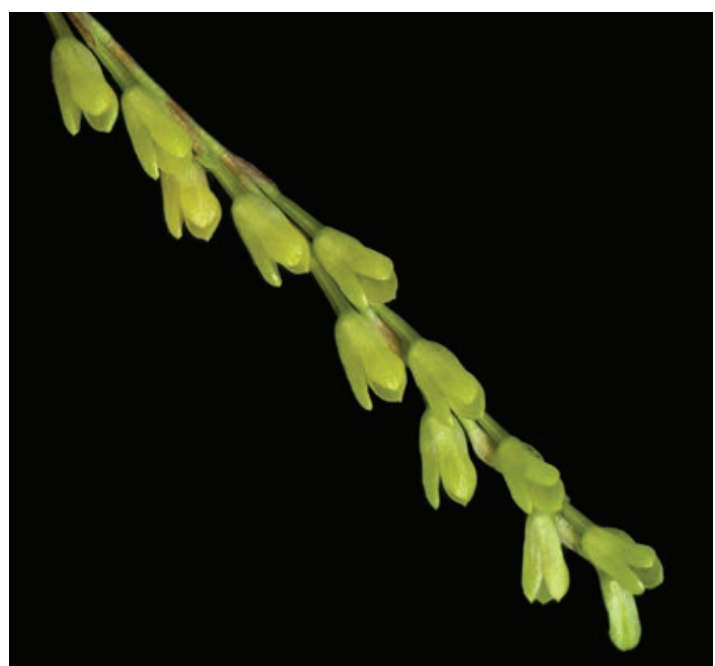

FiguRE 14. Stelis punctulata (Rchb.f.) Soto Arenas, type species of genus Lomax (=Stelis subgen. Physosiphon). Photograph by AK.

Pleurothallis tuerckheimii Schltr., Repert. Spec. Nov. Regni Veg. 10(251-253): 292. 1912.

Syn. Salpistele Dressler, Orquideologia 14: 6. 1979.

Type: Salpistele brunnea Dressler, Orquideología 14(1): 6-8. 1979.

Syn. Mystacorchis Szlach. \& Marg., Polish Bot. J. 46: 117. 2001. Type: Pleurothallis mystax Luer, Selbyana 3: 146. 1976.

About three fourths of the 40 species that belong to Stelis subgen. Dracontia are endemic to Costa Rica and Panama. A few species extend northwards into Mexico and Guatemala, a couple are known from the Antilles, and three make it downwards into the Andes.

The floral morphology of this group is highly variable, lacking apparent diagnostic features. It is made up of a clade with the species of Luer's Pleurothallis subgen. Dracontia, together with Pleurothallis subgen. Mystax, intermingled with several species placed in Pleurothallis subgen. Effusia Lindl. and one of Pleurothallis sect. Elongatae Lindl. It includes a clade composed of the species of Salpistele and Pleurothallis sect. Petiolatae. Despite the discrepancy in floral morphology, there is no doubt that species of Dracontia, Mystax, Petiolatae and Salpistele are closely related as suspected from vegetative features and consistently demonstrated by DNA studies (Pridgeon et al. 2001, Solano-Gómez 2005, Karremans 2010, Karremans et al. 2013, Pérez-Escobar et al. 2017, Wilson et al. 
2017). Future genetic studies are necessary to confirm the placement of some species listed here that have not been previously analyzed, especially those placed by Luer in Pleurothallis subgen. Effusia.

Despite its distinctive floral morphology, the recognition of genus Salpistele as originally circumscribed necessarily entails the recognition of Dracontia, Mystacorchis and several other small genera. The more distinctive groups are here given sectional status.

\section{Stelis subgen. Dracontia sect. Dracontia}

Syn. Pleurothallis sect. Brobdingnagia Luer, Monogr. Syst. Bot. Missouri Bot. Gard. 72: 66. 1998. Type: Pleurothallis grandis Rolfe, Bull. Misc. Inform. Kew 1918(7): 234. 1918.

Syn. Pleurothallis sect. Cylindria Luer, Monogr. Syst. Bot. Missouri Bot. Gard. 72: 66. 1998. Type: Pleurothallis macrantha L.O.Williams, Ann. Missouri Bot. Gard. 28(4): 417. 1941.

Stelis aenigma Karremans \& M.Díaz, Lankesteriana 17(2): 197. 2017.

Stelis alajuelensis Pridgeon \& M.W.Chase, Lindleyana 17(2): 98. 2002.

Repl. syn.: Pleurothallis ramonensis Schltr., Repert. Spec. Nov. Regni Veg. Beih. 19: 193194. 1923. Dracontia ramonensis (Schltr.) Luer, Monogr. Syst. Bot. Missouri Bot. Gard. 95: 257. 2004. Stelis ramonensis (Schltr.) Pridgeon \& M.W.Chase, Lindleyana 16: 266. 2001, nom. illeg. Non Stelis ramonensis Schltr., Repert. Spec. Nov. Regni Veg. Beih. 19: 176. 1923.

Stelis alta Pridgeon \& M.W.Chase, Lindleyana 17(2): 98. 2002. (Fig. 15)

Repl. syn.: Pleurothallis grandis Rolfe, Bull. Misc. Inform. Kew 1918(7): 234. 1918. Dracontia grandis (Rolfe) Luer, Monogr. Syst. Bot. Missouri Bot. Gard. 95: 257. 2004. Stelis grandis (Rolfe) Pridgeon \& M.W.Chase, Lindleyana 16: 263. 2001, nom. illeg. Non Stelis grandis Rchb.f., Bonplandia (Hannover) 3: 70. 1855.

Stelis carnosilabia (A.H.Heller \& A.D.Hawkes) Pridgeon \& M.W.Chase, Lindleyana 16(4): 261. 2001.

Bas.: Pleurothallis carnosilabia A.H.Heller \& A.D.Hawkes, Phytologia 14(1): 9-10. 1966.
Syn.: Dracontia carnosilabia (A.H.Heller \& A.D.Hawkes) Luer, Monogr. Syst. Bot. Missouri Bot. Gard. 95: 257. 2004.

Stelis cobanensis (Schltr.) Pridgeon \& M.W.Chase, Lindleyana 16(4): 262. 2001.

Bas.: Pleurothallis cobanensis Schltr., Repert. Spec. Nov. Regni Veg. 11(271-273): 42. 1912. Syn.: Dracontia cobanensis (Schltr.) Luer, Monogr. Syst. Bot. Missouri Bot. Gard. 95: 257. 2004. Rhynchopera cobanensis (Schltr.) Luer, Monogr. Syst. Bot. Missouri Bot. Gard. 112: 121. 2007.

Stelis conochila (Luer) Pridgeon \& M.W.Chase, Lindleyana 16(4): 262. 2001.

Bas.: Pleurothallis conochila Luer, Lindleyana 11: 75. 1996. Syn.: Dracontia cobanensis (Schltr.) Luer, Monogr. Syst. Bot. Missouri Bot. Gard. 95:257.2004.

Stelis convoluta (Lindl.) Pridgeon \& M.W.Chase, Lindleyana 16(4): 262. 2001.

Bas.: Pleurothallis convoluta Lindl., Ann. Mag. Nat. Hist. 15: 107. 1845. Syn.: Effusiella convoluta (Lind1.) Luer, Monogr. Syst. Bot. Missouri Bot. Gard. 112: 106. 2007.

Stelis cylindrata Pridgeon \& M.W.Chase, Lindleyana 17(2): 98. 2002. (Fig. 16)

Repl. syn.: Pleurothallis macrantha L.O.Williams, Ann. Missouri Bot. Gard. 28(4): 417. 1941. Dracontia macrantha (L.O.Williams) Luer, Monogr. Syst. Bot. Missouri Bot. Gard. 95: 257. 2004. Stelis macrantha (L.O.Williams) Pridgeon \& M.W.Chase, Lindleyana 16: 264. 2001, nom. illeg. Non Stelis macrantha Rolfe, Bull. New York Bot. Gard. 4: 450. 1907.

Stelis dies-natalis Karremans \& M.Díaz, Lankesteriana 17(2): 194. 2017.

Stelis dilatata (C.Schweinf.) Pridgeon \& M.W.Chase, Lindleyana 16(4): 262. 2001.

Bas.: Pleurothallis dilatata C.Schweinf., Bot. Mus. Leafl. 10: 177. 1942. Syn.: Effusiella dilatata (C.Schweinf.) Luer, Monogr. Syst. Bot. Missouri Bot. Gard. 112: 106. 2007.

Stelis dracontea (Luer) Pridgeon \& M.W.Chase, Lindleyana 16(4): 262. 2001. (Fig. 17)

Bas.: Pleurothallis dracontea Luer, Phytologia 49(3): 204-205. 1981. Syn.: Dracontia dracontea 


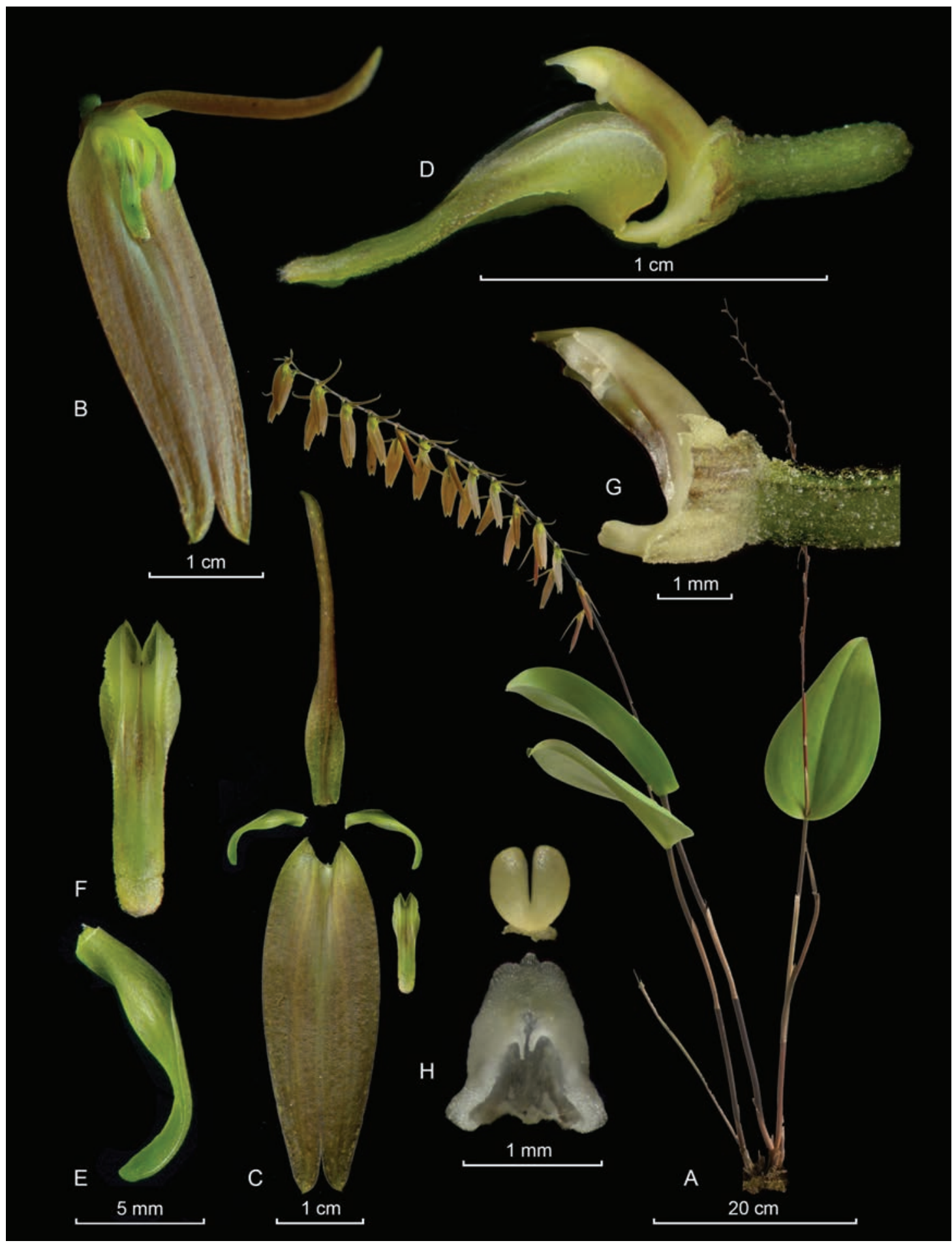

FIGURE 15. LCDP of Stelis alta Pridgeon \& M.W.Chase, type species of Pleurothallis sect. Brobdingnagia Luer (= Stelis sect. Dracontia). A. Habit. B. Flower. C. Dissected perianth. D. Column with lip, lateral view. E. Petal. F. Lip. G. Column side view. H. Anther cap and pollinarium. Photographs by F. Pupulin based on Bogarín 4604 (JBL-spirit). 


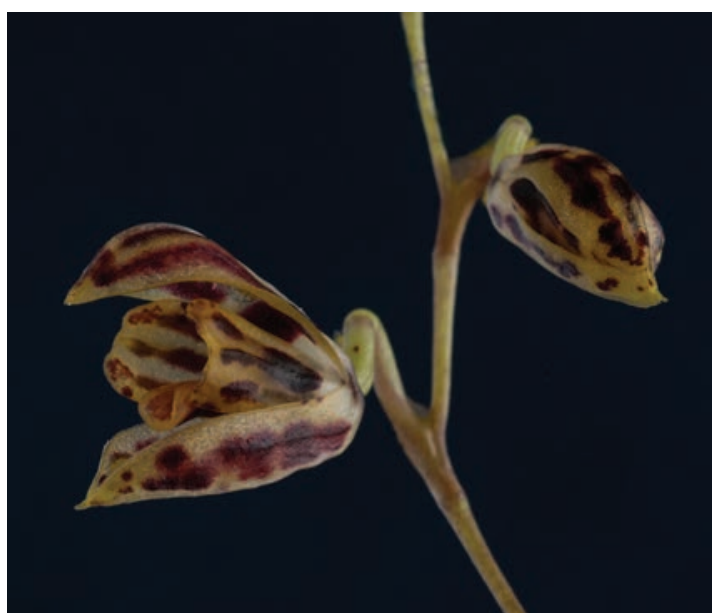

FIGURE 16. Stelis cylindrata Pridgeon \& M.W.Chase, type species of Pleurothallis sect. Cylindria Luer (= Stelis sect. Dracontia). Photograph by AK.

Right, Figure 17. Stelis dracontea, a typical species of Stelis sect. Dracontia. Photograph by AK based on Bogarín 616 (JBL-spirit).

(Luer) Luer, Monogr. Syst. Bot. Missouri Bot. Gard. 95: 257. 2004.

Stelis ferrelliae Pridgeon \& M.W.Chase, Lindleyana 17(2): 99. 2002.

Repl. syn.: Pleurothallis ingramii Luer, Lindleyana 11(2): 81. 1996. Dracontia ingramii (Luer) Luer, Monogr. Syst. Bot. Missouri Bot. Gard. 95: 257. 2004. Stelis ingramii (Luer) Pridgeon \& M.W.Chase, Lindleyana 16: 263. 2001, nom. illeg. Non Stelis ingramii Luer, Lindleyana 11: 100. 1996.

Stelis fortunae (Luer \& Dressler) Pridgeon \& M.W.Chase, Lindleyana 16(4): 263. 2001.

Bas.: Pleurothallis fortunae Luer \& Dressler, Lindleyana 6(2): 97, 100. 1991. Syn.: Dracontia fortunae (Luer \& Dressler) Luer, Monogr. Syst. Bot. Missouri Bot. Gard. 95: 257. 2004.

Stelis gigantea Pridgeon \& M.W.Chase, Lindleyana 17(2): 99. 2002.

Repl. syn.: Pleurothallis powellii Schltr., Repert. Spec. Nov. Regni Veg. Beih. 17: 22. 1922. Dracontia powelli (Schltr.) Luer, Monogr. Syst. Bot. Missouri Bot. Gard. 95: 257. 2004. Stelis powellii (Schltr.) Pridgeon \& M.W.Chase, Lindleyana 16: 265. 2001, nom. illeg. Non Stelis powellii Schltr., Repert. Spec. Nov. Regni Veg. Beih. 17: 16. 1922.

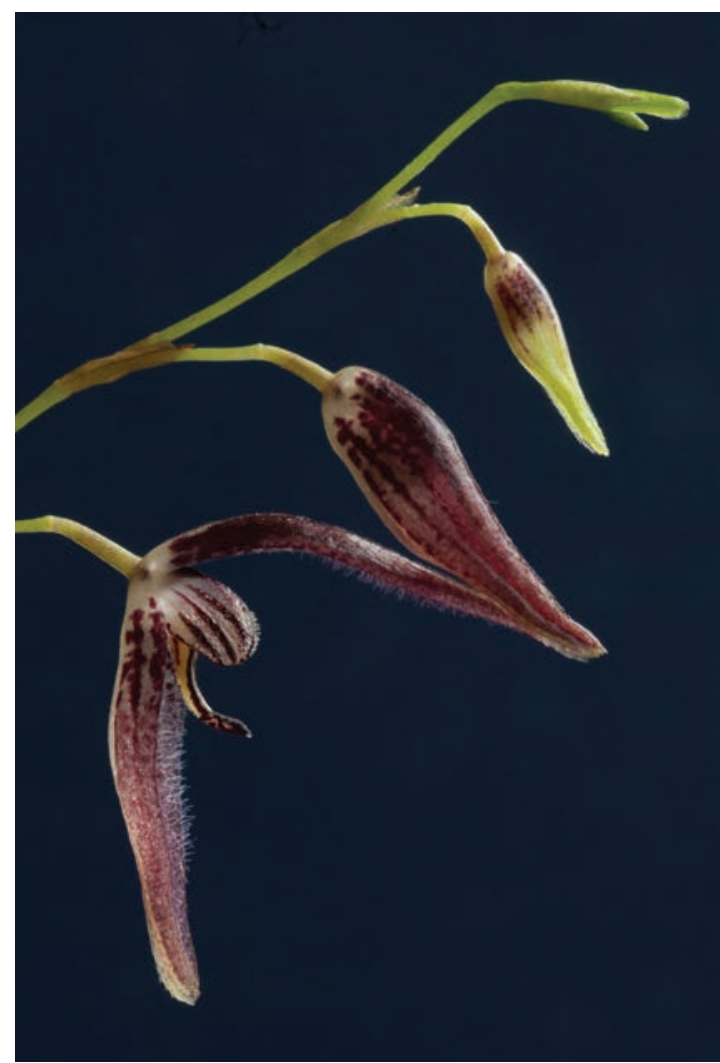

Stelis hydra (Karremans \& C.M.Sm.) Karremans, Phytotaxa 203(3): 292. 2015.

Bas.: Dracontia hydra Karremans \& C.M.Sm., Harvard Pap. Bot. 17(1): 13. 2012.

Stelis lueriana (Karremans) J.M.H.Shaw, Orchid Rev. 122(1308): 77. 2014.

Bas.: Dracontia lueriana Karremans, Ann. Naturhist. Mus. Wien, Ser. B, Bot. Zool. 113: 128. 2012.

Stelis megachlamys (Schltr.) Pupulin, Lankesteriana 4: 74. 2002. (Fig. 18)

Bas.: Pleurothallis megachlamys Schltr., Repert. Spec. Nov. Regni Veg. Beih. 19: 108. 1923.

Syn.: Pleurothallis tuerckheimii Schltr., Repert. Spec. Nov. Regni Veg. 10(251-253): 292. 1912. Dracontia tuerckheimii (Schltr.) Luer, Monogr. Syst. Bot. Missouri Bot. Gard. 95: 257. 2004. Non Stelis tuerckheimii Schltr., Repert. Spec. Nov. Regni Veg. 8(191-195): 564. 1910.

Stelis megachlamys f. viridiflavens (Roeth \& Baumbach.) Karremans, comb. nov. 


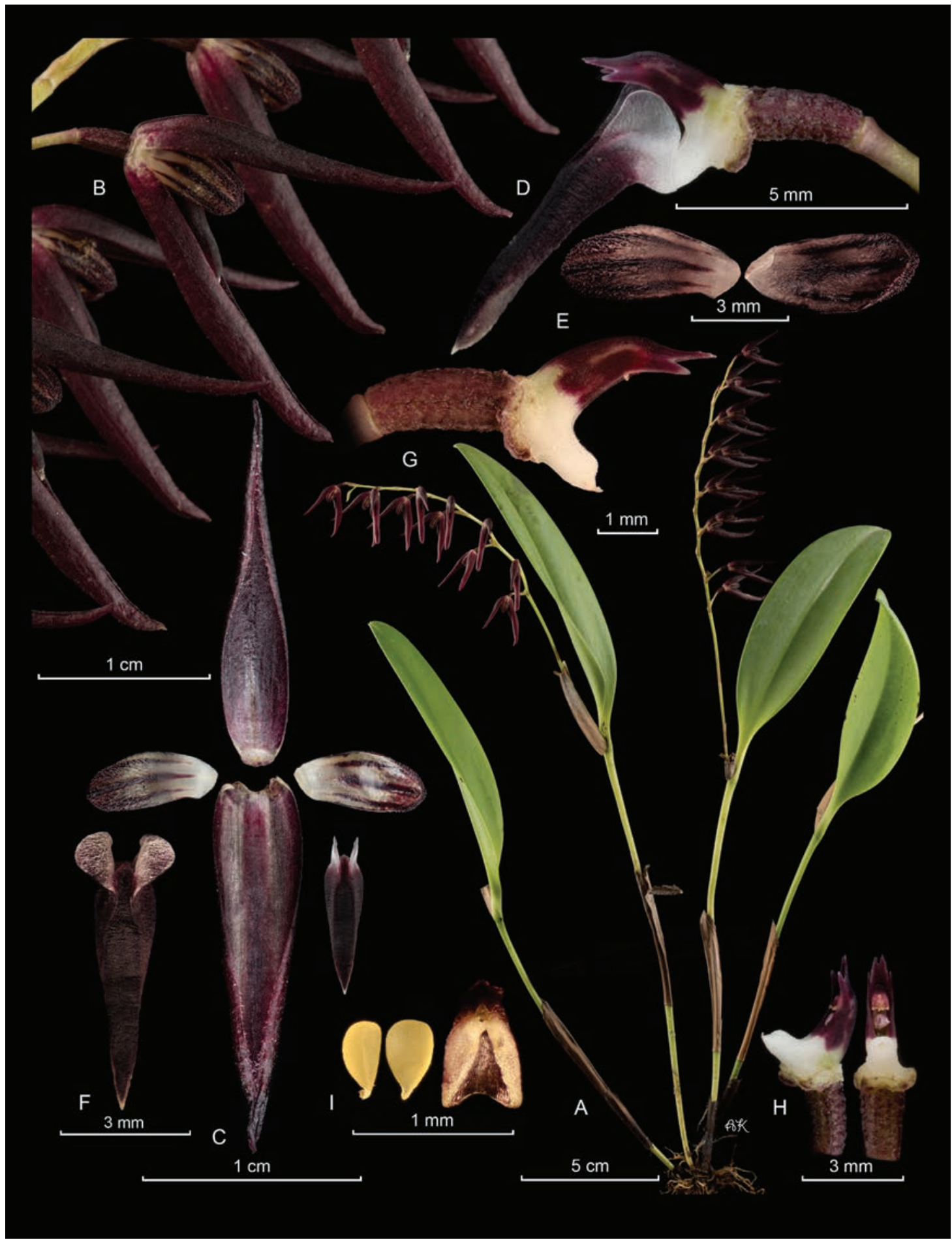

Figure 18. LCDP of Stelis megachlamys (Schltr.) Pupulin, type species of Stelis subgen. Dracontia. A. Habit. B. Inflorescence. C. Dissected perianth. D. Column with lip, lateral view. E. Petals. F. Lip. G. Column lateral view. H. Column ventral and side view. I. Anther cap and pollinarium. Photographs by AK based on Bogarín 2161 (JBL-spirit). 
Bas.: Dracontia tuerckheimii f. viridiflavens Roeth \& Baumbach, Orchidee (Hamburg) 58: 98. 2007.

Syn.: Pleurothallis kelloggii Archila, Rev. Guatem. 15(1): 106. 2012.

Stelis montis-mortense (Karremans \& Bogarín) Bogarín \& Karremans, Lankesteriana 14(3): 270. 2014.

Bas.: Dracontia montis-mortense Karremans \& Bogarín, Syst. Bot. 38(2): 307. 2013.

Stelis multirostris (Rchb.f.) Pridgeon \& M.W.Chase, Lindleyana 17(2): 100. 2002.

Bas.: Pleurothallis multirostris Rchb.f., Linnaea 41: 49. 1877.

Syn.: Epidendrum racemiflorum Sw., Prodr. 125, 1788. Dendrobium racemiflorum (Sw.) Sw., Nov. Act. Upsal. 6: 83, 1799. Pleurothallis racemiflora (Sw.) Lindl. in Hook. Exot. Fl. 2: t. 123.1825 [1824]. Anathallis racemiflora (Sw.) Pridgeon \& M.W.Chase, Lindleyana 16: 250. 2001, nom. inval. Stelis racemiflora (Sw.) Pridgeon \& M.W.Chase, Lindleyana 16: 266. 2001, nom. inval. Non Stelis racemiflora (Lindl. ex Lodd.) W.H.Baxter in J.C.Loudon, Hort. Brit., Suppl. 3: 643. 1850.

Syn.: Pleurothallis oblongifolia Lindl., Companion Bot. Mag. 2(24): 355. 1836. Stelis oblongifolia (Lindl.) Pridgeon \& M.W.Chase, Lindleyana 16: 265. 2001, nom. illeg. Dracontia oblongifolia (Lindl.) Luer, Monogr. Syst. Bot. Missouri Bot. Gard. 95: 257. 2004. Rhynchopera oblongifolia (Lindl.) Luer, Monogr. Syst. Bot. Missouri Bot. Gard. 112: 121. 2007. Non Stelis oblongifolia Lindl., Fol. Orchid. 8: 12.1859.

Syn.: Pleurothallis tricostata Cogn., Symb. Antill. 7: 175, 1912.

Even though Epidendrum racemiflorum Sw. has priority over P. oblongifolia and P. multirostris, the name is already occupied by Stelis racemiflora (Lindl. ex Lodd.) W.H.Baxter which is not based on the same taxon. The true identity of Epidendrum racemiflorum Sw. has been confused since the nineteen hundreds, and the taxonomy of this name continues to be highly confused today. The available type material shows a species belonging to Stelis sect. Dracontia, which has generally been known as Pleurothallis oblongifolia. However, when Lindley, in Hooker, transferred Swartz's name to Pleurothallis, he described and illustrated a different species. That other species is here treated under the name Pleurothallis quadrifida (Lex.) Lindl., and it is further discussed below.

Pridgeon and Chase (2001) proposed the names Anathallis racemiflora and Stelis racemiflora using the basionym "Pleurothallis racemiflora Lindl. ex Lodd. in Hook., Exot. Fl. 2: t. 123. 1825". Both names are invalid for two reasons, under article 36.3 (ICN; Turland et al. 2018) for being published simultaneously and under article 41.5 (ICN; Turland et al. 2018) for the erroneous citation and reference to the publication of the basionym. Although not the only interpretation, it is more parsimonious to assume that the authors referred to Pleurothallis racemiflora (Sw.) Lindl. in Hook., Exot. Fl. 2: t. 123. 1825 [1824], which is based on Epidendrum racemiflorum Sw., Prodr. 125, 1788. In Pridgeon and Chase (2002), the authors placed their S. racemiflora under the synonymy of $A$. racemiflora, but did not validate the name, for they failed to indicate this was intended, and again cited the wrong basionym.

Stelis pachyglossa (Lindl.) Pridgeon \& M.W.Chase, Lindleyana 16(4): 265. 2001.

Bas.: Pleurothallis pachyglossa Lindl., Edwards's Bot. Reg. 26: Misc. 68. 1840. Syn.: Dracontia pachyglossa (Lindl.) Luer, Monogr. Syst. Bot. Missouri Bot. Gard. 95: 257. 2004.

Stelis papillifera (Rolfe) Pridgeon \& M.W.Chase, Lindleyana 16(4): 265. 2001.

Bas.: Pleurothallis papillifera Rolfe, Bull. Misc. Inform. Kew 1916(3): 77. 1916. Bas.: Dracontia papillifera (Rolfe) Luer, Monogr. Syst. Bot. Missouri Bot. Gard. 95: 257. 2004.

Stelis pileata (Karremans \& Bogarín) Karremans \& Bogarín, Phytotaxa 203(3): 293. 2015.

Bas.: Dracontia pileata Karremans \& Bogarín, Syst. Bot. 38(2): 308, 310-311. 2013.

Stelis platystylis (Schltr.) Solano \& Soto Arenas, Icon. Orchid. (Mexico) 10: t. 1097. 2008.

Bas.: Pleurothallis platystylis Schltr., Repert. Spec. Nov. Regni Veg. 10(257-259): 395. 1912. Syn.: Effusiella platystylis (Schltr.) Luer, Monogr. Syst. Bot. Missouri Bot. Gard. 112: 107. 2007. Anathallis platystylis (Schltr.) Pridgeon \& M.W.Chase, Lindleyana 16(4): 250. 2001. 
Stelis prolixa (Luer \& Hirtz) Pridgeon \& M.W.Chase, Lindleyana 16(4): 265. 2001.

Bas.: Pleurothallis prolixa Luer \& Hirtz, Lindleyana 11(3): 179-180. 1996. Syn.: Effusiella prolixa (Luer \& Hirtz) Luer, Monogr. Syst. Bot. Missouri Bot. Gard. 112: 107. 2007.

Stelis simplex (Ames \& C.Schweinf.) Pridgeon \& M.W.Chase, Lindleyana 16(4): 266. 2001.

Bas.: Pleurothallis simplex Ames \& C.Schweinf., Sched. Orch. 10:37-38. 1930. Syn.: Crocodeilanthe simplex (Ames \& C.Schweinf.) Toscano, Harvard Pap. Bot. 23(1): 54. 2018.

Stelis tenebrosa (Archila, Szlach. \& Chiron) Karremans, Phytotaxa 203: 293. 2015.

Bas.: Dracontia tenebrosa Archila, Szlach. \& Chiron, Revista Guatemal. 16(1): 30. 2013.

Stelis thymochila (Luer) Pridgeon \& M.W.Chase, Lindleyana 16(4): 267. 2001.

Bas.: Pleurothallis thymochila Luer, Selbyana 3(3-4): 398-399, f. 299. 1977. Syn.: Dracontia thymochila (Luer) Luer, Monogr. Syst. Bot. Missouri Bot. Gard. 95: 257. 2004.

Stelis tintinnabula (Luer) Pridgeon \& M.W.Chase, Lindleyana 16(4): 267. 2001.

Bas.: Pleurothallis tintinnabula Luer, Lindleyana 11(2): 94. 1996. Syn.: Dracontia tintinnabula (Luer) Luer, Monogr. Syst. Bot. Missouri Bot. Gard. 95: 257. 2004.

Stelis tortilis (Luer \& R.Escobar) Pridgeon \& M.W.Chase, Lindleyana 16(4): 267. 2001.

Bas.: Pleurothallis tortilis Luer \& R.Escobar, Orquideología 14(2): 180. 1981. Syn.: Effusiella tortilis (Luer \& R.Escobar) Luer, Monogr. Syst. Bot. Missouri Bot. Gard. 112: 107. 2007.

Stelis viridiflava (Karremans \& Bogarín) Karremans, Phytotaxa 203(3): 294. 2015.

Bas.: Dracontia viridiflava Karremans \& Bogarín, Syst. Bot. 38(2): 311. 2013.

Thirty species belong to Stelis sect. Dracontia. DNA data is available for Stelis alta, S. carnosilabia, S. cobanensis, S. conochila, S. cylindrata, S. hydra, S ferrelliae, S. gigantea, S. hydra, S. lueriana, S. megachlamys, S. multirostris, S. pachyglossa, S. papillifera, S. pileata, S. platystylis, S. ramonensis and S. viridiflava

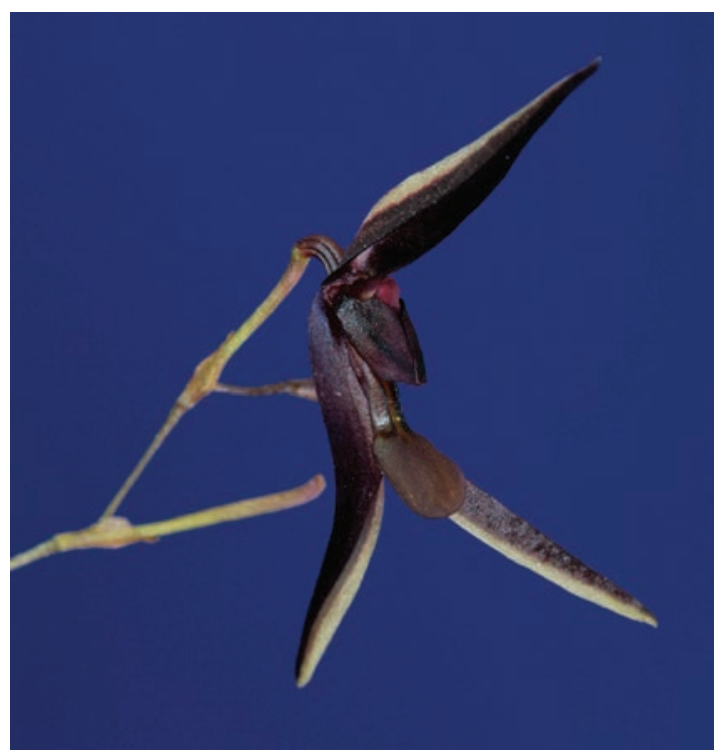

FiguRE 19. Stelis mystax, type species of Stelis sect. Mystax (Luer) Karremans. Photograph by D. Bogarín based on Bogarin 2988 (JBL-spirit).

(Pridgeon et al. 2001, Solano-Gómez 2005, Karremans 2010, Karremans et al. 2013, Pérez-Escobar et al. 2017, Ponert et al. 2019). They have consistently been shown to belong to Stelis sensu lato, where, despite the floral appearances, they are most closely related to species of Stelis sect. Mystax, Stelis sect. Petiolatae and Stelis sect. Salpistele. Although the flowers are quite unique, the plants of species belonging to this group are virtually indistinguishable from many typical Stelis species (Stelis s.s.). So much so, that Stelis simplex has not been associated with this group given the simple, very Stelis-like, flowers. The same happens with Stelis platystylis, S. prolixa and $S$. tortilis which due to their rather undifferentiated flowers have not been placed here.

Stelis subgen. Dracontia sect. Mystax (Luer) Karremans, comb. et stat. nov.

Bas. Pleurothallis subgen. Mystax Luer, Monogr. Syst. Bot. Missouri Bot. Gard. 20: 50. 1986. Type: Pleurothallis mystax Luer, Selbyana 3: 146. 1976. Syn. Mystacorchis Szlach. \& Marg., Polish Bot. J. 46: 117. 2001. Type: Pleurothallis mystax Luer, Selbyana 3: 146. 1976.

Stelis mystax (Luer) Pridgeon \& M.W.Chase, Lindleyana 16(4): 264. 2001. (Fig. 19) 


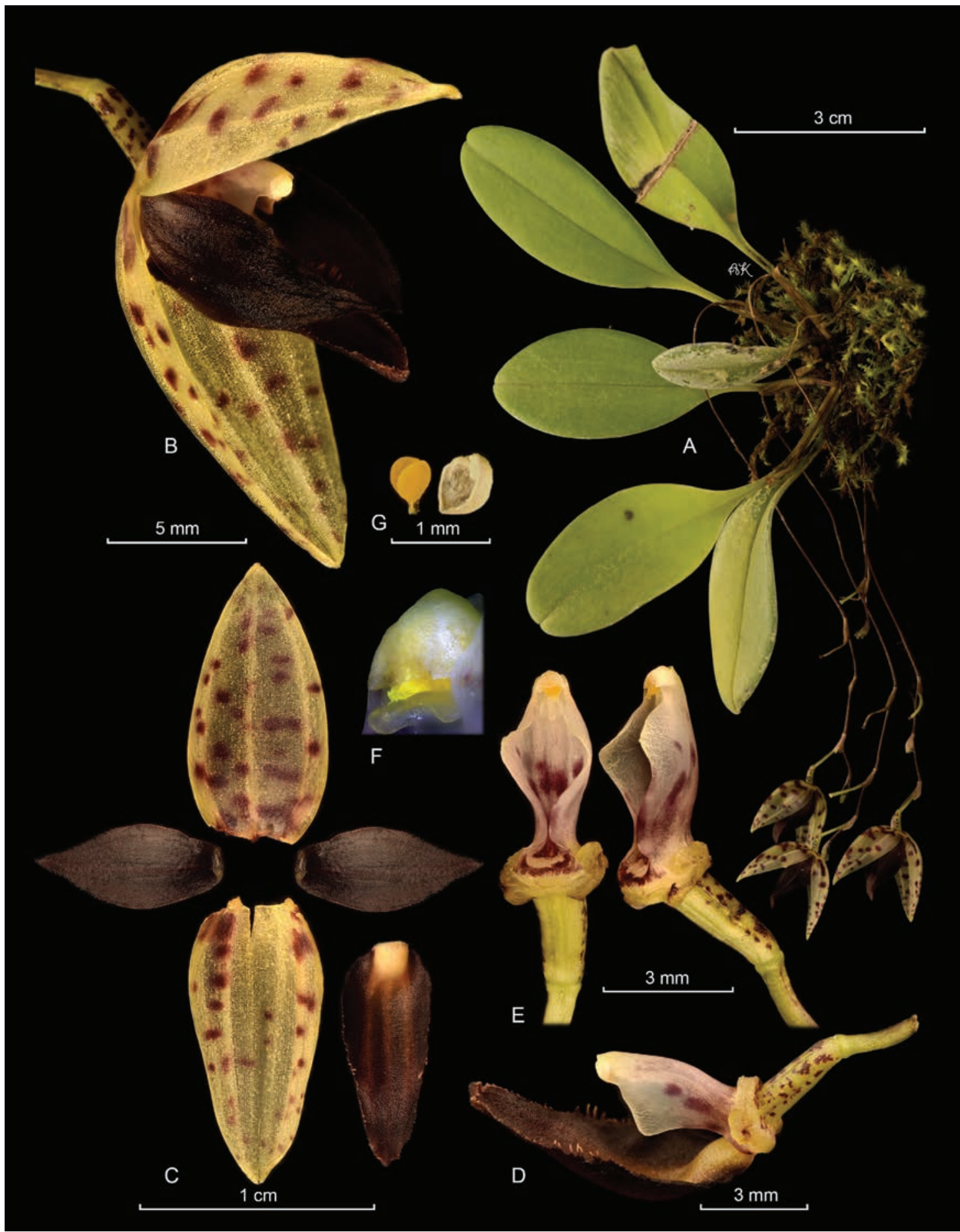

FiguRE 20. LCDP of Stelis guttata (Luer) Pridgeon \& M.W.Chase, type species of Stelis sect. Petiolatae (Luer) Karremans. A. Habit. B. Flower. C. Dissected perianth. D. Column with lip, lateral view. E. Column ventral and lateral views. F. Column apex. G. Anther cap and pollinarium, placed in the stigma. Photographs by AK based on Karremans 7201 (JBL-spirit). 
Bas.: Pleurothallis mystax Luer, Selbyana 3(1-2): 146-147, f. 176. 1976. Syn.: Mystacorchis mystax (Luer) Szlach. \& Marg., Polish Bot. J. 46(2): 117. 2001.

A single, aberrant species belongs to Stelis sect. Mystax. It is endemic to Panama, and morphologically has no close relatives. The available accessions of this species have been consistently found to group with other members of Stelis subgen. Dracontia, namely the very distinct, and also unique, Central American species, Stelis carpinterae and Stelis convallaria (Karremans et al. 2013, Pérez-Escobar et al. 2017). The plant and flower morphology are somewhat reminiscent of species belonging to Stelis sect. Dracontia, but the spathulate lip is quite unique.

Stelis subgen. Dracontia sect. Petiolatae (Luer) Karremans, comb. nov.

Bas. Pleurothallis sect. Petiolatae Luer, Monogr. Syst. Bot. Missouri Bot. Gard. 52: 70. 1994. Type: Pleurothallis guttata Luer, Selbyana 3(12): 116-177. 1976.

Stelis guttata (Luer) Pridgeon \& M.W.Chase, Lindleyana 16(4): 263. 2001. (Fig. 20)

Bas.: Pleurothallis guttata Luer, Selbyana 3(1-2): 116-177. 1976. Syn.: Elongatia guttata (Luer) Luer, Monogr. Syst. Bot. Missouri Bot. Gard. 95: 257. 2004.

Stelis janetiae (Luer) Pridgeon \& M.W.Chase, Lindleyana 16(4): 264. 2001.

Bas.: Pleurothallis janetiae Luer, Selbyana 5(2): 169-170. 1979. Syn.: Elongatia janetiae (Luer) Luer, Monogr. Syst. Bot. Missouri Bot. Gard. 95: 257. 2004.

Only two species are known to belong to Stelis sect. Petiolatae, and DNA data is available for both. Luer (1994) placed them in Elongatia (= Pleurothallis), with which they indeed share a very similar floral morphology. However, these two species endemic to Costa Rica and Panama belong without a doubt in Stelis sensu lato (Karremans 2010, Karremans et al. 2013, Pérez-Escobar et al. 2017). They are the closest relatives of Stelis sect. Salpistele, and even though their flowers are very different, the plants are basically larger versions of those.
Stelis subgen. Dracontia sect. Salpistele (Dressler) Karremans, comb. nov.

Bas. Salpistele Dressler, Orquideologia 14: 6. 1979. Type: Salpistele brunnea Dressler, Orquideología 14(1): 6-8. 1979.

Stelis brunnea (Dressler) Pridgeon \& M.W.Chase, Lindleyana 16(4): 261. 2001. (Fig. 21)

Bas.: Salpistele brunnea Dressler, Orquideología 14(1): 6-8. 1979.

Stelis cymbisepala Pridgeon \& M.W.Chase, Lindleyana 17(2): 98-99. 2002.

Repl. syn.: Salpistele dressleri Luer, Monogr. Syst. Bot. Missouri Bot. Gard. 39: 128. 1991. Non Stelis dressleri Luer, Phytologia 49(3): 227-228. 1981.

Stelis deutroadrianae J.M.H.Shaw, Orchid Rev. 122(1308): 77. 2014.

Repl. syn.: Salpistele adrianae Luer \& Sijm, Selbyana 30(1): 18. 2009. Stelis adriananijhuisae Bogarín \& Serr., Lankesteriana 14(3): 265. 2014, nom. superfl. Non Stelis adrianae Luer, Monogr. Syst. Bot. Missouri Bot. Gard. 88: 36. 2002.

Stelis gnoma Pridgeon \& M.W.Chase, Lindleyana 17(2): 99. 2002.

Repl. syn.: Salpistele parvula Luer \& Dressler, Monogr. Syst. Bot. Missouri Bot. Gard. 39: 132. 1991. Non Stelis parvula Lindl., Fol. Orchid. $\sim$ Stelis (8): 7. 1852-1855 [1859].

Stelis maculata Pridgeon \& M.W.Chase, Lindleyana 17(2): 99. 2002.

Repl. syn.: Salpistele lutea Dressler, Orquideología 14(1): 8-10. 1979. Non Stelis lutea Lindl., Fol. Orchid. Stelis 7. 1852-1855 [1859].

Five species are known to belong to Stelis sect. Salpistele, and DNA data is available for Stelis brunnea, $S$. deutroadrianae and $S$. maculata. Despite their Lepanthes-like flowers, species of this group have been consistently shown to belong to Stelis sensu lato based on DNA analyses (Pridgeon et al. 2001, Solano-Gómez 2005, Karremans 2010, Karremans et al. 2013, PérezEscobar et al. 2017; Wilson et al. 2017). Although not evident from floral morphology, they are without a doubt sister to the members of Stelis sect. Petiolatae, with which they share the small plants with petiolate leaves and a creeping inflorescence with successive flowers. 


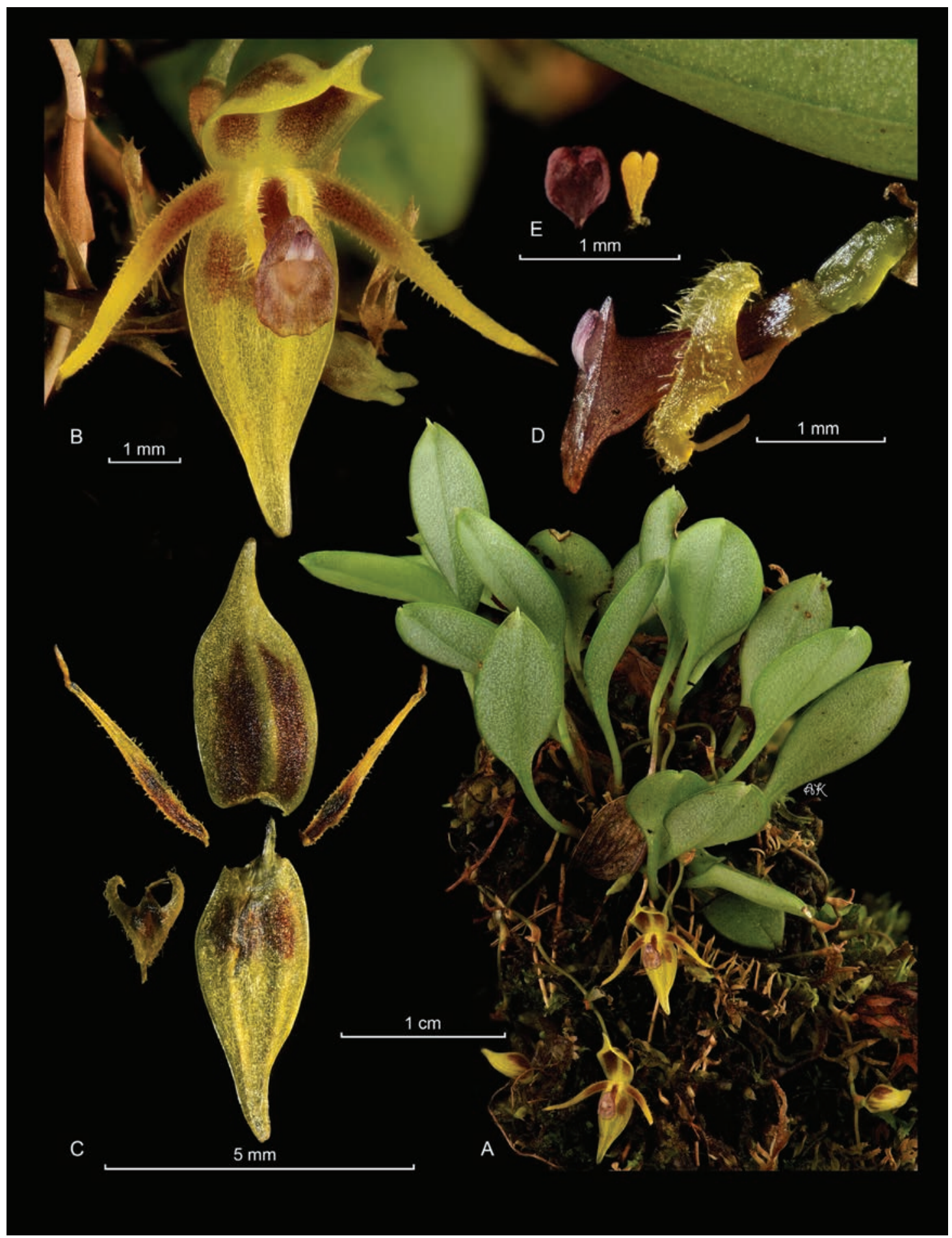

FIGURE 21. LCDP of Stelis brunnea, type species of Stelis sect. Salpistele (Dressler) Karremans. A. Habit. B. Flower. C. Dissected perianth. D. Column with lip, lateral view. E. Anther cap and pollinarium. Photographs by AK based on Karremans 8260 (JBL-spirit). 
With them they also share the geographical area, both groups are restricted to Costa Rica and Panama.

\section{Stelis subgen. Dracontia sect. Carpinterae} Karremans, sect. nov.

Etymology: The name honors Los Cerros de La Carpintera, in Cartago, Costa Rica, where the type material of its only species was collected.

Type: Pleurothallis carpinterae Schltr., Repert. Spec. Nov. Regni Veg. Beih. 19: 105. 1923.

This section can be easily recognized by the long, slender ramicauls that bear a significantly shorter, thin, ovate to sub-cordate, acute leaf. The successive, few-flowered inflorescence reclines on the leaf, the glabrous sepals are yellowish-cream spotted purple. The petals have more or less the same pattern but are darker, spathulate. The lip is as long as the sepals, orange, pandurate, unguiculate. The column slender, clavate, with a thick pedestallike base.

Stelis carpinterae (Schltr.) Pridgeon \& M.W.Chase, Lindleyana 16(4): 261. 2001. (Fig. 22)

Bas.: Pleurothallis carpinterae Schltr., Repert. Spec. Nov. Regni Veg. Beih. 19: 105. 1923. Syn.: Elongatia carpinterae (Schltr.) Luer, Monogr. Syst. Bot. Missouri Bot. Gard. 95: 257. 2004.

The only species belonging to Stelis sect. Carpinterae is restricted to Costa Rica and western Panama. Even though Luer (1994) placed it among the species of Elongatia (= Pleurothallis), morphologically it has no close relatives. The accessions of this species were consistently found to group with other members of Stelis subgen. Dracontia, namely the very distinct, and also unique, Central American species, Stelis mystax and Stelis convallaria (Karremans et al. 2013, Pérez-Escobar et al. 2017).

Stelis subgen. Dracontia sect. Convallaria Karremans, sect. nov.

ETYMology: The name refers to the similarity of its bell-shaped flowers to those of genus Convallaria L. (Asparagaceae), a terrestrial herb from Europe and Asia that is known as Lilly of the valley.

Type: Pleurothallis convallaria Schltr., Repert. Spec. Nov. Regni Veg. Beih. 19: 185-186. 1923.

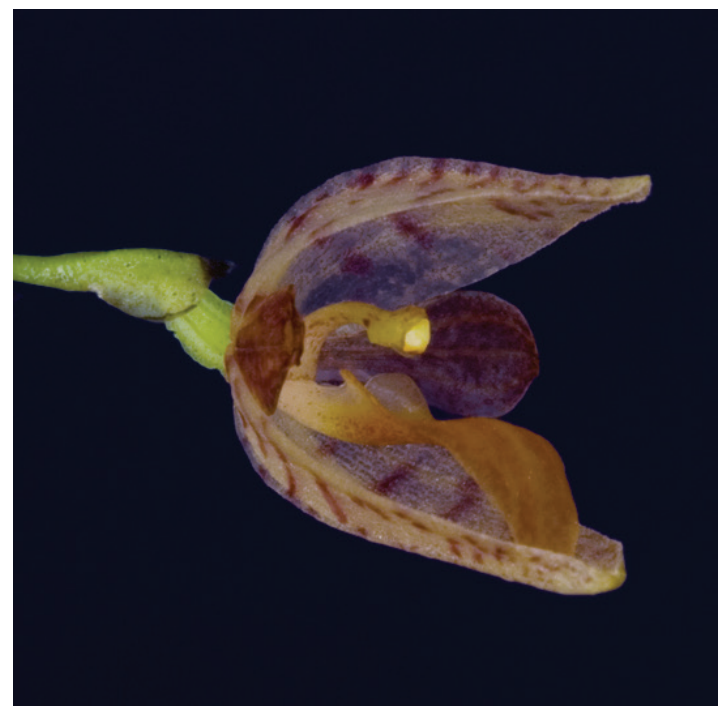

FIGURE 22. Stelis carpinterae, type species of Stelis sect. Carpinterae Karremans. Photograph by D. Bogarín based on Bogarin 7159 (JBL-spirit).

The habit is similar to other species belonging to Stelis subgen. Dracontia, except that the multiple inflorescences are clasped basally by the leaf. The inflorescences are semi-erect and bear multiple drooping bell-shaped flowers. The dark purple sepals are covered in a striking white a pubescens that trembles in the wind. The dark purple petals are unusual in that they are widest apically, truncate and bilobed. The lip is transversally bilobed, long-unguiculate and tricarinate. The column is elongate, bent, with a broad clinandrium.

Stelis convallaria (Schltr.) Pridgeon \& M.W.Chase, Lindleyana 16(4): 262. 2001. (Fig. 23)

Bas.: Pleurothallis convallaria Schltr., Repert. Spec. Nov. Regni Veg. Beih. 19: 185-186. 1923. Effusiella convallaria (Schltr.) Luer, Monogr. Syst. Bot. Missouri Bot. Gard. 112: 106. 2007.

The single species belonging to Stelis sect. Convallaria is known from Guatemala, Nicaragua, Costa Rica and Panama. Although morphologically somewhat aberrant, the accessions of this species are consistently found to be related to other members of Stelis subgen. Dracontia, especially two other unique Central American species, Stelis mystax and Stelis carpinterae (Karremans et al. 2013, Pérez-Escobar et al. 2017). 


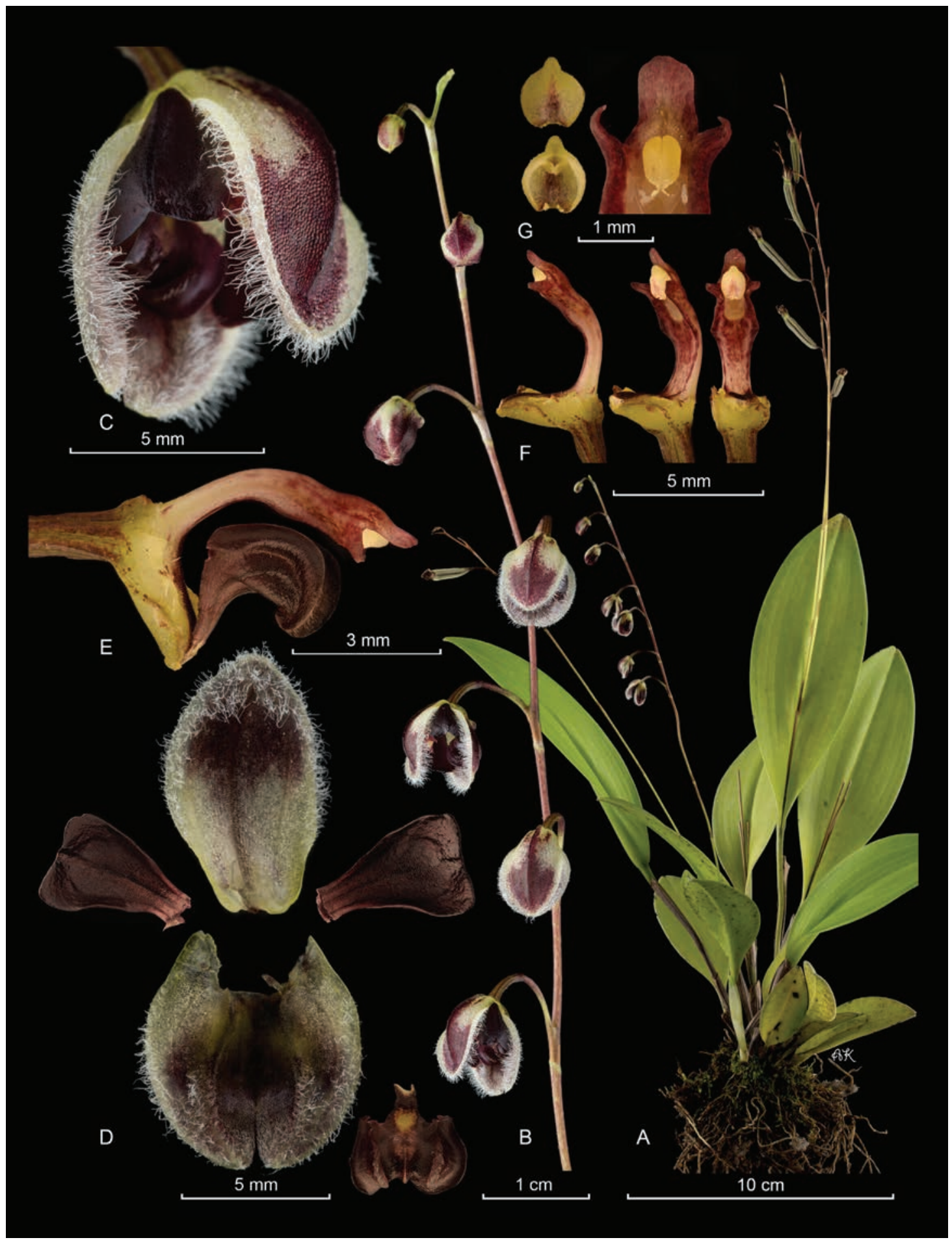

FIgURE 23. LCDP of an autogamous specimen of Stelis convallaria, type species of Stelis sect. Convallaria. A. Habit. B. Inflorescence. C. Flower. D. Dissected perianth. E. Column with lip, lateral view. F. Column ventral and lateral views. G. Anther cap and pollinarium, placed in the stigma. Photographs by K based on Karremans 7201 (JBL-spirit). 
Stelis subgen. Unciferia (Luer) Karremans, comb. nov.

Bas. Pleurothallis subgen. Unciferia (Luer) Luer, Monogr. Syst. Bot. Missouri Bot. Gard. 72: 89. 1998. Pleurothallis sect. Unciferae Luer, Monogr. Syst. Bot. Missouri Bot. Gard. 20: 94. 1986. Unciferia (Luer) Luer, Monogr. Syst. Bot. Missouri Bot. Gard. 95: 265. 2004, nom. illeg. Type: Pleurothallis segoviensis Rchb.f., Bonplandia (Hannover) 3(15-16): 223-224. Non Uncifera Lindl., J. Proc. Linn. Soc., Bot. 3: 39. 1859.

Syn. Effusiella Luer, Monogr. Syst. Bot. Missouri

Bot. Gard. 112: 106. 2007. Type: Pleurothallis amparoana Schltr., Repert. Spec. Nov. Regni Veg. Beih. 19: 23, 104. 1923.

Stelis amaliae (Luer \& R.Escobar) Pridgeon \& M.W.Chase, Lindleyana 16(4): 261. 2001.

Bas.: Pleurothallis amaliae Luer \& R.Escobar, Orquideología 14(2): 124. 1981. Syn.: Unciferia amaliae (Luer \& R.Escobar) Luer, Monogr. Syst. Bot. Missouri Bot. Gard. 95: 265. 2004.

Stelis ancistra (Luer \& Hirtz) Pridgeon \& M.W.Chase, Lindleyana 16(4): 261. 2001.

Bas.: Pleurothallis ancistra Luer \& Hirtz, Lindleyana 11(3): 144-145. 1996. Syn.: Unciferia ancistra (Luer \& Hirtz) Luer, Monogr. Syst. Bot. Missouri Bot. Gard. 95: 265. 2004.

Stelis bifalcis (Schltr.) Pridgeon \& M.W.Chase, Lindleyana 16(4): 261. 2001.

Bas.: Pleurothallis bifalcis Schltr., Beih. Bot. Centralbl., Abt. 2 36(2): 395. 1918. Unciferia bifalcis (Schltr.) Luer, Monogr. Syst. Bot. Missouri Bot. Gard. 95: 265. 2004.

Stelis brenneri (Luer) Karremans, Phytotaxa 203(3): 292. 2015.

Bas.: Pleurothallis brenneri Luer, Selbyana 3(12): 64. 1976. Syn.: Effusiella brenneri (Luer) Luer, Monogr. Syst. Bot. Missouri Bot. Gard. 112: 106. 2007.

Stelis canae (Ames) Pridgeon \& M.W.Chase, Lindleyana 16(4): 261. 2001.

Bas.: Pleurothallis canae Ames, Sched. Orch. 2: 18-19. 1923. Syn.: Unciferia canae (Ames) Luer, Monogr. Syst. Bot. Missouri Bot. Gard. 95: 265. 2004.
Stelis chlorina (Luer) Pridgeon \& M.W.Chase, Lindleyana 16(4): 261. 2001.

Bas.: Pleurothallis chlorina Luer, Phytologia 47(2): 75. 1980. Syn.: Effusiella chlorina (Luer) Luer, Monogr. Syst. Bot. Missouri Bot. Gard. 112: 106. 2007.

Stelis crenata (Lind1.) Pridgeon \& M.W.Chase, Lindleyana 16(4): 262. 2001.

Bas.: Pleurothallis crenata Lindl., Gard. Chron. 6(13): 207. 1846. Syn.: Pabstiella crenata (Lind1.) Luer, Monogr. Syst. Bot. Missouri Bot. Gard. 112: 119. 2007.

Stelis cypripedoides (Luer) Pridgeon \& M.W.Chase, Lindleyana 16(4): 262. 2001.

Bas.: Pleurothallis cypripedioides Luer, Selbyana 1(1): 70. 1975. Syn.: Effusiella cypripedioides (Luer) Luer, Monogr. Syst. Bot. Missouri Bot. Gard. 112: 106. 2007.

Stelis diminuta (Luer) Pridgeon \& M.W.Chase, Lindleyana 16(4): 262. 2001.

Bas.: Pleurothallis diminuta Luer, Phytologia 49(3): 204. 1981. Effusiella diminuta (Luer) Luer, Monogr. Syst. Bot. Missouri Bot. Gard. 112: 106. 2007.

Stelis fornicata (Luer) Pridgeon \& M.W.Chase, Lindleyana 16(4): 263. 2001.

Bas.: Pleurothallis fornicata Luer, Lindleyana 11(3): 160-161. 1996. Syn.: Effusiella fornicata (Luer) Luer, Monogr. Syst. Bot. Missouri Bot. Gard. 112: 106. 2007.

Stelis immersa (Linden \& Rchb.f.) Pridgeon \& M.W.Chase, Lindleyana 16(4): 263. 2001.

Bas.: Pleurothallis immersa Linden \& Rchb.f., Bonplandia (Hannover) 3(15-16): 224. 1855. Syn.: Effusiella immersa (Linden \& Rchb.f.) Luer, Monogr. Syst. Bot. Missouri Bot. Gard. 112: 106. 2007.

Stelis insectifera Karremans, nom. nov.

Repl. syn.: Pleurothallis melicoides Schltr., Repert. Spec. Nov. Regni Veg. 19: 24. 1923. Syn.: Stelis melicoides (Schltr.) Bogarín, Proc. 22nd World Orchid Conf. I. 354. 2019, nom. illeg. Non Stelis melicoides Schltr., Repert. Spec. Nov. Regni Veg. Beih. 9: 66. 1921. 
Stelis jalapensis (Kraenzl.) Pridgeon \& M.W.Chase, Lindleyana 16(4): 263. 2001.

Bas.: Masdevallia jalapensis Kraenzl., Repert. Spec. Nov. Regni Veg. Beih. 34: 117-118. 1925. Syn.: Pleurothallis jalapensis (Kraenzl.) Garay, Bot. Mus. Leafl. 30(3): (58)192. 1985 [1986]. Pleurothallis jalapensis (Kraenzl.) Luer, Lindleyana 6(2): 103, f.. 1991, nom. illeg. Specklinia jalapensis (Kraenzl.) Luer, Monogr. Syst. Bot. Missouri Bot. Gard. 95: 261. 2004. Effusiella jalapensis (Kraenzl.) Luer, Monogr. Syst. Bot. Missouri Bot. Gard. 112: 106. 2007, nom. inv. Effusiella jalapensis (Kraenzl.) Archila, Revista Guatemal. 17(2): 76. 2014.

Stelis kefersteiniana (Rchb.f.) Pridgeon \& M.W.Chase, Lindleyana 17(2): 99. 2002.

Bas.: Pleurothallis kefersteiniana Rchb.f., Bot. Zeitung (Berlin) 10: 673. 1852.

Syn.: Specklinia flexuosa Poepp. \& Endl., Nov. Gen. Sp. P1. 1: 52, t. 90. 1835. Pleurothallis flexuosa (Poepp. \& Endl.) Lindl., Edwards's Bot. Reg. 28: Misc. 69, no. 7. 1842. Syn.: Effusiella flexuosa (Poepp. \& Endl.) Luer, Monogr. Syst. Bot. Missouri Bot. Gard. 112: 106. 2007, nom. inval. Stelis flexuosa (Poepp. \& Endl.) Pridgeon \& M.W.Chase, Lindleyana 16(4): 263. 2001, nom. illeg. Non Stelis flexuosa Lindl., Ann. Mag. Nat. Hist. 12(79): 397. 1843.

Stelis lehmanneptis (Luer \& R.Escobar) Pridgeon \& M.W.Chase, Lindleyana 16(4): 264. 2001.

Bas.: Pleurothallis lehmanneptis Luer \& R.Escobar, Orquideología 21: 100. 1998. Effusiella lehmanneptis (Luer \& R.Escobar) Luer, Monogr. Syst. Bot. Missouri Bot. Gard. 112: 106. 2007.

Stelis lehmannii Pridgeon \& M.W.Chase, Lindleyana 17(2): 99. 2002.

Repl. syn.: Pleurothallis petiolaris Luer, Orquideología 20: 220. 1996. Effusiella petiolaris (Luer) Luer, Monogr. Syst. Bot. Missouri Bot. Gard. 112: 107. 2007. Stelis petiolaris (Luer) Pridgeon \& M.W.Chase, Lindleyana 16(4): 265. 2001, nom. illeg. Non Stelis petiolaris Schltr., Repert. Spec. Nov. Regni Veg. Beih. 27: 36. 1924.
Stelis listerophora (Schltr.) Pridgeon \& M.W.Chase, Lindleyana 16(4): 264. 2001.

Bas.: Pleurothallis listerophora Schltr., Repert. Spec. Nov. Regni Veg. 3(33-34): 107. 1906. Syn.: Effusiella listerophora (Schltr.) Luer, Monogr. Syst. Bot. Missouri Bot. Gard. 112: 106. 2007.

Stelis niesseniae (Luer) Karremans, Phytotaxa 406(5): 265. 2019.

Bas.: Pleurothallis niesseniae Luer, Orquideología 22(1): 59-61. 2001. Syn.: Effusiella niesseniae (Luer) Luer, Monogr. Syst. Bot. Missouri Bot. Gard. 112: 107. 2007.

Stelis nigriflora (L.O.Williams) Pridgeon \& M.W.Chase, Lindleyana 16(4): 264. 2001.

Bas.: Pleurothallis nigriflora L.O.Williams, Amer. Orchid Soc. Bull. 11(5): 168. 1942. Effusiella nigriflora (L.O.Williams) Luer, Monogr. Syst. Bot. Missouri Bot. Gard. 112: 107. 2007.

Stelis nonresupinata Solano \& Soto Arenas, Icon. Orchid. (Mexico) 5-6: t. 688. 2002 [2003].

Stelis oestlundiana (L.O.Williams) Pridgeon \& M.W.Chase, Lindleyana 16(4): 265. 2001.

Bas.: Pleurothallis oestlundiana L.O.Williams, Bot. Mus. Leafl. 12(7): 243. 1946. Syn.: Effusiella oestlundiana (L.O.Williams) Luer, Monogr. Syst. Bot. Missouri Bot. Gard. 112: 107. 2007.

Stelis ornata (Rchb.f.) Pridgeon \& M.W.Chase, Lindleyana 16(4): 265. 2001. (Fig. 24)

Bas.: Pleurothallis ornata Rchb.f., Garten Zeitung 1: 106. 1882. Effusiella ornata (Rchb.f.) Luer, Monogr. Syst. Bot. Missouri Bot. Gard. 112: 107. 2007.

Stelis oscargrouchii Karremans, Phytotaxa 203(3): 293. 2015.

Repl. syn.: Specklinia ximenae Luer, Monogr. Syst. Bot. Missouri Bot. Gard. 103: 311. 2005. Syn.: Pleurothallis ximenae Luer \& Hirtz, Monogr. Syst. Bot. Missouri Bot. Gard. 95: 238, 242. 2004, nom. inval. Specklinia ximenae (Luer \& Hirtz) Luer, Monogr. Syst. Bot. Missouri Bot. Gard. 95: 265. 2004, nom. inval. Effusiella ximenae (Luer \& Hirtz) Luer, Monogr. Syst. Bot. Missouri Bot. Gard. 112: 107. 2007, nom. inval. Non Stelis ximenae Luer \& Hirtz, Monogr. Syst. Bot. Missouri Bot. Gard. 95: 175. 2004. 


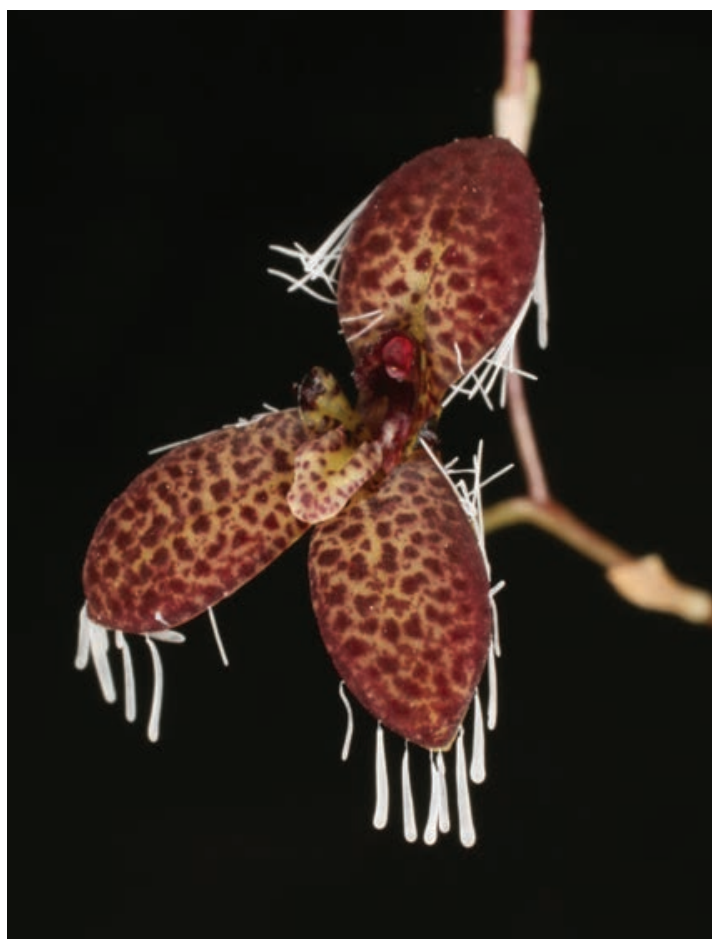

FiguRE 24. Stelis ornata (Rchb.f.) Pridgeon \& M.W.Chase, a species with striking appendages on the sepals, but otherwise a typical member of Stelis subgen. Unciferia (Luer) Karremans. Photograph by H. Oakeley.

Stelis pilosa Pridgeon \& M.W.Chase, Lindleyana 17(2): 100. 2002. (Fig. 25)

Repl. syn.: Pleurothallis amparoana Schltr., Repert. Spec. Nov. Regni Veg. Beih. 19: 23, 104. 1923. Effusiella amparoana (Schltr.) Luer, Monogr. Syst. Bot. Missouri Bot. Gard. 112: 106. 2007. Stelis amparoana (Schltr.) Pridgeon \& M.W.Chase, Lindleyana 16: 261. 2001, nom. illeg. Non Stelis amparoana Schltr., Repert. Spec. Nov. Regni Veg. Beih. 19: 16. 1923.

Stelis pilostoma (Luer) Pridgeon \& M.W.Chase, Lindleyana 16(4): 265. 2001.

Bas.: Pleurothallis pilostoma Luer, Lindleyana 11(2): 89. 1996. Unciferia pilostoma (Luer) Luer, Monogr. Syst. Bot. Missouri Bot. Gard. 95: 265. 2004.

Stelis pompalis (Ames) Pridgeon \& M.W.Chase, Lindleyana 16(4): 265. 2001.

Bas.: Pleurothallis pompalis Ames, Sched. Orch. 7: 23-25. 1924. Syn.: Unciferia pompalis (Ames) Luer,

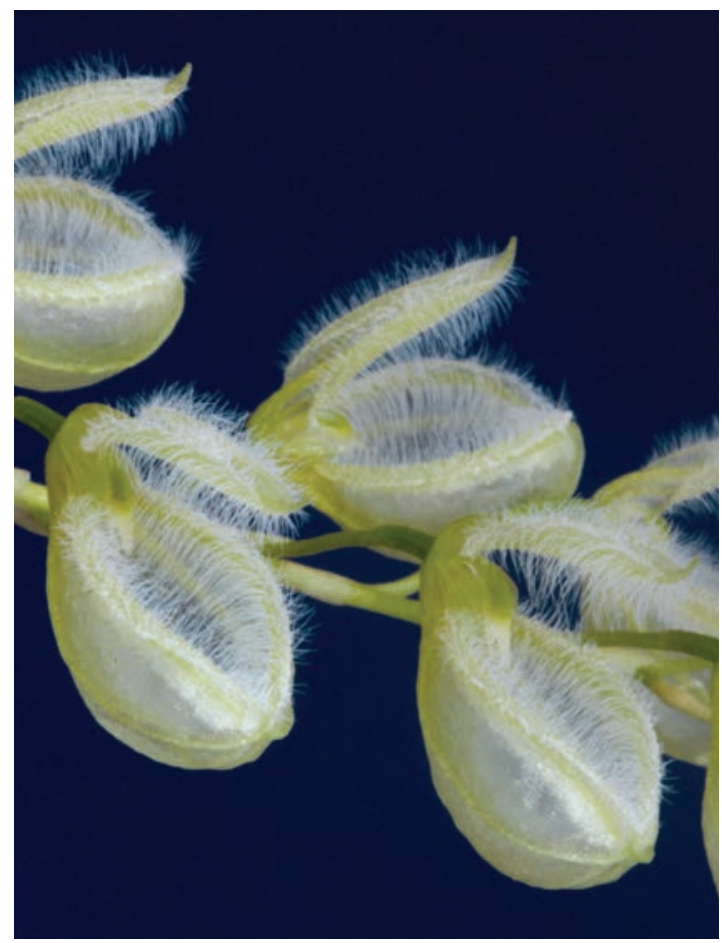

FIgURE 25. Stelis pilosa Pridgeon \& M.W.Chase, type species of genus Effusiella (Luer) Luer (= Stelis subgen. Unciferia). Photograph by AK.

Monogr. Syst. Bot. Missouri Bot. Gard. 95: 265. 2004.

Stelis pseudocheila (Luer \& R.Escobar) Pridgeon \& M.W.Chase, Lindleyana 16(4): 266. 2001.

Bas.: Pleurothallis pseudocheila Luer \& R.Escobar, Orquideología 16(2): 173. 1984. Syn.: Effusiella pseudocheila (Luer \& R.Escobar) Luer, Monogr. Syst. Bot. Missouri Bot. Gard. 112: 107. 2007.

Stelis psilantha (Luer) Pridgeon \& M.W.Chase, Lindleyana 16(4): 266. 2001.

Bas.: Pleurothallis psilantha Luer, Monogr. Syst. Bot. Missouri Bot. Gard. 72: 95. 1998. Syn.: Unciferia psilantha (Luer) Luer, Monogr. Syst. Bot. Missouri Bot. Gard. 95: 265. 2004.

Stelis resupinata (Ames) Pridgeon \& M.W.Chase, Lindleyana 16(4): 266. 2001.

Bas.: Pleurothallis resupinata Ames, Orchidaceae 2: 272. 1908. Syn.: Effusiella resupinata (Ames) Luer, Monogr. Syst. Bot. Missouri Bot. Gard. 112: 107. 2007. 


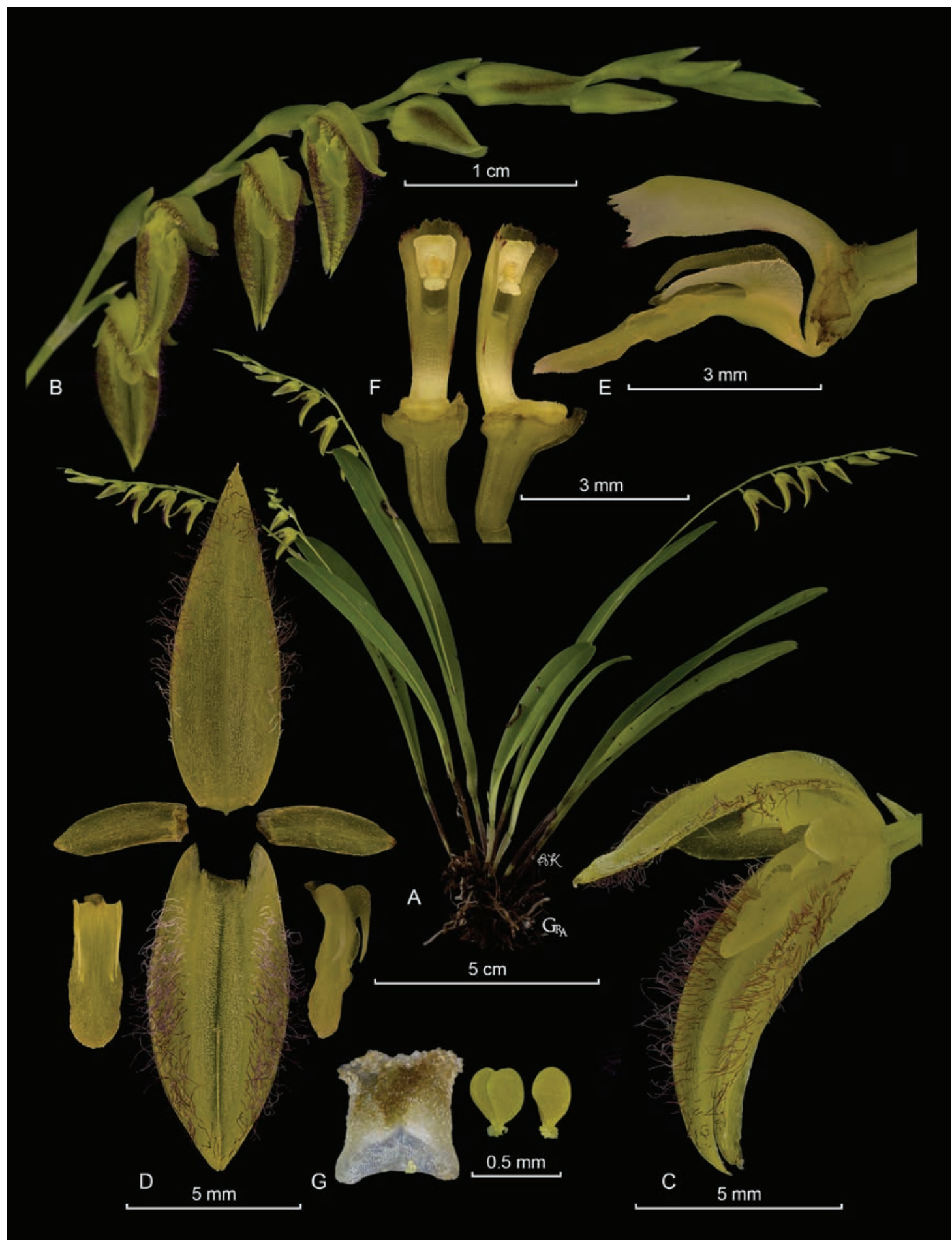

Figure 26. LCDP of Stelis segoviensis, type species of Stelis subgen. Unciferia. A. Habit. B. Inflorescence. C. Flower. D. Dissected perianth. E. Column with lip, lateral view. F. Column ventral and lateral view. G. Anther cap and pollinarium. Photographs by AK based on Rojas-Alvarado 311 (JBL-spirit). 
Stelis retusa (Lex.) Pridgeon \& M.W.Chase, Lindleyana 16(4): 266. 2001.

Bas.: Dendrobium retusum Lex., Nov. Veg. Descr. 2(Orchid. Opusc.): 40. 1825. Specklinia retusa (Lex.) Lindl., Edwards's Bot. Reg. 21: sub t. 1797. 1835. Pleurothallis retusa (Lex.) Lindl., Edwards's Bot. Reg. 28: Misc. 81-82. 1842. Syn.: Effusiella retusa (Lex.) Luer, Monogr. Syst. Bot. Missouri Bot. Gard. 112: 107. 2007, nom. inval.

Stelis rostratissima (Luer \& J. Portilla) Karremans, Phytotaxa 203(3): 293. 2015.

Bas.: Pleurothallis rostratissima Luer \& J. Portilla, Monogr. Syst. Bot. Missouri Bot. Gard. 88: 108. 2002. Syn.: Effusiella rostratissima (Luer \& J. Portilla) Luer, Monogr. Syst. Bot. Missouri Bot. Gard. 112: 107. 2007.

Stelis segoviensis (Rchb.f.) Pridgeon \& M.W.Chase, Lindleyana 16(4): 266. 2001. (Fig. 26)

Bas.: Pleurothallis segoviensis Rchb.f., Bonplandia (Hannover) 3(15-16): 223-224. 1855. Syn.: Unciferia segoviensis (Rchb.f.) Luer, Monogr. Syst. Bot. Missouri Bot. Gard. 95: 265. 2004.

Stelis thomasii (Luer) Pridgeon \& M.W.Chase, Lindleyana 16(4): 267. 2001.

Bas.: Pleurothallis thomasii Luer, Monogr. Syst. Bot. Missouri Bot. Gard. 79: 84, 130. 2000. Effusiella thomasii (Luer) Luer, Monogr. Syst. Bot. Missouri Bot. Gard. 112: 107. 2007.

Stelis trichostoma (Luer) Pridgeon \& M.W.Chase, Lindleyana 16(4): 267. 2001.

Bas.: Pleurothallis trichostoma Luer, Selbyana 5(2): 185. 1979. Effusiella trichostoma (Luer) Luer, Monogr. Syst. Bot. Missouri Bot. Gard. 112: 107. 2007.

Stelis trulla (Rchb.f. \& Warsz.) Pridgeon \& M.W.Chase, Lindleyana 16(4): 267. 2001.

Bas.: Pleurothallis trulla Rchb.f. \& Warsz., Bonplandia (Hannover) 2: 114. 1854. Effusiella trulla (Rchb.f. \& Warsz.) Luer, Monogr. Syst. Bot. Missouri Bot. Gard. 112: 107. 2007.

Stelis uncinata Pridgeon \& M.W.Chase, Lindleyana 17(2): 100. 2002.

Repl. syn.: Pleurothallis kareniae Luer, Lindleyana 11(2): 83, f. 19. 1996. Unciferia kareniae (Luer)
Luer, Monogr. Syst. Bot. Missouri Bot. Gard. 95: 265. 2004. Stelis kareniae (Luer) Pridgeon \& M.W.Chase, Lindleyana 16(4): 264. 2001, nom. illeg. Non Stelis kareniae Luer, Lindleyana 11(2): 100, f. 31. 1996.

Stelis villosa (Knowles \& Westc.) Pridgeon \& M.W.Chase, Lindleyana 16(4): 267. 2001.

Bas.: Pleurothallis villosa Knowles \& Westc., Fl. Cab. 2: 78. 1838. Syn.: Effusiella villosa (Knowles \& Westc.) Luer, Monogr. Syst. Bot. Missouri Bot. Gard. 112: 107. 2007.

Stelis vinacea (Ames) Bogarín, Proc. 22nd World Orchid Conf. I. 358. 2019.

Bas.: Pleurothallis vinacea Ames, Schedul. Orchid. 6: 69. 1923.

Stelis wagneri (Schltr.) Pridgeon \& M.W.Chase, Lindleyana 16(4): 267. 2001.

Bas.: Pleurothallis wagneri Schltr., Repert. Spec. Nov. Regni Veg. 17(8-12): 141. 1921. Unciferia wagneri (Schltr.) Luer, Monogr. Syst. Bot. Missouri Bot. Gard. 95: 265. 2004.

Stelis werckleana Bogarín \& Pupulin, Proc. 22nd World Orchid Conf. I. 358. 2019.

Repl. syn.: Pleurothallis wercklei Schltr., Repert. Spec. Nov. Regni Veg. 17: 141. 1921. Non Stelis wercklei Schltr., Repert. Spec. Nov. Regni Veg. Beih. 19: 20. 1923.

Stelis xerophila (Schltr.) Soto Arenas, Icon. Orchid. (Mexico) 5-6: t. 695. 2002 [2003].

Bas.: Pleurothallis xerophila Schltr., Beih. Bot. Centralbl., Abt. 2 36(2): 398. 1918. Syn.: Specklinia xerophila (Schltr.) Luer, Monogr. Syst. Bot. Missouri Bot. Gard. 95: 265. 2004.

Stelis zootrophionoides Castañeda-Zárate \& RamosCastro, PLoS ONE 7(11): 5. 2012.

Syn.: Effusiella zootrophionoides (CastañedaZárate \& Ramos-Castro) Archila, Revista Guatemal. 17(2): 76. 2014.

The 42 species that belong to Stelis subgen. Unciferia are found only from Mexico to Bolivia and Peru, they are especially diverse in Middle America and no records exist for the Antilles or Brazil.

DNA data is available for Stelis canae, S. immersa, S. jalapensis, S. kefersteiniana, S. listerophora, 


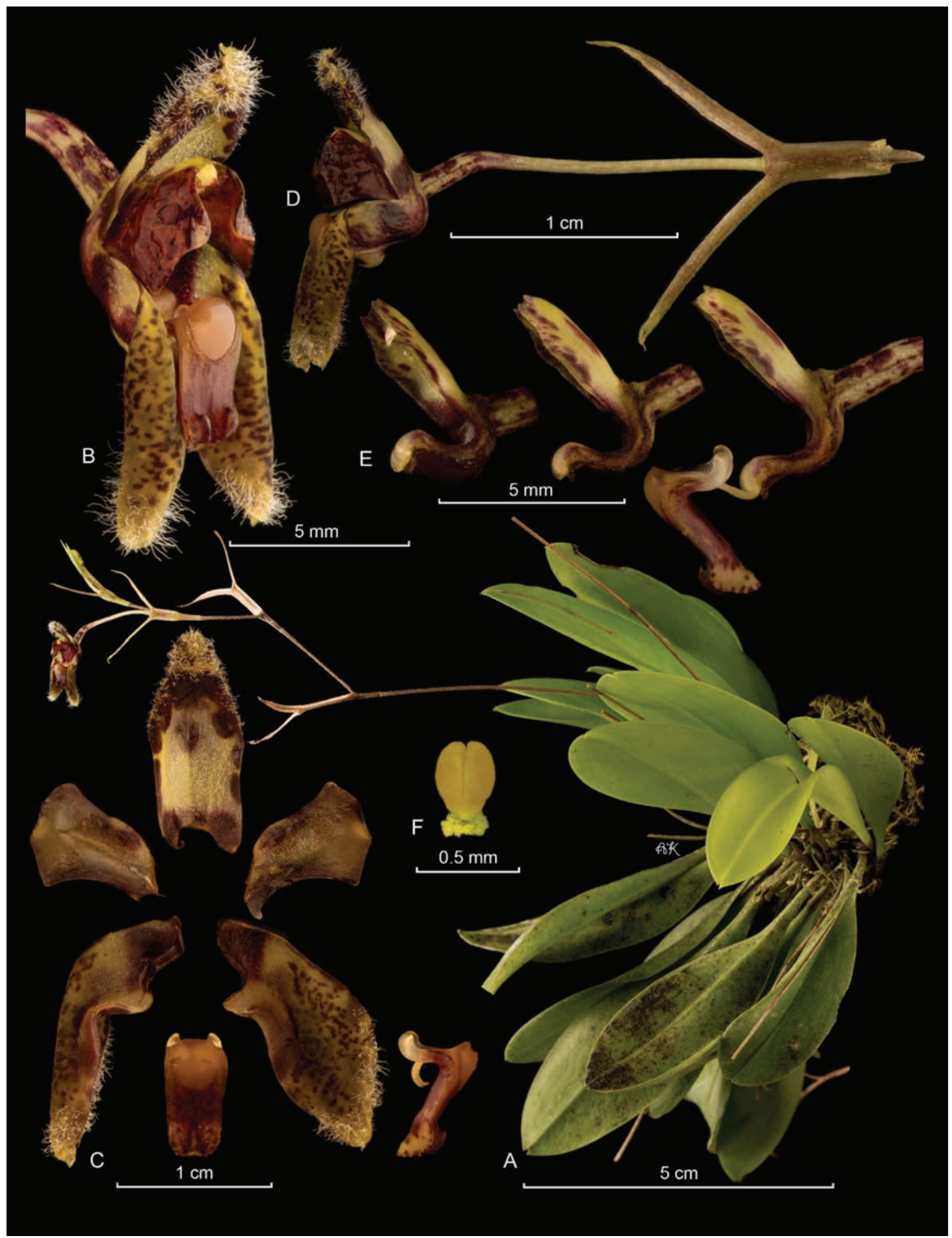

Figure 27. LCDP of Stelis furculifera, one of the two members of Stelis subgen. Condylago (Luer) Karremans. A. Habit. B. Flower. C. Dissected perianth. D. Flower, floral bract, lateral view. E. Column semi-ventral, side view, with and without the lip attached. F. Pollinarium. Photographs by AK based on Bogarin 5901 (JBL-spirit).. 
S. nigriflora, S. ornata, S. pilosa, S. pompalis, $S$. resupinata, $S$. retusa, $S$. segoviensis, $S$. trichostoma, S. zootrophionoides (Pridgeon et al. 2001, SolanoGómez 2005, Karremans 2010, Ramos-Castro et al. 2012; Karremans et al. 2013, Pérez-Escobar et al. 2017, Ponert et al. 2019). They all consistently appear within Stelis in the broad sense, and mostly as sisters to the members of Stelis subgen. Dracontia. However, diverse analyses (using different genes, methods or taxa) provide contradicting relationships among them. Stelis pilosa, type species of genus Effusiella, appears to be a close relative of Stelis segoviensis, type species of genus Unciferia, but there is also support for a relationship between some of the members of Stelis subgen. Unciferia and species of either Stelis subgen. Condylago and Stelis subgen. Dracontia. It may therefore not be a monophyletic group and requires further analysis.

Stelis subgen. Condylago (Luer) Karremans, comb. nov.

Bas. Condylago Luer, Orquideologia 15: 118. 1982. Type: Condylago rodrigoi Luer, Orquideología 15(2-3): 118-122. 1982.

Stelis furculifera (Dressler \& Bogarín) Bogarín, Lankesteriana 14(3): 267. 2014. (Fig. 27)

Bas.: Condylago furculifera Dressler \& Bogarín, Harvard Pap. Bot. 12(1): 2-5. 2007.

Stelis rodrigoi (Luer) Pridgeon \& M.W.Chase, Lindleyana 16(4): 266. 2001.

Bas.: Condylago rodrigoi Luer, Orquideología 15(23): 118-122. 1982.

The two species that belong to Stelis subgen. Condylago are restricted to Panama and Colombia respectively. DNA data is only available for Stelis rodrigoi and most analyses find it as a sister to the rest of Stelis sensu lato (Karremans 2010, Ramos-Castro et al. 2012; Karremans et al. 2013, Pérez-Escobar et al. 2017). However, a relationship with members of Stelis subgen. Unciferia was also found by authors (Pridgeon et al. 2001, Ponert et al. 2019).

\section{Stelis subgen. Umbralia Karremans, subgen. nov.}

Eтymology: From the Latin umbra, shade or shadow, in reference to the short twisted inflorescence hidden under the shade of the convex leaf.
Type: Pleurothallis imraei Lindl., Fol. Orchid. $\sim$ Pleurothallis $\sim 9.1859$.

Distinguished from all other subgenera by the large caespitose plants bearing ovate to suborbicular leaves that are typically convex. The inflorescence is significantly shorter than the leaf and twists in such a way that the flowers are frequently hidden behind the leaf blade. The ovary is strongly bent, causing the flowers to be oriented upwards. The sepals are internally pubescent, the lateral sepals forming a synsepal with a mentum at the base. The petals are conspicuously spathulate, obtuse. The lip is convex in natural position, unguiculate, delicately hinged to the column foot, lanceolate when extended, obtuse. The column is cylindrical, incurved, with a pair of small wings, apically denticulate. Pollinia two, forming a whale-tail type pollinarium with a pair of flattish caudicles.

Stelis cocornaënsis (Luer \& R.Escobar) Pridgeon \& M.W.Chase, Lindleyana 16(4): 262. 2001.

Bas.: Pleurothallis cocornaënsis Luer \& R.Escobar, Orquideología 20: 45. 1996. Syn.: Specklinia cocornaënsis (Luer \& R.Escobar) Luer, Monogr. Syst. Bot. Missouri Bot. Gard. 95: 259. 2004. Effusiella cocornaënsis (Luer \& R.Escobar) Luer, Monogr. Syst. Bot. Missouri Bot. Gard. 112: 106. 2007.

Stelis erucosa (Luer \& R.Escobar) Pridgeon \& M.W.Chase, Lindleyana 16(4): 262. 2001.

Bas.: Pleurothallis erucosa Luer \& R.Escobar, Orquideología 21(1): 88. 1998. Syn.: Specklinia erucosa (Luer \& R.Escobar) Luer, Monogr. Syst. Bot. Missouri Bot. Gard. 95: 260. 2004. Effusiella erucosa (Luer \& R.Escobar) Luer, Monogr. Syst. Bot. Missouri Bot. Gard. 112: 106. 2007.

Stelis imraei (Lindl.) Pridgeon \& M.W.Chase, Lindleyana 16(4): 263. 2001. (Fig. 28)

Bas.: Pleurothallis imraei Lindl., Fol. Orchid. $\sim$ Pleurothallis $\sim$ 9. 1859. Syn.: Humboldtia imraei (Lindl.) Kuntze, Revis. Gen. Pl. 2: 667. 1891. Specklinia imraei (Lindl.) Luer, Monogr. Syst. Bot. Missouri Bot. Gard. 95: 261. 2004. Effusiella imraei (Lind1.) Luer, Monogr. Syst. Bot. Missouri Bot. Gard. 112: 106. 2007.

Syn.: Pleurothallis umbraticola Schltr., Repert. Spec. Nov. Regni Veg. 27(1-8): 56-57. 1929. 


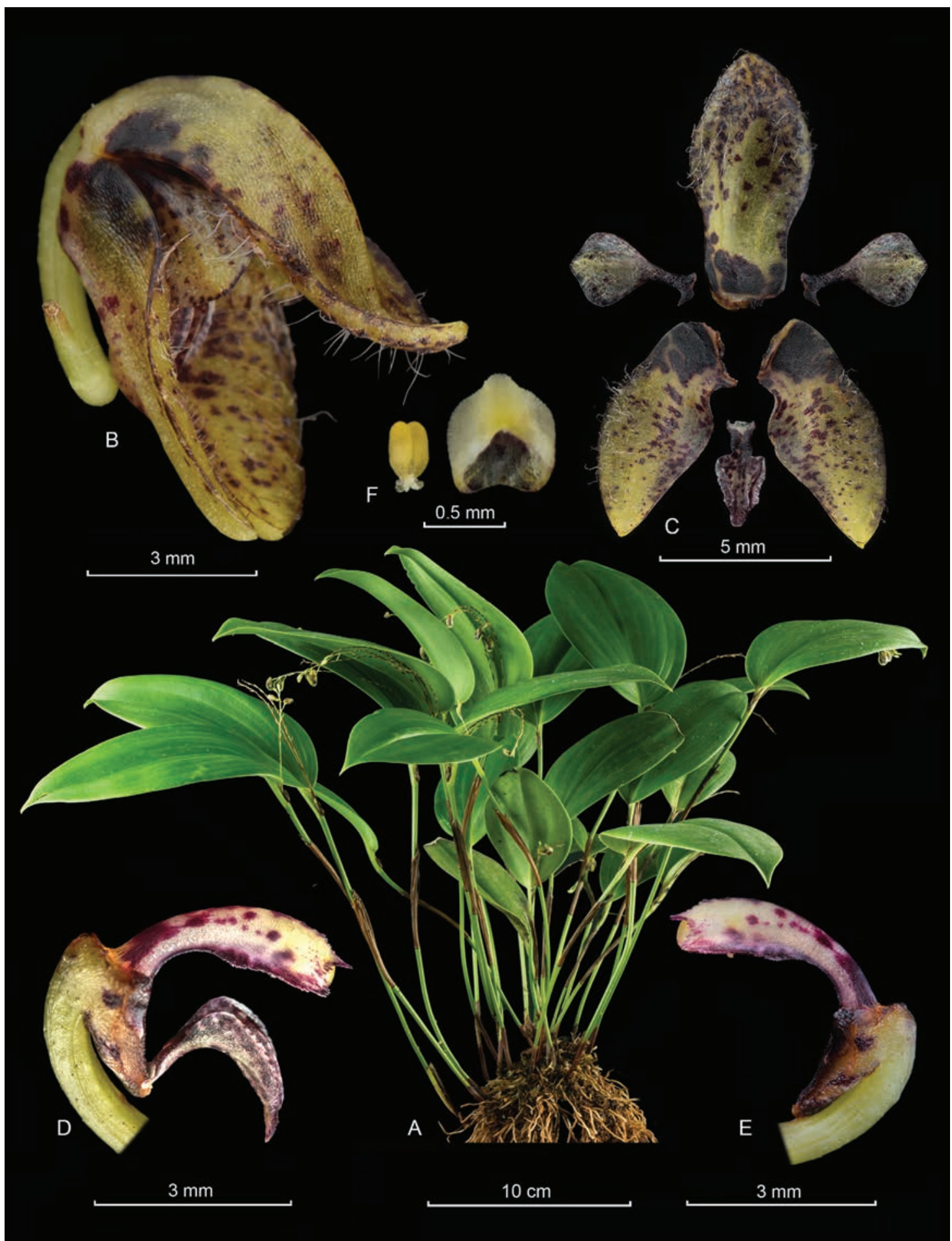

Figure 28. LCDP of Stelis imraei, type species of Stelis subgen. Umbralia Karremans. A. Habit. B. Flower. C. Dissected perianth. D. Column with lip, lateral view. D. Column lateral view. E. Anther cap and pollinarium. Photographs by I. Chinchilla based on Bogarín 752 (JBL-spirit). 
Stelis tarantula (Luer \& Hirtz) Pridgeon \& M.W.Chase, Lindleyana 16(4): 267. 2001.

Bas.: Pleurothallis tarantula Luer \& Hirtz, Lindleyana 11(3): 186-187. 1996. Syn.: Specklinia tarantula (Luer \& Hirtz) Luer, Monogr. Syst. Bot. Missouri Bot. Gard. 95: 264. 2004. Effusiella tarantula (Luer \& Hirtz) Luer, Monogr. Syst. Bot. Missouri Bot. Gard. 112: 107. 2007.

Stelis vaginata (Schltr.) Pridgeon \& M.W.Chase, Lindleyana 16(4): 267. 2001.

Bas.: Pleurothallis vaginata Schltr., Repert. Spec. Nov. Regni Veg. Beih. 19: 197. 1923. Syn.: Specklinia vaginata (Schltr.) Luer, Monogr. Syst. Bot. Missouri Bot. Gard. 95: 264. 2004. Effusiella vaginata (Schltr.) Luer, Monogr. Syst. Bot. Missouri Bot. Gard. 112: 107. 2007. Pleurothallis imraei var. vaginata (Schltr.) O. Gruss \& M. Wolff, Orchid Atlas 359. 2007.

Five species are currently recognized as belonging to Stelis subgen. Umbralia. They are mostly found from Costa Rica to Ecuador, with the highest diversity in Colombia. This subgenus includes the very variable Stelis imraei, which is most like a species complex distributed from Costa Rica to Peru and Bolivia, the Guyanas, and the Lesser Antilles.

Although Luer (2000) placed these species among the Effusiella, and the flowers are indeed similar, vegetative morphology is quite unlike any other Stelis. Not surprisingly, the DNA data available for Stels imraei places it as sister to all other members of Stelis in the broad sense (Karremans 2010, Karremans et al. 2013). A multigene analysis of the Pleurothallidinae including an accession of Stelis cocornaënsis places it as sister to Stelis subgen. Dracontia (Ponert et al. 2019). It is certainly possible to segregate this group into a genus of its own, however, such a proposal would be inconsistent with the current interpretation that this group is best treated a single genus at this time.

\section{EXCLUDED TAXA}

The following groups are still associated with Stelis in the broad sense, or with certain species groups therein, in literature. They are here explicitly stated with hopes that they can be definitively be excluded from Stelis and no longer be associated with any taxa belonging to it.

Pleurothallis sect. Alatae Luer, Monogr. Syst. Bot. Missouri Bot. Gard. 76: 99. 1999. Type: Specklinia obovata Lindl. Edwards's Bot. Reg. 25: Misc. 75. 1842. (Fig. 29) = Anathallis Barb.Rodr.

DNA data has consistently shown that members of Pleurothallis subgen. Acuminatia sect. Acuminatae belong in Stelis, whilst those placed in Acuminatia sect. Alatae belong to Anathallis (Karremans et al. 2013; Karremans 2014, Pérez-Escobar et al. 2017). Morphologically this is easily diagnosable as species of sect. Alatae, like other species of Anathallis, have starshaped flowers, with acuminate petals that are as long as the sepals, a flattened lip and the sharply winged, apically fringed column. Whereas species of sect. Acuminatae, like other species of Stelis, bear obtuse petals, that are significantly shorter than the sepals, have a non-flattened lip, and the column is not prominently winged or fringed (Karremans 2014; 2016).

Pleurothallis subgen. Effusia Luer, Monogr. Syst. Bot. Missouri Bot. Gard. 79: 54. 2000. Syn.: Pleurothallis sect. Effusae Lindl. Edwards's Bot. Reg. 28: Misc. 74. 1842. Type: Pleurothallis hypnicola Lindl. Edwards's Bot. Reg. 28: Misc. 75. 1842. (Fig. 30)= Pabstiella Brieger \& Senghas

DNA data has consistently shown that $P$. hypnicola and its relatives belong in Pabstiella rather than Stelis (Karremans et al. 2013, Pérez-Escobar et al. 2017). Even though not closely related, there is a striking similarity between species of Pabstiella and some members of Stelis subgen. Unciferia, a convergence that most likely responds to a similar pollination syndrome. With few exceptions, species of Pabstiella are found in Brazil, where the members of Stelis subgen. Unciferia are absent. The latter instead are most diverse in Middle America, where very few Pabstiella species have been recorded.

Elongatia (Luer) Luer, Monogr. Syst. Bot. Missouri Bot. Gard. 95: 257 (2004). Bas.: Pleurothallis subgen. Elongatia Luer, Monogr. Syst. Bot. Missouri Bot. Gard. 20: 41. 1986. Syn.: Pleurothallis sect. Elongatae Lindl. Edwards's Bot. Reg. 28: Misc. 68. 


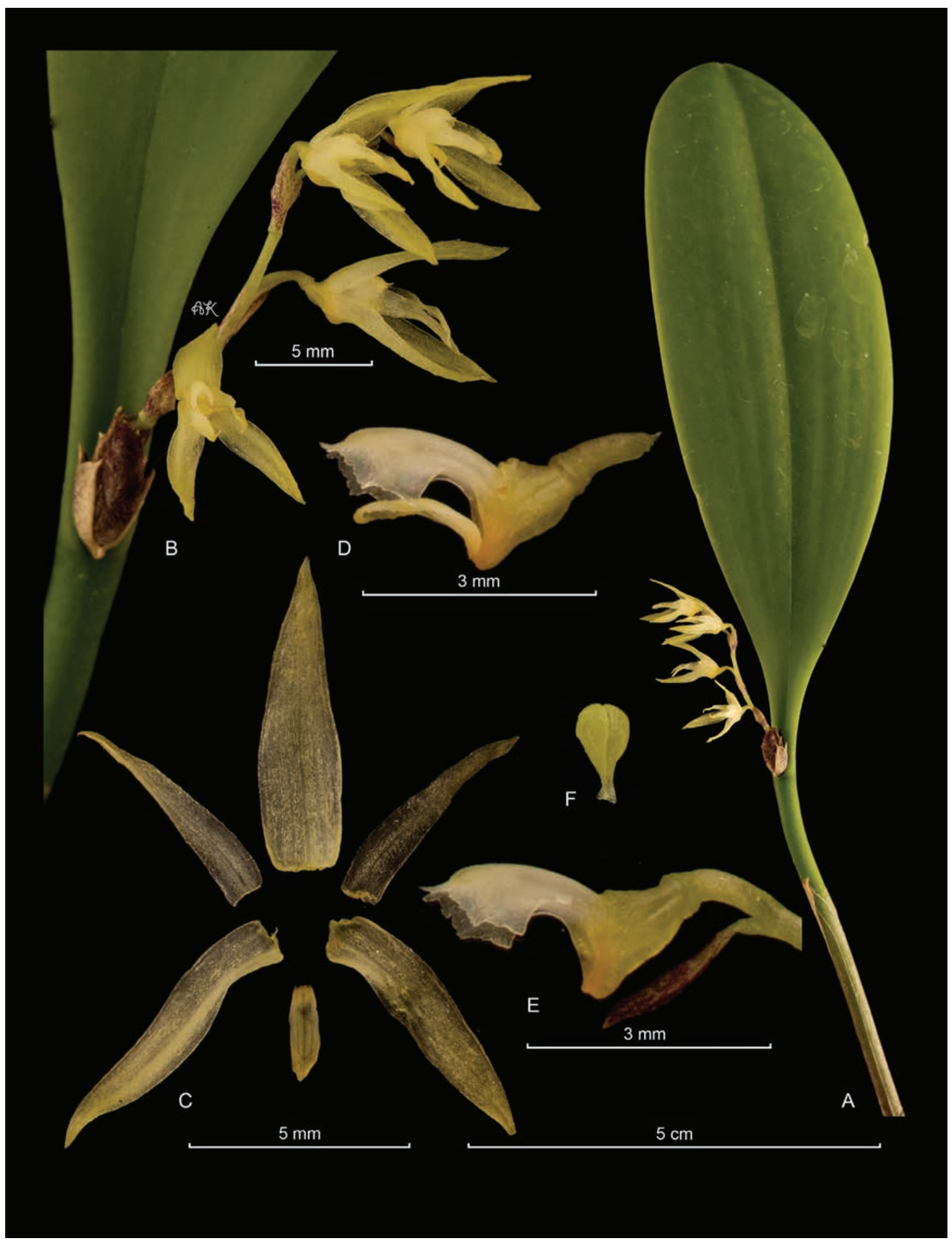

Figure 29. LCDP of Anathallis obovata, type species of Anathallis. A. Habit. B. Inflorescence. C. Dissected perianth. D. Column with lip, lateral view. D. Column ventral and lateral view. E. Pollinarium. Photographs by AK based on $J B L-$ 28233 (JBL-spirit). 


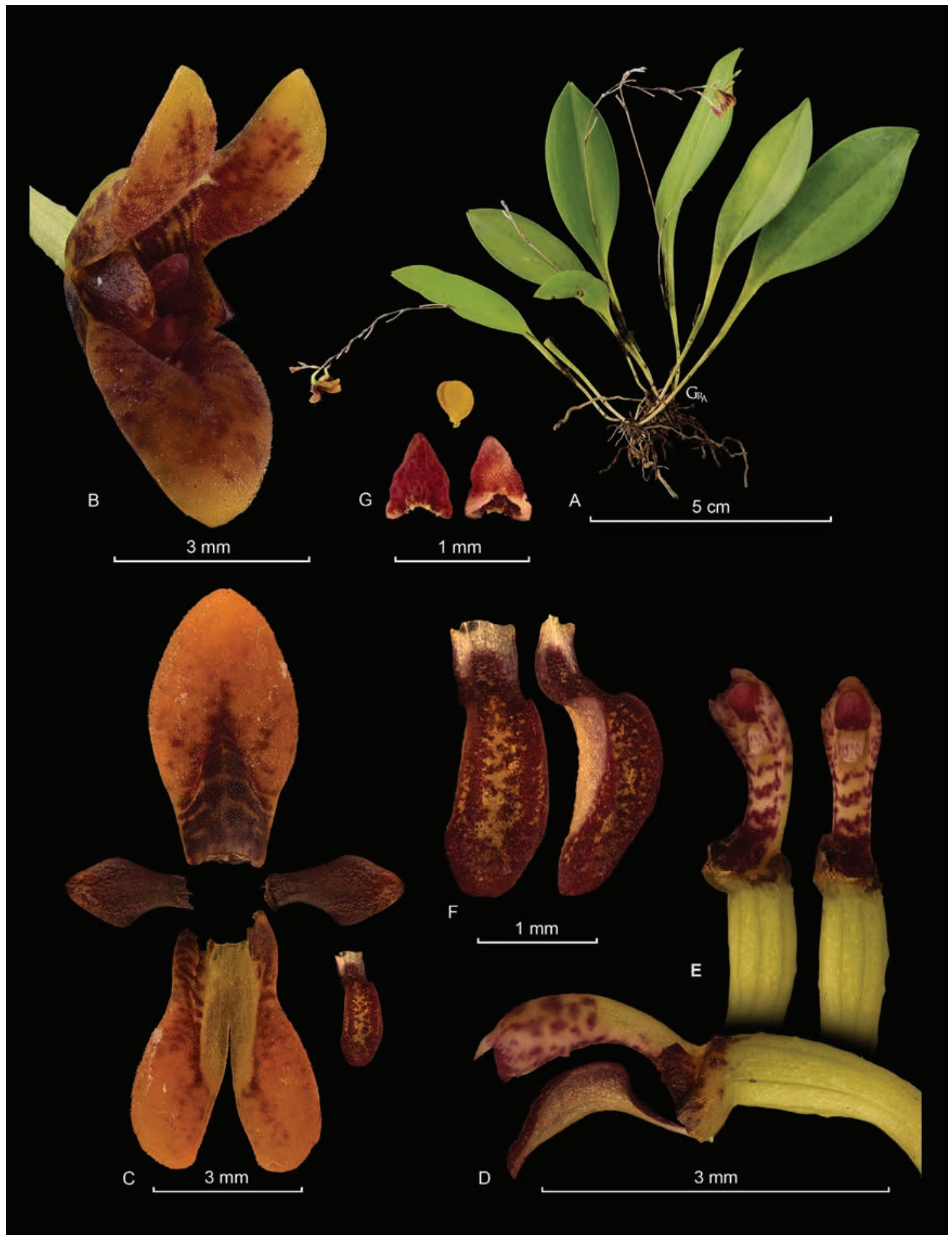

Figure 30. LCDP of Pabstiella hypnicola, type species of Pleurothallis subgen. Effusia (= Pabstiella). A. Habit. B. Flower. C. Dissected perianth. D. Column with lip, lateral view. E. Column ventral and lateral view. F. Lip. G. Anther cap and pollinarium. Photographs by G. Rojas-Alvarado based on HBL960631 (JBL-spirit). 


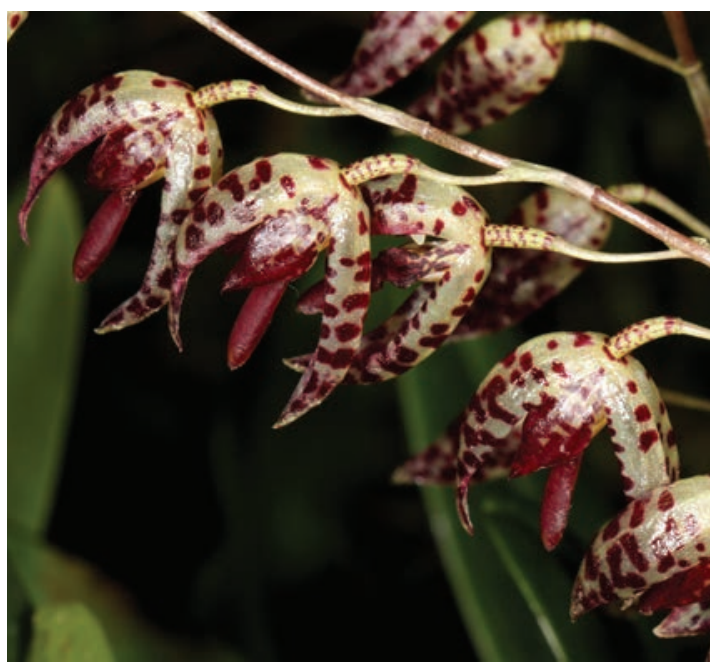

FIgURE 31. Pleurothallis restrepioides Lindl., type species of Elongatia (= Pleurothallis). Photograph by J. Varigos.

1842. Lectotype: Pleurothallis restrepioides Lindl. Companion Bot. Mag. 2: 356. 1836. (Fig. 31) = Pleurothallis R.Br.

DNA data has consistently shown that $P$. restrepioides, type species of Elongatia, and its closest relatives belong in Pleurothallis rather than Stelis (Karremans et al. 2013; Wilson et al. 2013, PérezEscobar et al. 2017). The flowers of Elongatia are superficially similar to the members of Stelis sect. Carpinterae and Stelis sect. Petiolatae. From the first they are distinguished by very large plants, with thick coriaceous leaves, from the second by the large plants with sessile leaves. From both, Elongatia species are distinguished by the erect, elongate inflorescence with multiple simultaneous flowers.

Pleurothallis subgen. Lalexia (Luer) Karremans, comb. et stat. nov.

Bas.: Lalexia Luer, Harvard Pap. Bot. 16: 358. 2011. Syn. Loddigesia Luer, Monogr. Syst. Bot. Missouri Bot. Gard. 105: 251. 2006, nom. illeg. Non Loddigesia Sims Bot. Mag. 24: pl. 965. 1806. Type: Dendrobium quadrifidum Nov. Veg. Descr, 2(Orch. Opusc.): 40-41. 1825. (Fig. 32)

Morphologically this taxon could be confused with a member of Stelis in the broad sense, and in fact many authors still place it in Stelis rather than Pleurothallis. Stenzel (2004) doubted the results of his own phylogenetic reconstruction in which two accessions of Pleurothallis ghiesbreghtiana A.Rich. \& Galeotti (= P. quadrifida) were found sister to Pleurothallis rather than Stelis. However, except for the phylogenetic inference presented by Solano-Gómez (2005), all other DNA based studies consistently show that $P$. quadrifida, type species of Lalexia, is sister to the remaining species of Pleurothallis rather than Stelis (Stenzel 2004, Karremans et al. 2013, Wilson et al. 2013, 2017, Pérez-Escobar et al. 2017). The exclusion from Stelis is supported by multi-gene genomic studies (Ponert et al. 2019).

Its only member, Pleurothallis quadrifida, is a widely distributed and common species without any close relatives. It is easily recognized by the thick coriaceous leaves, erect, elongate, simultaneous inflorescences bearing large bright yellow flowers. It is unique in the glabrous flowers, with petals similar in size the sepals, the pandurate lip and the simple column with sub-apical anther. Unlike the majority of the members of the subtribe, the sweetly fragrant bright yellow flowers of this species may be adapted to pollination by Hymenoptera rather than Diptera, as a parasitoid wasp was documented removing pollinaria (Karremans \& Díaz-Morales 2019).

Pleurothallis quadrifida (Lex.) Lindl., Edwards's Bot. Reg. 28(Misc.): 70. 1842.

Bas.: Dendrobium quadrifidum Lex. in P.de La Llave \& J.M.de Lexarza, Nov. Veg. Descr. 2(Orchid. Opusc.): 40. 1825. Humboltia quadrifida (Lex.) Kuntze, Revis. Gen. P1. 2: 668. 1891. Stelis quadrifida (Lex.) Solano \& Soto Arenas, Icon. Orchid. 5-6: xi. 2002 [2003]. Specklinia quadrifida (Lex.) Luer, Monogr. Syst. Bot. Missouri Bot. Gard. 95: 263. 2004. Loddigesia quadrifida (Lex.) Luer, Monogr. Syst. Bot. Missouri Bot. Gard. 105: 251. 2006. Lalexia quadrifida (Lex.) Luer, Harvard Pap. Bot. 16: 358. 2011.

Syn.: Pleurothallis racemiflora Lindl. ex Lodd. Bot. Cab. 10: t. 949. 1824 [1825], nom. illeg. Non Pleurothallis racemiflora (Sw.) Lindl. in Hook. Exot. F1. 2: t. 123. 1825 [1824]. Stelis racemiflora (Lindl. ex Lodd.) W.H.Baxter in J.C.Loudon, Hort. Brit., Suppl. 3: 643. 1850, nom. illeg. Pleurothallis longissima Lindl., Fol. Orchid. $\sim$ Pleurothallis $\sim 31$. 1859. 


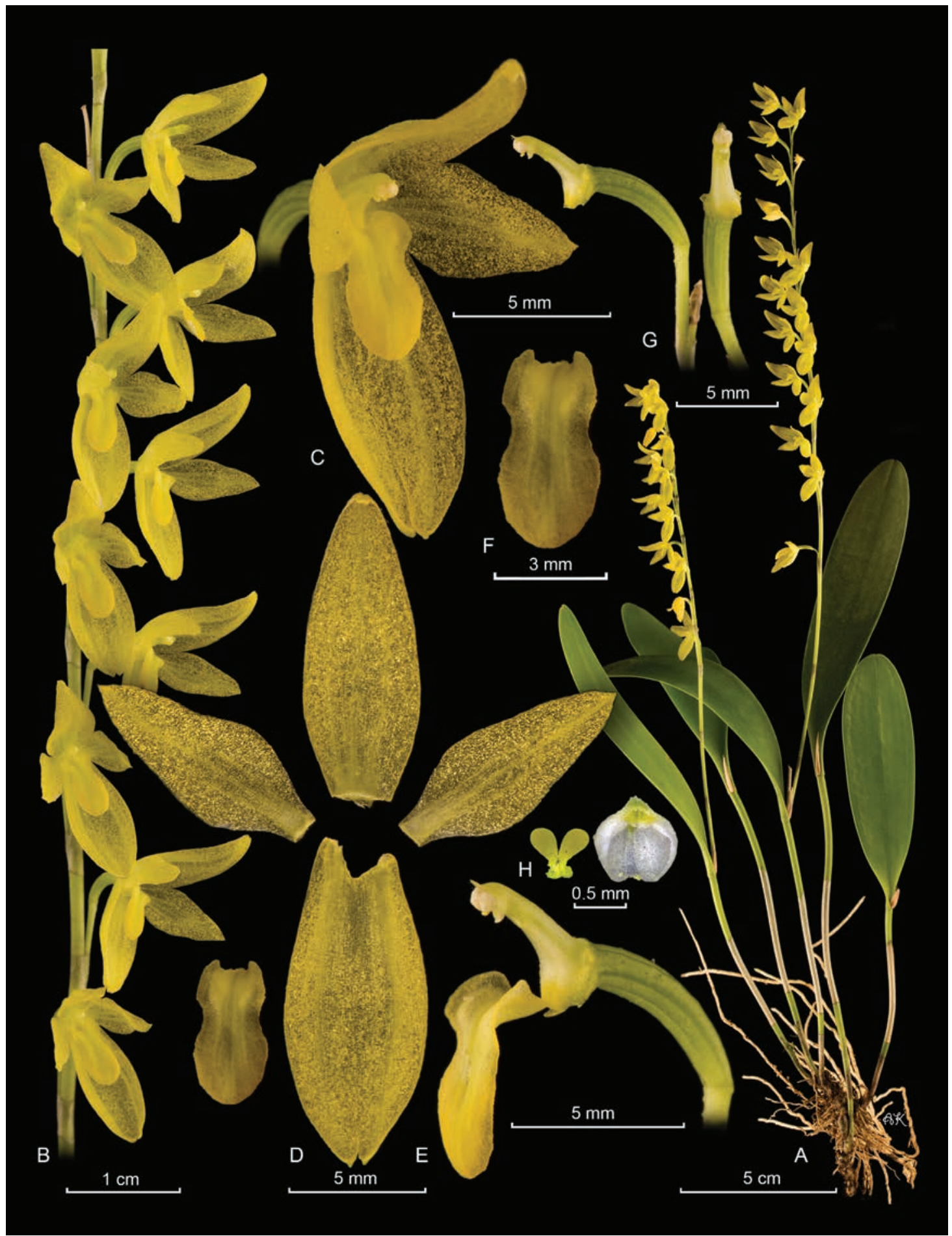

Figure 32. LCDP of Pleurothallis quadrifida, type species of Lalexia (= Pleurothallis subgen. Lalexia). A. Habit. B. Inflorescence. C. Flower. D. Dissected perianth. E. Column with lip, lateral view. F. Lip. G. Column ventral and lateral view. H. Anther cap and pollinarium. Photographs by AK based on Karremans 6436 (JBL-spirit). 
Great taxonomical confusion surrounds the name Pleurothallis racemiflora in commonly used databases and literature, warranting the current note. When Lindley, in Hooker (1824), transferred Swartz's Epidendrum racemiflorum to Pleurothallis, rather than describing and illustrating Swartz's species (treated above as Stelis multirostris) he presented another species, treated here as Pleurothallis quadrifida. Lindley later realized his initial mistake and rectified "P. longissima (P. racemiflora, Lindl. in Hook. Exot. Fl. t 123, nec Swartzii)... It is not the Dendrobium racemiflorum Sw. as I formerly supposed" and that "P. racemiflora (Dendrobium racemiflorum Swartz, Fl. Ind. Occ. 1543. P. oblongifolia Lindl. in Comp. Bot. Mag. 2. 355)... Original specimens from Swartz show that this is the plant meant by Swartz".

However, the damage was already done. In the Botanical Cabinet, Loddiges (1825) features the same Pleurothallis racemiflora that Lindley had misinterpreted (thus Pleurothallis quadrifida), and not that of Swartz (= Stelis multirostris). Loddiges' name has been regarded by various authors as a combination for the basionym Epidendrum racemiflorum Sw. or simply as a citation of $P$. racemiflora (Sw.) Lindl. Nevertheless, in the original publication there is no reference to either, and as both text and illustration are based on Loddiges' own material that actually represents a different species as that of Swartz, it must be interpreted that the author is publishing a new taxon. The name is therefore to be cited correctly as P. racemiflora Lindl. ex Lodd. and it is an heterotypic homonym of $P$. racemiflora (Sw.) Lindl.

As $P$. racemiflora (Sw.) Lindl. latter was published a few months prior to $P$. racemiflora Lindl. ex Lodd., it has priority. Therefore, $P$. racemiflora Lindl. ex Lodd. is valid, yet illegitimate under article 53.1 (Turland et al. 2018). The name Stelis racemiflora published by Baxter in the "Supplement to J.C. Loudon's Hortus Britannicus" clearly cites Loddiges as author, and thus should be correctly cited as Stelis racemiflora (Lindl. ex Lodd.) W.H.Baxter. Although most names from the Hortus Britannicus are considered invalid, this new combination is in accordance with articles 35.2, 38.1, 38.2 and 41.4 as it associates the genus and final epithet and associating the new combination with a basionym and earlier description (Turland et al. 2018). However, it is based on an illegitimate name, and thus illegitimate too. Both are here regarded as heterotypic synonyms of $P$. quadrifida as they are based on Loddiges' material rather than Swartz's. Pleurothallis longissima Lindl. is based on the same type as $P$. racemiflora Lindl. ex Lodd., and thus can be considered a replacement name.

Conclusions. To be, or not to be a Stelis, that is the question. For that we hope to have an answer. Recognizing a member of Stelis in the classic strict sense is certainly straightforward. Most species (not all) have a standard and distinctive floral morphology. If the group was an isolated lineage within the Pleurothallidinae there would be no need for the current discussion. However, that is not the case. We now know for a fact that many groups of species that lack the typical Stelis-flower are actually close relatives. An alternative would be not to add these groups to a broader Stelis but to recognize each of them as genera as well. But is that alternative more intuitive or informative? It doesn't seem to be that way at all.

Sadly, none of the possible ways in which we can translate the evolutionary history of this group of species into a stable classification system appears to be very appealing. Stelis in the broad sense defined here is made up of a series of strikingly different species groups that indisputably share a common ancestor and a common evolutionary history. In the past, flower morphology has been the main source for information regarding evolutionary history between taxa, however today we know that flower morphology in distant taxa may appear very similar due to convergence evolution. Why, despite their indistinguishable flowers, are we happy to accept that Bulbophyllum careyanum Spreng., B. striatellum Ridl., B. laxiflorum Lindl., B. maxillare Rchb.f. and B. tremulum Wight, are not actually species of Pleurothallidinae belonging to the genera Acianthera Scheidw., Muscarella Luer, Myoxanthus Poepp. \& Endl., Masdevallia Ruiz \& Pav. and Trichosalpinx Luer, respectively? Because it has been established beyond a doubt that these groups are unrelated and their floral similarity is merely a consequence of convergent evolution due to similar pollination syndromes. 
Similarly, we should accept that convergent morphologies occur within the Pleurothallidinae, the group with highest diversification rates and species number in Orchidaceae. It is a fact that species of Andinia (Luer) Luer are not closely related to species of Lepanthes Sw., and that neither of them is a close relative of species of Salpistele Dressler (= Stelis), despite having almost identical flowers. In the same way, it has been proven that species of Anathallis Barb.Rodr. are not closely related to the florally similar of Lankesteriana Karremans. We know that those floral convergences result from adaptation to the same pollinators or pollination strategies (Wilson et al. 2017; Bogarín et al. 2018; Karremans \& DíazMorales 2019). Specifically, in the case of Stelis s.l., Karremans \& Díaz-Morales (2019) stress the point that species of Stelis subgen. Unciferia have been reported to be pollinated by flies of the families Phoridae and Chloropidae which are exactly the same families of flies that pollinate species of Acianthera, an unrelated genus with flowers that are indeed much more similar than those of Stelis s.s. The authors also show that the transitional morphology of species belonging to Stelis subgen. Crocodeilanthe results in the placement of pollinaria on the top of the head of their pollinators, which is midway between the scutellum placement of members of Stelis subgen.
Unciferia and the placement close to the mouthparts observed in Stelis s.s. (Karremans \& Díaz-Morales 2019).

As circumscribed here, Stelis includes 1243 species, making it the most species rich genus in the Pleurothallidinae, and one of the largest in Orchidaceae. The most specious group in the genus is Stelis subgen. Stelis, which harbors some 1030 species with the more classical Stelis flower morphology. The other 213 species are divided into eight subgenera that although florally different are closely related and share the same common ancestor of Stelis s.s.

Acknowledgements. Franco Pupulin, Gustavo RojasAlvarado, Juan Sebastián Moreno and Isler Chinchilla were kind enough to authorize the reproduction of their LCDPs. Diego Bogarín, Benjamín Collantes, Jan Meijvogel, Henry Oakeley and Grettel Salguero are thanked for providing photographs used in this manuscript. Two anonymous reviewers are thanked for their kind suggestions improving the manuscript. The Hortus Botanicus Leiden, and staff associated, is thanked for some of the plant material reproduced here provided through an exchange with Lankester Botanical Garden. The staff of the horticulture department at Lankester Botanical Garden is thanked for their invaluable support to this study. Kanchi Gandhi is thanked for his comments regarding nomenclatural issues discussed herein.

\section{LiTERATURE CITED}

Bogarín, D., Fernández, M., Borkent, A., Heemskerk, A., Pupulin, F., Ramírez, S., Smets, E., \& Gravendeel, B. (2018). Pollination of Trichosalpinx (Orchidaceae: Pleurothallidinae) by biting midges (Diptera: Ceratopogonidae). Botanical Journal of the Linnean Society, 186, 510-543.

Carnevali, G. \& Dorr, L. J. (2014). Orchidaceae. Flora of Guaramacal (Venezuela): Monocotyledons. Smithsonian Contributions to Botany, 100, 106-209.

Chiron, G. R., Guiard, J. \& van den Berg, C. (2012). Phylogenetic relationships in Brazilian Pleurothallis sensu lato (Pleurothallidinae, Orchidaceae): evidence from nuclear ITS rDNA sequences. Phytotaxa, 46, 34-58.

Chumová, Z., Trávníček, P., Ponert, J., Záveská, E., Mandákova, T., Hloušková, P., Čertner, M. \& Schmidt, P.-A. (2018). Pleurothallidinae - a hyperdiverse subtribe with hyperdiverse genomes. Poster presented at the European Orchid Show \& Conferences, Paris, March 23-25th, 2018.

Damián, A. (2019). Crocodeilanthe chachapoyensis (Orchidaceae: Pleurothallidinae), a new species from Amazonas, Peru. Annales Botanici Fennici, 56(4-6), 301-304.

Govaerts, R., Dransfield, J., Zona, S., Hodel, D. R. \& Henderson, A. (2019). World Checklist of Orchidaceae. Facilitated by the Royal Botanic Gardens, Kew. Retrieved from http://apps.kew.org/wcsp/ (Accessed 3 October 2019).

Karremans, A. P. (2010). Phylogenetics of Stelis (Orchidaceae: Pleurothallidinae) and closely related genera, based on molecular data, morphological characteristics and geographical distribution in the Central American and Andean Cordilleras. M.Sc. Thesis, Plant Sciences Group and Biosystematics Group, Wageningen University.

Karremans, A. P. (2014). Lankesteriana, a new genus in the Pleurothallidinae (Orchidaceae). Lankesteriana, 13(3), $319-332$. DOI: $10.15517 /$ LANK.V13I3.14368 
Karremans, A. P. (2016). Genera Pleurothallidinarum: an updated phylogenetic overview of Pleurothallidinae. Lankesteriana, 16(2), 219-241. DOI: 10.15517/LANK.V16I2.26008

Karremans, A. P. \& Bogarín, D. (2013). Three new species of Dracontia (Pleurothallidinae, Orchidaceae) from Costa Rica. Systematic Botany, 38(2), 307-315.

Karremans, A. P. \& Díaz-Morales, M. (2019). The Pleurothallidinae: extremely high speciation driven by pollinator adaptation. In: A. M. Pridgeon \& A. R. Arosemena (Eds.), Proceedings of the 22nd World Orchid Conference, vol. 1 (pp. 363-388). Guayaquil, Ecuador: Asociación Ecuatoriana de Orquideología.

Karremans, A. P., Albertazzi, F. J., Bakker, F. T., Eurlings, M. C. M., Pridgeon, A., Pupulin, F. \& Gravendeel, B. (2016). Phylogenetic reassessment of Specklinia and its allied genera in the Pleurothallidinae (Orchidaceae). Phytotaxa, 272, 1-36. https://doi.org/10.11646/phytotaxa.272.1.1

Karremans, A. P., Bakker, F. T., Pupulin, F., Solano-Gómez, R. \& Smulders, M. J. M. (2013). Phylogenetics of Stelis and closely related genera (Orchidaceae: Pleurothallidinae). Plant Systematics and Evolution, 29(1), 69-86.

Karremans, A. P., Bogarín, D., Díaz-Morales, M., Fernández, M., Oses, L. \& Pupulin, F. (2016). Phylogenetic reassessment of Acianthera (Orchidaceae: Pleurothallidinae). Systematic Botany, 21, 171-187. https://doi.org/10.3100/hpib. v21iss2.2016.n4

Lindley, J. (1859). Folia Orchidacea. An enumeration of the known species of orchids. Pleurothallis. London, published for the author by J. Matthew.

Loddiges, C. (1825). Pleurothallis racemiflora. Botanical Cabinet, 10, t. 949.

Luer, C.A. (1986). Icones Pleurothallidinarum. III. Systematics of the genus Pleurothallis (Orchidaceae). Monographs in Systematic Botany from the Missouri Botanical Garden, 20.

Luer, C.A. (1994). Icones Pleurothallidinarum. XI. Systematics of Lepanthes Subgenus Brachycladium and Pleurothallis Subgenus Aenigma, Subgenus Elongatia, Subgenus Kraenzlinella (Orchidaceae). Monographs in Systematic Botany from the Missouri Botanical Garden, 52.

Luer, C. A. (1999). Icones Pleurothallidinarum. XVIII. Systematics of Pleurothallis Subgen. Pleurothallis Sect. Pleurothallis Subsect. Antenniferae, Subsect. Longiracemosae, Subsect. Macrophyllae-Racemosae, Subsect. Perplexae, Subgen. Pseudostelis, Subgen. Acuminatia. Monographs in Systematic Botany from the Missouri Botanical Garden, 76.

Luer, C.A. (2000). Icones Pleurothallidinarum. XX. Systematics of Jostia, Andinia, Barbosella, Barbrodia, Pleurothallis subgen. Antilla, subgen. Effusia, subgen. Restrepioidia. Addenda to Lepanthes, Masdevallia, Platystele, Pleurothallis, Restrepiopsis, Scaphosepalum, and Teagueia. Monographs in Systematic Botany from the Missouri Botanical Garden, 79.

Luer, C.A. (2009). Icones Pleurothallidinarum. XXX. Lepanthes of Jamaica and Systematics of Stelis, Stelis of Ecuador, part four and addenda: systematics of Masdevallia, new species of Lepanthes from Ecuador, and miscellaneous new combinations. Monographs in Systematic Botany from the Missouri Botanical Garden, 115, 1-265.

Neyland, R., Urbatsch, L. E. \& Pridgeon, A. M. (1995). A phylogenetic analysis of subtribe Pleurothallidinae (Orchidaceae). Botanical Journal of the Linnaean Society, 117, 13-28.

Pérez-Escobar, O. A., Chomicki, G., Condamine, F. L., Karremans, A. P., Bogarín, D., Matzke, N. J., Silvestro, D. \& Antonelli, A. (2017). Recent origin and rapid speciation of Neotropical orchids in the world's richest plant biodiversity hotspot. New Phytologist, 215. DOI: https://doi.org/10.1111/nph.14629.

Pfeiffer, L. K. G. (1873). Physosiphon Lindl. Nomenclator botanicus (Pfeiffer), 2(1), 705.

Ponert, J., Chumová, Z., Záveská, E., Mandákova, T., Hloušková, P., Čertner, M., Schmidt, P.-A. \& Trávníček, P. (2019). Understanding of complex diversity in Pleurothallidinae as the way to effective conservation. Poster presented at the 7th International Orchid Conservation Congress, Kew, London, May 28th-June 1st, 2019.

Pridgeon, A. M., Solano-Gómez, R. \& Chase, M. W. (2001). Phylogenetic relationships in Pleurothallidinae (Orchidaceae): combined evidence from nuclear and plastid DNA sequences. American Journal of Botany, 88(12), 2286-2308.

Pridgeon, A. M. \& Chase, M. W. (2002). Nomenclatural notes on Pleurothallidinae (Orchidaceae). Lindleyana, 17, 98-101.

Pridgeon, A. M. (2005). Subtribe Pleurothallidinae. In: A. M. Pridgeon, P. J. Cribb, M. W. Chase \& F. N. Rasmussen (eds.), Genera Orchidacearum. Volume 4 Epidendroideae (Part One) (pp. 319-422). Oxford: Oxford University Press.

Ramos-Castro, S. E., Castañeda-Zárate, M., Solano-Gómez, R. \& Salazar, G. A. (2012). Stelis zootrophionoides (Orchidaceae: Pleurothallidinae), a new species from Mexico. PLoS One, 7. DOI: https://doi.org/10.1371/journal. pone. 0048822 .

Santos, M. C., Toscano de Brito, A. L. V. \& Smidt, E. C. (2018). Nomenclatural notes in Anathallis microphyta (Pleurothallidinae, Orchidaceae). Phytotaxa, 346, 104-112.

Santos, M. C., Toscano de Brito, A. L. V. \& Smidt, E. C. (2019). Anathallis (Orchidaceae: Pleurothallidinae) no estado do 
Paraná, Brasil. Rodriguésia, 70, e02722017. DOI: https://dx.doi.org/10.1590/2175-7860201970031

Solano-Gómez, R. (2005). Inference of the phylogenetic relationships in Stelis sensu lato clade based upon morphology and sequences of the ITS region data sets. In A. Raynal-Roques, A. Roguenant \& D. Prat (eds.), Proceedings of the 18th World Orchid Conference, Dijon, France, 11-20 March, 2005. France: Naturalia Publications.

Solano-Gómez, R. \& Salazar, G. (2013). What delimitation for Stelis should be used? Lankesteriana, 13(1-2), 137-138. DOI: $10.15517 /$ LANK.V0I0.11566

Stenzel, H. (2000). Pollen morphology of the subtribe Pleurothallidinae Lindl. (Orchidaceae). Grana, 39, 108-125.

Stenzel, H. (2004). Systematics and evolution of the genus Pleurothallis R.Br. (Orchidaceae) in the Greater Antilles. Dissertation Thesis. Mathematisch-Naturwissenschaftlichen Fakultät I der Humboldt- Universität zu Berlin.

Toscano de Brito, A. L. V. (2018a). New combinations in Crocodeilanthe (Pleurothallidinae, Orchidaceae). Harvard Papers in Botany, 23(1), 53-55.

Toscano de Brito, A. L. V. (2018b). A new species of Anathallis (Orchidaceae: Pleurothallidinae) from Brazil. Lankesteriana, 18(3), 177-181. DOI: 10.15517/LANK.V18I3.34556

Turland, N. J., Wiersema, J. H., Barrie, F. R., Greuter, W., Hawksworth, D. L., Herendeen, P. S., Knapp, S., Kusber, W. H., Li, D. Z., Marhold, K., May, T. W., McNeill, J., Monro, A. M., Prado, J., Price, M. J. \& Smith, G. F. (2018). International code of nomenclature for algae, fungi, and plants (Shenzhen Code) adopted by the Nineteenth International Botanical Congress Shenzhen, China, July 2017. Regnum vegetabile 159. Koeltz, Glashütten. Retrieved from https://doi. org $/ 10.12705 /$ Code.2018

Wilson, M., Belle, C., Dang, A., Hannan, P., Kellogg, L., Kenyon, C., Low, H., Mochizuki, A., Nguyen, A., Sheade, N., Shan, L., Shum, A., Stayton, T., Volz, C., Vosburgh, B., Wellman, H. \& Woolley, M. A. (2013). A preliminary phylogenetic analysis of Pleurothallis sensu lato based upon nuclear and plastid sequences. Abstract of poster presented at 4th Scientific Conference on Andean Orchids, November 2012, Guayaquil, Ecuador. Lankesteriana, 13(1-2), 139. DOI: 10.15517/LANK.V0I0.11568

Wilson, M., Frank, G. S., Jost, L., Pridgeon, A. M., Vieira-Uribe, S. \& Karremans, A. P. (2017). Phylogenetic analysis of Andinia (Pleurothallidinae; Orchidaceae) and a systematic re-circumscription of the genus. Phytotaxa, 295(2), 101-131. 
